\title{
4 Auf beiden Seiten der Mauer: Tansanische Studierende im geteilten Deutschland
}

Die BRD und die DDR waren keineswegs die naheliegendsten Optionen für TansanierInnen mit der Absicht, einen Universitätsabschluss zu erlangen. ${ }^{1}$ Britische Standards und Strukturen bezüglich Bildungswegen und -abschlüssen prägten das tansanische Bildungs- und Berufssystem auch lang nach der Unabhängigkeit. ${ }^{2}$ Außerhalb der anglofonen Sphäre musste man nicht nur eine neue Sprache lernen, was das Studium erschwerte und die Studiendauer verlängerte. Probleme mit der vollen Anerkennung der Universitätsabschlüsse in Tansania und der oft wenig prestigereiche Ruf von Universitäten außerhalb des angloamerikanischen Raumes waren weitere Vorbehalte. Die weithin bevorzugten Studienländer waren daher die Vereinigten Staaten und Großbritannien. Trotzdem studierten TansanierInnen 1973/74 in über 30 Ländern, darunter Kenia (248 Studierende), die Sowjetunion (298), Indien (170), Rumänien (118), die DDR (97), Kuba (71), Kanada (63), Ungarn (55) und China (54). ${ }^{3}$ Die innerhalb weniger Jahre rasant gestiegene Anzahl der Destinationen zeigt den Erfolg der tansanischen Strategie, Ressourcenquellen in den Zwischenräumen von Kaltem Krieg und Dekolonisierung anzuzapfen und entwicklungspolitische Erwägungen pragmatisch zu nutzen, um die Stipendienangebote zu diversifizieren. Bei aller Pragmatik spielten Ideologie und Politik aber durchaus eine wichtige Rolle, sowohl in der Bereitstellung der Stipendien und Studienplätze als auch in den persönlichen Erfahrungen.

Dieses Kapitel befasst sich mit den Konjunkturen des Überseestudiums während der Dekolonisierung und des Kalten Krieges am Beispiel tansanischer Studierender in den beiden deutschen Staaten. Es diskutiert die wechselhaften politischen und ökonomischen Interessen der jeweiligen Staaten an dieser Form der entwicklungspolitischen Kooperation und lotet die Handlungsspielräume derjenigen aus, die zum Studium aufbrachen und damit Bildungs- und Aufstiegsmöglichkeiten verfolgten. DDR wie BRD wollten leitende „Kader der jungen Nationalstaaten“ bzw. „Fach- und Führungskräfte“ ausbilden und hegten die Erwartung, dass diese Proto-Eliten entweder West oder Ost - und keinen dazwi-

1 BArch Koblenz, B 138/34578, Rainer Henseleit, Die Rolle der deutschen Hochschulen im NordSüd-Dialog, November 1978, S. 41; Interview \#1, Tansanischer Doktoratsstudent in BRD.

2 Archiv des Deutschen Akademischen Austauschdienstes (DAAD-Archiv), B 212/91392/4, Anlage zum Stipendienangebot 1977/78, S. 1 .

3 URT, Annual Manpower Report to the President 1974, Dar es Salaam 1975, S. 47; URT, Annual Manpower Report to the President 1975, Dar es Salaam 1976, S. 94. Die Statistik umfasst lediglich Studierende mit Regierungsstipendien.

Ә OpenAccess. ( 2021 Eric Burton, publiziert von De Gruyter. (cc)BY Dieses Werk ist lizenziert unter der Creative Commons Attribution 4.0 International Lizenz. https://doi.org/10.1515/9783110705621-007 
schen liegenden oder gänzlich andersartigen Weg - „wählen“ würden. ${ }^{4}$ Die in ihrer Simplizität ebenso falsche wie hartnäckige Annahme war, dass die ideologische Gunst auf jene Seite fallen würde, wo auch das Studium stattgefunden hatte. Ein Bonmot, das während des Kalten Krieges in Tansania und anderswo verbreitet war, kehrte die Annahme ins Gegenteil um, wie sich ein tansanischer Ingenieur erinnerte:

The most capitalist people who came back here are the ones who had gone to the Soviet Union. [...]. [T]hey learned the bad side of socialism by going to the Soviet Union. But for us, it was mainly theoretical and the only socialism we knew was the one in Tanzania. Which had a human face. [...] So we used to joke and say that if you want a capitalist, send them to study to the Soviet Union or to Cuba. If you want a socialist, send them to a Western country. ${ }^{5}$

Dieses Bonmot bleibt einerseits der bipolaren Welt des Kalten Krieges verhaftet, geht aber mit dem Bezug auf den Sozialismus mit „menschlichem Antlitz“ in Tansania, der keiner der beiden Seiten zugerechnet wird, auch darüber hinaus. Grundlage für den vermeintlich paradoxen Ideologisierungseffekt, so führte der hier zitierte tansanische Ingenieur (der selbst mit einem DAAD-Stipendium in den USA studiert hatte) weiter aus, war die Erfahrung mit den Realitäten vor Ort. Im Osten boten die Mangelwirtschaft und weitgehende Reisefreiheit für ausländische Studierende Möglichkeiten, unternehmerische Energie zu entwickeln. In den USA hingegen belegten Obdachlosigkeit und Verbrechen einen inakzeptablen Grad sozialer Ungleichheit. In beiden „Blöcken“ schließlich mussten zahlreiche Studierende Bekanntschaft mit verschiedenen Formen rassistischer Diskriminierung machen und Strategien finden, damit umzugehen.

Diese Diskrepanz zwischen offiziellen Darstellungen und Erwartungen einerseits und persönlichen Motiven und Erfahrungen andererseits wirft Fragen nach dem Eigen-Sinn der Überseestudierenden, ihren Aneignungsstrategien und Handlungsspielräumen im Rahmen des Auslandsstudiums auf. Dieses Kapitel diskutiert die Mobilitätsform des Überseestudiums hier als Emanation des entwicklungspolitischen Feldes und schlägt dabei Brücken zwischen der Makro-

4 Quinn Slobodian, Bandung in Divided Germany. Managing Non-Aligned Politics in East and West, 1955-63, in: The Journal of Imperial and Commonwealth History 41/4 (2013), S. 644-662, hier: S. 647.

5 Interview \#4, Tansanischer Doktoratsstudent (mit DAAD-Drittlandsstipendium) in den Vereinigten Staaten. Der Witz soll auch unter KubanerInnen verbreitet gewesen sein (Persönliches Gespräch mit Anne Dietrich, Universität Leipzig). Siehe ebenso den Artikel "How the Soviets create African capitalists”, New African, Oktober 1987; Interview \#75, Tansanischer Student in der DDR und Doktoratsstudent in der BRD. 
ebene globaler ideologischer Rivalitäten und Ungleichheiten, der Mesoebene gesellschaftlicher Ungleichheiten und der Mikroebene persönlicher Begegnungen und Erfahrungen. ${ }^{6}$ Jüngere, meist historisch-anthropologisch angelegte Arbeiten über Studierende aus der „Dritten Welt“ in kommunistischen Ländern haben sich der letzteren, alltagsnahen Perspektive verschrieben. ${ }^{7}$ Sie gehen damit über frühere Forschungen hinaus, die einen sehr selektiven Blick auf die Aufenthalte warfen, der von den Interessen stipendienvergebender Institutionen geprägt blieb und sich oft darauf beschränkte, die Situation ausländischer Studierender technokratisch durch Kategorien wie Lebensbedingungen, Studienerfolg und Rückkehrbereitschaft $\mathrm{zu}$ fassen. ${ }^{8}$

Der Blick über ideologische und politische Systemgrenzen hinweg weist das Überseestudium als Paradebeispiel für eine Verflechtungsgeschichte zwischen Tansania und den beiden deutschen Staaten aus. ${ }^{9}$ Vor allem Studierende in der DDR nutzten ihre Reisemöglichkeiten und machten den Iron Curtain für verschiedene Zwecke zum Nylon Curtain. ${ }^{10}$ Gleichzeitig wurden Konzepte und Modelle selektiv angeeignet und verschiedene eigensinnige Strategien im Umgang

6 Zum Forschungsfeld und methodologischen Ansätzen in diesem Spannungsfeld siehe Eric Burton, Introduction: Journeys of Education and Struggle: African Mobility in Times of Decolonization and the Cold War, in: Stichproben. Vienna Journal of African Studies 18/34 (2018), S.1-17. 7 Hauke Dorsch, Trans-Atlantic Educational Crossroads: Experiences of Mozambican Students in Cuba, in: Ingrid Kummels u.a., Hg., Transatlantic Caribbean. Dialogues of People, Practices, Ideas, Bielefeld, Berlin 2014, S. 77-96; ders., Red or Black Atlantic? Mozambican Students in Cuba and their Re-Integration at Home, in: Zeitschrift für Ethnologie 136/2 (2011), S. 65-86; Hatzky, Kubaner in Angola; Tanja R. Müller, „Memories of Paradise“ - Legacies of Socialist Education in Mozambique, in: African Affairs 109/436 (2010), S. 451-470; Jeannett Martin, Been-To, Burger, Transmigranten? Zur Bildungsmigration von Ghanaern und ihrer Rückkehr aus der Bundesrepublik Deutschland, Münster 2005; Andrea Schmelz, Bildungsmigranten aus Afrika und Asien. Interkulturalität, Umbrüche und Neuorientierungen im geteilten und wiedervereinigten Deutschland, Frankfurt/Main, London 2004; Monique de Saint Martin u.a., Hg., Étudier à l'Est. Expériences de diplômés africains, Paris 2015; weiters auch Constantin Katsakioris, Leçons soviétiques: la formation des étudiants africains et arabes en URSS pendant la guerre froide, $\mathrm{PhD}$ Dissertation, Paris 2015.

8 Kritische Zusammenfassungen älterer Studien über ausländische Studierende in der BRD finden sich in Sabine Grosskopf, Kulturschock und Fremdverhaltensunterricht. Ausländische Studenten in der BRD, Hamburg 1982, S. 226-261. Eine chronologische, die Jahre 1958 bis 1982 umfassende Bibliographie ist abgedruckt in der groß angelegten Studie von Bernd Gross u.a., Akademiker aus Entwicklungsländern in der Bundesrepublik Deutschland. Zwischen Brain Drain und Rückkehr: eine Studie im Auftrag des Centrums für internationale Migration und Entwicklung, Saarbrücken 1982.

9 Werner/Zimmermann, Beyond Comparison.

10 György Péteri, Nylon Curtain - Transnational and Transsystemic Tendencies in the Cultural Life of State-Socialist Russia and East-Central Europe, in: Slavonica 10/2 (2013), S. 113-123. 
mit Kontroll-, Indoktrinierungs- und Überwachungspraktiken auf beiden Seiten der Mauer ausgeübt. ${ }^{11}$ Im Rahmen dieser Verflechtungsgeschichte zeigt sich auch, wie Bedingungen im Entsendeland Tansania die Erfahrungen in Übersee formten. Eine wichtige Rolle spielte bei vielen TansanierInnen bis weit in die 1970er-Jahre der feste Glaube an Ujamaa und die Verheißungen nationaler Entwicklung, was sich nicht zuletzt damit erklären lässt, dass viele von ihnen ihren sozialen Aufstieg der staatlichen Bildungspolitik verdankten. Die wirtschaftliche Krise Tansanias ab Mitte der 1970er Jahre führte allerdings auch bei den Studierenden zu einer Neubewertung des Wertes eines Auslandsstudiums.

Das Kapitel skizziert zuerst die Rahmenbedingungen und persönlichen Motive der Studienaufenthalte. Danach geht es um Erfahrungen und Handlungsstrategien der tansanischen StudentInnen in den beiden deutschen Staaten. Der asymmetrischen Quellenlage ist geschuldet, dass der Schwerpunkt auf der DDR liegt - die Versuche ostdeutscher Behörden, die ausländischen Studierenden zu kontrollieren und die „politisch-ideologische“ Deutungshoheit zu behalten, haben einen dichten Korpus aus Überwachungsberichten, persönlichen Einschätzungen und mikrosoziologischen Befunden von der Ministeriums- bis hinunter auf die Ebene von FDJ-Gruppen hinterlassen, während BRD-Quellen zu ausländischen Studierenden einen verstreuten, fragmentarischen und oft technokratischen Charakter aufweisen. ${ }^{12}$ Für Personen, die über private Kanäle in die BRD kamen, lässt sich zudem fast nur auf Interviews und autobiografische Dokumente zurückgreifen; die Erfahrungen derjenigen, die durch staatliche Kanäle an Stipendien kamen, stehen folglich im Vordergrund. In einem dritten Schritt wird die Rückkehr nach Tansania analysiert, darunter Erfahrungen von Statusgewinn und sozialem Aufstieg, aber auch die Schwierigkeiten, das akkumulierte Kapital zu transferieren und zu konvertieren.

\subsection{Konjunkturen des Überseestudiums}

Die Mobilitätsform des Überseestudiums hat wesentliche Strukturmerkmale über die Unabhängigkeiten hinweg beibehalten: Kolonial wie postkolonial führte der Weg von der Peripherie für einen spezifischen Zweck und eine begrenzte Anzahl von Jahren ins Zentrum (oder in subimperiale Zentren) und dann, oft unter Um-

11 Eric Burton, Navigating Global Socialism: Tanzanian Students in and Beyond East Germany, in: Cold War History 19/1 (2019), S. 63-83.

12 Sara Pugach, African Students in Cold War Leipzig: Using University Archives to Recover a Forgotten History, in: Geert Castryck u.a., Hg., Sources and Methods for African History and Culture: Essays in Honour of Adam Jones, Leipzig 2016, S. 541-564. 
wegen, wieder zurück in die Peripherie, wo der Abschluss einen sozialen Aufstieg ermöglichte. Die vorgesehene Richtung des Wissenstransfers und der Ressourcenflüsse blieb im Wesentlichen gleich: von Nord nach Süd. Weitere Möglichkeiten der Bildungsmigration waren auf Einzelpersonen und sehr spezifische Gruppen beschränkt. Mit der Dynamisierung der Dekolonisierung in den 1950erJahren vollzog sich jedoch ein partieller Bruch vom vorherrschenden imperialen Muster: Die Bildungszirkulationen zwischen kolonialer Peripherie und Metropole wurde um Ost-Süd- und Süd-Süd-Beziehungen erweitert. ${ }^{13}$

Die Mobilitätsformen diversifizierten sich angesichts von Systemkonkurrenz und Dekolonisierung nun von dem vorherrschenden Muster, dass Bildungsaufenthalte in der jeweiligen Kolonialmetropole bzw. innerhalb des Imperiums stattfanden. Afrikanische PolitikerInnen und transnationale Aktivistennetzwerke knüpften bereits in der spätkolonialen Phase neue Kontakte, schufen neue Kanäle der Bildungsmigration und zapften die Ressourcenquellen an, die sich aus dem Zusammenspiel von Dekolonisierung und Kaltem Krieg eröffneten. ${ }^{14}$ Die USA und die Sowjetunion, aber auch andere Staaten in „Ost“, „West“ und „Süd“ gewannen nun im Rahmen der Systemkonkurrenz und weiterer, oft national spezifischer Motive, ein stärkeres Interesse, Studienplätze bereitzustellen und so auch den Prozess der Dekolonisierung zu ihren Gunsten zu nutzen oder gar beeinflussen. ${ }^{15}$

13 Für derartige Verbindungen gab es durchaus Vorläufer; die Kontinuitätslinien zum „roten Mekka“ Moskau der Zwischenkriegszeit aber waren durch den Zweiten Weltkrieg und Stalins Isolationismus unterbrochen. $\mathrm{Zu}$ den Vorläufern siehe u.a. Hakim Adi, Pan-Africanism and Communism. The Communist International, Africa and the Diaspora, 1919-1939, Trenton, NJ 2013; Irina Filatova, Indoctrination or Scholarship? Education of Africans at the Communist University of the Toilers of the East in the Soviet Union, 1923-1937, in: Paedagogica Historica 35/1 (1999), S. 41-66; Patrice Yengo, Jalons pour une historiographie des élites africaines formées dans le Bloc soviétique, in: Michèle Leclerc-Olive, Hg., Les mondes universitaires face au marché. Circulation des savoirs et pratiques des acteurs, Paris 2011, S. 135-148; Maxim Matusevich, Journeys of Hope. African Diaspora and the Soviet Society, in: African Diaspora 1/1 (2008), S. $53-85$.

14 Detailliert hierzu Eric Burton, Decolonisation, the Cold War and Africans' routes to higher education overseas, 1957-1965, in: Journal of Global History 15/1 (2020), S. 169-191.

15 Monique de Saint Martin u. a., Introduction, in: dies. u. a., Hg., Étudier à l’Est. Expériences de diplômés africains, Paris 2015, S. 17-33, hier: S. 20; Svetlana Boltovskaja, Bildungsmigranten aus dem subsaharischen Afrika in Moskau und St. Petersburg. Selbst- und Fremdbilder, Herbolzheim 2014, S. 57; Constantin Katsakioris, Sowjetische Bildungsförderung für afrikanische und asiatische Länder, in: Bernd Greiner u. a., Hg., Macht und Geist im Kalten Krieg, Hamburg 2011, S. 396 415; Abigail Judge Kret, „We Unite with Knowledge“: The Peoples‘ Friendship University and Soviet Education for the Third World, in: Comparative Studies of South Asia, Africa and the Middle East 33/2 (2013), S. 239-256; Tobias Rupprecht, Gestrandetes Flaggschiff. Die Moskauer Universität der Völkerfreundschaft, in: Osteuropa 1 (2010), S. 95-114. 
Fast alle westlichen Länder widmeten dem Überseestudium (und anderen Ausbildungsformaten) nun spezifische Programme, oft in Kooperation mit Missionen und Privatfirmen mit Produktionsstandorten in Afrika, die mit der Stipendienvergabe bereits Erfahrungen und ein besonderes Interesse hatten, die Agenda zu ihren Gunsten zu beeinflussen. ${ }^{16}$ Hierzu gehörten auch westdeutsche Kirchenverbände, Missionswerke, Stiftungen und Betriebe, die selbst oft eine eigene Präsenz in Tansania besaßen oder aufbauen wollten. ${ }^{17}$

\section{Staatliche Interessen und der patriotisch-entwicklungspolitische Imperativ}

Die BRD vergab öffentliche Stipendien in erster Linie durch den Deutschen Akademischen Austauschdienst (DAAD). Westdeutsche Universitäten verdreifachten ihr Angebot für ausländische Studierende zwischen 1957 und 1960 von 3.053 auf 9.282 Plätze, wovon insbesondere Ägypten, der Iran und Indien profitierten. Nigeria und Ghana wurden Schwerpunktländer im subsaharischen Afrika. In der DDR stellte die Aufnahme von 11 nigerianischen GewerkschafterInnen nach den Weltfestspielen 1951 die Geburtsstunde des DDR-,Ausländerstudiums“ dar. Zwischen 1956 und 1960 verfünffachte sich die Zahl von Studierenden aus Afrika und Asien an ostdeutschen Universitäten von 225 auf 1.342, etwa ein Drittel aller ausländischen Studierenden stammte aus Nordkorea, weitere große Gruppen kamen aus arabischen Ländern. ${ }^{18}$ In beiden deutschen Staaten entstanden im Zusammenhang mit der Dekolonisierung gezielte Vorbereitungsprogramme und Studienangebote für Personen aus dem globalen Süden, bisweilen mit einem spezifischen entwicklungspolitischen Bezug. ${ }^{19}$

Die Konjunkturen des Auslandsstudiums in den beiden deutschen Staaten lassen sich im Rahmen der bereits vorgestellten Periodisierung interpretieren (siehe Kapitel 3). Mit der Hoffnung auf diplomatische Anerkennung erweiterte die DDR in der zweiten Hälfte der 1960er-Jahre ihr Stipendienangebot für Tansania,

16 T. L. Maliyamkono u. a., Higher Education and Development in Eastern Africa, London 1982, S. 37-38.

17 Für einen Überblick über stipendienvergebende Organisationen aus der BRD siehe DAADArchiv, B 212/91392/4, Tansanische Botschaft an CDG, DAAD, FES, FNS, KAS, OBS, DSE, Bonn, 8. 3. 1976; zu Firmen siehe BArch Koblenz, B 212/26037, Hauck (DAAD), Aktenvermerk, 8.4.1963.

18 Slobodian, Bandung, S. 647; Mac Con Uladh, Damian, Studium bei Freunden? Ausländische Studierende in der DDR bis 1970, in: Christian T. Müller/Patrice G. Poutrus, Hg., Ankunft, Alltag, Ausreise: Migration und interkulturelle Begegnung in der DDR-Gesellschaft, Köln 2005, S. 175 220, hier: S. 178.

19 Hans Mathias Müller, Die Bildungshilfe der Deutschen Demokratischen Republik, Frankfurt/ Main, New York 1995, S. 103. 
während die BRD aufgrund der diplomatischen Krise keine neuen Stipendien vergab. Erst als Tansania zu einem entwicklungspolitischen Schwerpunktland wurde, nahm die Zahl tansanischer Studierender in der BRD deutlich zu. In den 1980er-Jahren sank das Interesse der DDR und damit die Zahl der StipendiatInnen weiter, während die BRD aus entwicklungspolitischen und finanziellen Gründen schon seit den 1970er-Jahren zunehmend auf sogenannte sur place- und Drittlandsstipendien setzte und so auch dem brain drain entgegenwirken wollte, der verstärkt als unintendierte Konsequenz des Ausländerstudiums wahrgenommen wurde. Mangels vollständiger und v.a. vergleichbarer Daten sind quantitative Gegenüberstellungen nur bedingt aussagekräftig; allgemein lässt sich jedoch sagen, dass sich beide deutsche Staaten als aus tansanischer Sicht wichtige, wenngleich nicht herausragende Destinationen des Überseestudiums etablierten. Von 1070 tansanischen Studierenden in Übersee, die 1976 von staatlicher Seite registriert waren (tatsächlich handelte es sich um weitaus mehr), befanden sich 89 in der DDR und 70 in der BRD. ${ }^{20}$

Voraussetzung für jegliche staatlich organisierte Bildungsmigration war das Interesse tansanischer politischer Eliten am Überseestudium. Die TANU hatte bereits vor der Unabhängigkeit den Fachpersonalmangel als drängendes Problem erkannt und begonnen, Studierende nach Äthiopien und Liberia, aber auch in westliche Länder zu entsenden. ${ }^{21}$ Zwischen 1959 und 1963 gelangten 800 OstafrikanerInnen - darunter auch eine kleinere Gruppe aus Tanganjika - dank einer vom kenianischen Gewerkschafter Tom Mboya initiierten „Luftbrücke“ an nordamerikanische Universitäten. ${ }^{22}$ Auch an dieser Luftbrücke war die TANU ab 1960 beteiligt mit dem Ziel, das koloniale Personal sobald wie möglich überflüssig zu machen und durch eigene Fachkräfte zu ersetzen. Die Suche nach Studienplätzen folgte dem pragmatischen Motto „Beggars can’t be choosers“.23 Als Minimalkonsens zwischen den Regierungen und involvierten Institutionen in „West“, „Ost“ und „Süd“ bildete sich der patriotisch-entwicklungspolitische Imperativ heraus. Die Erwartung an den (stets männlich imaginierten) Studenten war, dass

20 Gross u.a., Akademiker, S. 302-303; UDSM Activity Report 1983/84, S. 211.

21 Bahru Zewde, The Quest for Socialist Utopia. The Ethiopian Student Movement, c. 1960 -1974, Woodbridge 2014, S. 102. Zu Stipendienangeboten siehe auch die Sitzungsprotokolle des TANUKomitees in CCMA, 53 (Mikutano ya Halmashauri Kuu).

22 Tom Shachtman, Airlift to America. How Barack Obama, Sr., John F. Kennedy, Tom Mboya, and 800 East African Students Changed Their World and Ours, New York 2010; James H. Meriwether, „Worth a Lot of Negro Votes“. Black Voters, Africa, and the 1960 Presidential Campaign, in: Journal of American History 95/3 (2008), S. 737-763.

23 Sadleir, Tanzania, S. 283; Niwako E. Mnzava, The Contribution of Overseas Scholarships to the High-Level Manpower Requirements in Tanzania, MA Thesis, University of Dar es Salaam 1978, S. 48 . 
er „seine hier erworbenen Kenntnisse und Erfahrungen in den Dienst seines Volkes, das ihn braucht, zu stellen bereit und dazu auch in der Lage ist““. ${ }^{24}$ Die individuellen Interessen sollten in den Dienst der Entwicklungsnotwendigkeiten des Entsendelandes gestellt und ihnen untergeordnet werden. Um zu gewährleisten, dass die KandidatInnen den Interessen der Entsenderegierungen bzw. institutionen entsprachen, setzte die DDR auf das „Delegierungsprinzip“, das ähnlich auch in bundesdeutschen Institutionen zur Anwendung kam: Dieses Prinzip sah vor, nur Studierende aufzunehmen, „die von den Vertragspartnern selbst ausgewählt und in mit dem Partner nach den Möglichkeiten der DDR und den Interessen des Partners vereinbarten Fachrichtungen zum Studium delegiert werden.“25 Nicht weniger als EntwicklungsexpertInnen sind „Studierende aus Entwicklungsländern“ damit eine spezifische Figur und Erscheinungsform, eine „Ausgeburt“26 des entwicklungspolitischen Feldes.

Über Gewerkschaftskanäle und Kontakte antikolonialer Organisationen gelangten schon vor der Unabhängigkeit 1963 kleinere Gruppen von Sansibaris in die DDR, insbesondere über Kairo, das etwa zwischen 1958 und 1963 einen Umschlagplatz zwischen Afrika und den Ländern des Ostblocks darstellte. ${ }^{27}$ Mit der Union von Tanganjika und Sansibar kamen ab 1964 auch zunehmend TansanierInnen vom Festland hinzu. Ein ökonomischer Vorteil von Stipendienvergaben im Vergleich zu Industrieprojekten oder Personalentsendung war der geringe Devisenaufwand; erwartet wurde auch ein vergleichsweise großer politischer Nutzen. Bildung galt als entscheidendes Mittel im Kampf gegen „koloniale Einflüsse“ und zur Propagierung der Gesellschaftsordnung der DDR: „Die ausländischen Studierenden“, forderte der Leiter der Abteilung Ausländerstudium an der Karl-MarxUniversität Leipzig 1978, „müssen so viel von der DDR erkennen, dass sie mit dem Wunsch nach Hause fahren, die Zukunft ihres Landes ähnlich wie die DDR zu gestalten“. ${ }^{28}$ Die gesellschaftlichen Massenorganisationen wurden in die staatliche Politik eingebunden: 97 Kader des tansanischen Gewerkschaftsverbandes nahmen zwischen 1961 und 1976 an Lehrgängen der FDGB-Hochschule teil, 36

24 BArch Koblenz, B 138/34571, BMZ, Grundsatzüberlegungen zur Reintegration der in der BRD aus- und fortgebildeten Staatsangehörigen von Entwicklungsländern, Bonn, 4.9.1972, S. 3.

25 Universitätsarchiv Leipzig (UAL), DIB 259, Ausländische Studenten an Universitäten der DDR, Stand: Ende Studienjahr 1977/78, Bl. 51.

26 Der Begriff Ausgeburt findet sich bei Bourdieu/Wacquant, Reflexive Anthropologie, S. 138. 27 Burton, Hubs of Decolonization.

28 UAL, DIB 259, Aufzeichnung von Abteilungsleiter AS Dr. Jünger, Betr.: Ausführungen des stv. Ministers Gen. Prof. Dr. Heydorn auf der Sitzung des Komitees f. Ang. ausl. Studierender am 10.2. 1978 nach der Berichterstattung der TH KM-Stadt und KMU, Leipzig, o.O., 12.2.1978, Bl. 82-83; siehe auch Lorenzini, Dilemmas, S. 61. 
Kader des tansanischen Jugendverbands hatten bis 1980 FDJ-Lehrgänge besucht, 27 tansanische JournalistInnen waren an der Schule der Solidarität des Verbands der Journalisten der DDR gewesen und 75 tansanische BürgerInnen wurden in Sechs-Monats-Lehrgängen des Verbands der Konsumgenossenschaften geschult.

Die Zahl von TansanierInnen, die vom Staat zu Studienzwecken nach Übersee entsendet wurden, war seit der Unabhängigkeit kontinuierlich gewachsen und ging erst mit dem größer werdenden Angebot an der Universität Dar es Salaam wieder zurück; zwischen 1970 und 1975 verringerte sich die Zahl von TansanierInnen, die zum Auslandsstudium delegiert wurden, um 65 Prozent. ${ }^{29}$ Blockdenken spielte bei der Zielwahl eine untergeordnete Rolle, im Gegenteil manifestierte sich eher das Prinzip der Blockfreiheit in den offiziellen Entsendezahlen, während individuelle Entscheidungen oft pragmatisch zu lesen sind. So landeten Verwandte einflussreicher tansanischer Politiker, von denen einige versuchten, Stipendienkontingente privat anzuzapfen, in beiden „Lagern“. ${ }^{30}$ Bereits 1965 weilten fast ebenso viele offiziell delegierte TansanierInnen in westlichen (355) wie in kommunistischen (316) Ländern.

Ebenfalls Konsens unter den Regierungen war in den 1960er-Jahren die modernisierungstheoretische Annahme, dass Bildung eine Investition in zukünftiges Wirtschaftswachstum darstellte - und zwar nicht nur im Herkunftsland, sondern auch dort, wo das Studium absolviert wurde. In BRD galt es, „Studenten an deutschen Maschinen und Normen auszubilden“, um Exporte anzukurbeln, ${ }^{31}$ und auch in der DDR hoffte man, die AbsolventInnen würden sich an ihre Zeit in der DDR erinnern, wenn sie als Entscheidungsträger in ihren Heimatländern einmal „Prospekte westdeutscher Firmen in den Händen halten“ würden. ${ }^{32}$ Operationalisiert wurde diese Verbindung allerdings nur in der umgekehrten Reihenfolge: Wenn Industrieprojekte vereinbart wurden, war in der Regel auch eine Ausbildungskomponente Teil der Abkommen. Mindestens fünfzig TansanierInnen absolvierten allerdings Studien und Ausbildungen in der DDR, um die Produktion und Instandhaltung in der Textilfabrik Mbeya (siehe Kap. 3.4) übernehmen zu können - hier war das Studienangebot also eine flankierende Maßnahme zu ei-

29 URT, Manpower Report 1975, S. 38.

30 PAAA, MfAA, C 350, Generalkonsul Lessing an MfAA, Dar es Salaam, 30. 3.1966. Lessing sagte zu, wies aber darauf hin, dass die vertraglich festgelegten Bedingungen (u. a. passende Qualifikation) eingehalten werden müssten.

31 BArch Koblenz, B 102/86803, Bd. 3, BRD-Botschaft an AA, Dar es Salaam, 2.10.1969; Frank Hirschinger, Der Spionage verdächtig. Asylanten und ausländische Studenten in Sachsen-Anhalt 1945-1970, Göttingen 2009, S. 98.

32 UAL, DIB 259, Jünger (Abteilungsleiter AS), Ausführungen des stv. Ministers Heydorn, Leipzig, 12.2.1978, Bl. 82-83. Siehe auch Mac con Uladh, Studium, S. 178, S. 188. 
nem kommerziellen Projekt. ${ }^{33}$ Für das ab Ende der 1970er von der DDR forcierte „Kommerzstudium“, also die Vergabe von Studienplätzen gegen Devisen, fehlten Tansania, das angesichts der Bevorzugung der neuen „sozialistisch orientierten“ Regierungen in Mosambik, Angola und Äthiopien zudem seinen Schwerpunktstatus einbüßte, die Mittel. ${ }^{34}$

In der BRD nahm die Zahl tansanischer Studierender ab Mitte der 1970er (76) nach einem Zwischenhoch, das sich aus dem Schwerpunktstatus und zahlreichen neuen Projekten mit Ausbildungskomponente erklären lässt, ebenfalls wieder ab. Hier spielten wirtschaftliche und bildungspolitische Gründe die Hauptrolle. 1962 war auf der UNESCO-Konferenz in Antananarivo über die Entwicklung des höheren Erziehungswesens in Afrika festgelegt worden, dass die Ausbildung im Herkunftsland dem teureren und längeren Auslandsstudium vorzuziehen sei. Bereits im Jahr darauf begann der DAAD, sogenannte sur-place-Stipendien zu vergeben (die auch für andere afrikanische Länder galten), in deren Rahmen die Studierenden im Land selbst verblieben. ${ }^{35} 1967$ stellte sich für DAAD-Generalsekretär Hubertus Scheibe 1967 bei diesem Instrument noch die Frage: „Was springt für Deutschland heraus? "36 Mit einem enger werdenden Budgetrahmen, der Rezeption der brain drain-Theorie bei gleichzeitiger Feststellung, dass viele AbsolventInnen in der BRD bleiben wollten sowie der Rezession in den 1970er-Jahren mit dem einhergehenden Problem, Praktikumsplätze für ausländische Studierende in der Wirtschaft zu finden, wandten die BRD und andere westliche Länder diese Finanzierungsmethode jedoch immer häufiger an. ${ }^{37}$ Ab Anfang der 1980erJahre wurde die Stipendienzahl weiter reduziert und das „in-country-Programm“

3329 TansanierInnen sind erwähnt in BArch Berlin, DQ 4/5432. Laut Interview \#110 mit einem ehemaligen DDR-Diplomaten wurden insgesamt über 50 tansanische BürgerInnen eigens für Funktionen in Mbeya ausgebildet, von denen aber nur manche nach ihrer Rückkehr dort eingesetzt wurden.

34 Lediglich die Ausbildung tansanischer Offiziere (zu 25\% kostenpflichtig und damit ca. 10.500 US-Dollar pro Kopf entsprechend) durch die Nationale Volksarmee lässt sich hierunter subsumieren. Siehe Storkmann, Geheime Solidarität, S. 407.

35 Manfred Heinemann, Fakten und Zahlen zum DAAD. Personen, Programme und Projekte ein Rundblick, Band 2, 4. Aufl., Bonn 2000, S. 33.

36 BArch Koblenz, B 212/26037, Scheibe (DAAD) an Hellmann (DAAD), o.0., 12.9.1967.

37 DAAD, 40 Years Supporting Excellence. DAAD Regional Office for Africa, Bonn 2014, S. 16 - 17; Heinemann, Fakten, S. 60; BArch Koblenz, B 138/34583, Pfeifer (BMZ) an Bundestagsmitglied Schmedt, Bonn, 29.3.1984, S. 4. 
aufgrund der Finanzlage sogar kurzzeitig eingestellt, aber dann auf Drängen der Universität Dar es Salaam wieder aufgenommen. ${ }^{38}$

\section{Das Überseestudium als Bedingung und Bedrohung nationaler Entwicklung}

Tansanische Eliten fassten das Auslandsstudium gleichermaßen als Notwendigkeit wie auch als Gefährdung der Nationalisierungsbestrebungen auf. Sie befürchteten, dass die Entsandten nicht zurückkehrten oder sich von tansanischen Verhältnissen entfremdeten und Werte wie Gleichheit und Verzicht, die unter dem Schlagwort Ujamaa vermittelt werden sollten, missachteten; insbesondere, wenn sie sich an westliche Konsum- und Lebensstandards gewöhnt hatten. Bei diesen Vorbehalten handelte sich um ein Spiegelbild der Diskurse, in denen die Anwesenheit von expatriates im Rahmen von postkolonialen Souveränitätsansprüchen und spezifisch sozialistischen Anforderungen legitimiert und problematisiert wurde. Um die Risiken des Überseestudiums zu minimieren, sollten nur die notwendigsten Auslandsstudien zugelassen und ältere, charakterlich gefestigte und familiär gebundene Bewerber bevorzugt werden, wie die Universität Dar es Salaam 1978 einer dänischen Delegation mitteilte:

This philosophy is based on the fact that local training introduces young men to the problems of this country early on in their careers and there are less chances of such Tanzanian students wishing to stay permanently in foreign countries if they go there as mature people rather than immature. ${ }^{39}$

Eine Reihe von Maßnahmen wurden getroffen, um die Bildungsmigration auf das notwendige Maß zu reduzieren oder, wie im Zitat erwähnt, auf Personen zu beschränken, die formative Sozialisierungsprozesse bereits hinter sich gebracht hatten. Private Initiativen vieler Familien, Kinder schon für die schulische Ausbildung ins Ausland zu schicken, mussten ab Ende der 1960er-Jahre durch das tansanische Bildungsministerium ,im Interesse der Nation“ genehmigt werden auch, um die knappen Fremdwährungsreserven nicht $\mathrm{zu}$ belasten. ${ }^{40}$ Die Sorge

38 DAAD-Archiv, B 212/91198/1, DAAD an BRD-Botschaft Dar es Salaam, o.O., 22.6.1982; ebd., DAAD an BRD-Botschaft Dar es Salaam, o. O., 28.4.1981; ebd., B 212/91392/3, Zum Besuch des Vice-chancellors Kuhanga, Bonn, 16.7.1982, S. 2.

39 Tanzania National Archives (TNA), FA/E90/7, Part E, UDSM, A Brief for the Danish Parliamentarians, Dar es Salaam, 27.2.1978. Vgl. auch mit Bezug auf Sansibar BArch Berlin, DR 2/ 244452, Pfannenberg (DDR-Konsulat), Vermerk über Gespräch Schneider mit dem Vorsitzenden für Erziehunng und Bildung Sansibars Said idi Bavuia, Sansibar, 16.1.1972.

40 URT, Annual Manpower Report to the President 1969, Dar es Salaam 1970, S. 20 -21. 
über die Entfremdung vom Afrikanischen Sozialismus führte sogar dazu, dass das Bildungsministerium 1974 unter erheblichen finanziellen Aufwendungen ein Programm ins Leben rief, dass delegierten Studierenden ermöglichen sollte, alle zwei Jahre auf Regierungskosten nach Tansania zurückzukehren und Seminare zu aktuellen politischen Richtlinien $\mathrm{zu}$ besuchen. ${ }^{41}$ InterviewpartnerInnen zufolge war es zudem äußerst umständlich, ohne eine schriftliche Zusage für einen Stipendienplatz oder einen anderen offiziell anerkannten Grund für die Auslandsreise an einen Reisepass zu gelangen..$^{42}$ Bei manchen Bildungsangeboten, die im Außenministerium eintrudelten, sahen technokratische Verwaltungskräfte zudem keinen Gewinn. Eine DDR-Einladung für einen vierwöchigen Kurs über den kulturpolitischen Umgang mit den „Massen“ war nach Meinung eines Beamten im tansanischen Außenministerium politisch, kulturell und ökonomisch unattraktiv:

Ehrlich gesagt sehe ich keinen Grund, warum wir Einladungen dieser Art annehmen sollten. Da gibt es nichts zu lernen, das ist reine Politik. Kultur muss ursprünglich und authentisch sein. Das ist nichts als eine Vergnügungsfahrt und, wenn wir die Reisekosten übernehmen müssen, eine doppelte Verschwendung von Geld und Zeit. ${ }^{43}$

Sansibar, das über keine eigene Hochschule verfügte, ging unter Karumes Abschottungspolitik zeitweise den Weg völliger Abstinenz vom Auslandsstudium. Im Anschluss an die Revolution wurde die Entsendung zu Ausbildungszwecken vorerst in kommunistische Staaten umgelenkt: 1966 waren 123 Sansibaris zu Ausbildungszwecken in der DDR und damit mehr als in der UdSSR (58) und China (21) zusammen. ${ }^{44} 1972$ wurde dem DDR-Attaché mitgeteilt, dass man „Kader in erster Linie im Lande selbst ausbilden möchte, um sie nicht schädlichen Einflüßen besonders in westlichen Staaten auszusetzen““.45 Allerdings hatte Sansibar

41 Timothy Alan Nicholson, Teaching Tanzania: Education and the Creation of Tanzania in a Cold War World, PhD Dissertation, New York 2012, S. 229.

42 Siehe auch Hanna Schott, Matomora Matomora. Der längste Umweg führt nach Hause, Schwarzenfeld 2012, S. 66-67.

43 TNA, FA/E 160/11 Part C, Bl. 272: DDR-Botschaft Dar es Salaam an Ministry of Culture and Youth, Dar es Salaam, 26.1.1979 sowie die zugehörigen Aktenvermerke vom 1.2.1979 und 2.2.1979. Der zitierte Aktenvermerk im Original: „Kwa kweli sioni sababu kwanini [sic] tukubali mialiko namna hii. Hakuna mafunzo hapa. Hii yote ni politics. Culture must be original and authentic. Haya ni matembezi tu; na kama tunayalipia nauli it is a double waste money and time. Tuupeleke mwaliko Culture lakini tushauri kama hapo you.“

44 Burgess, A Socialist Diaspora, S. 281.

45 BArch Berlin, DR 2/24452, Pfannenberg (DDR-Konsulat), Vermerk über Gespräch Schneider mit dem Vorsitzenden für Erziehung und Bildung Sansibars Said Idi Bavuia, Sansibar, 16.10.1972. 
seit 1967 keine Studierenden oder Lehrlinge mehr in die DDR entsandt, weil Präsident Karume höhere Bildung und ExpertInnnen nunmehr als überflüssig erachtete und die Reisebestimmungen so weit verschärfte, dass sogar die Überfahrt zum Festland der Zustimmung der Partei bedurfte. ${ }^{46}$ Selbst ein Studium an der Universität Dar es Salaam war in dieser Zeit unmöglich. Der postkoloniale „Torwächterstaat“ machte die Schotten dicht. ${ }^{47}$ Der Mauerbau in der DDR wenige Jahre zuvor kommt hier unweigerlich als Parallele in den Sinn, denn diese Maßnahmen wurden vor allem getroffen, um die Abwanderung von Fachkräften zu verhindern, von denen viele mit den Verhältnissen im postrevolutionären Sansibar haderten. Erst unter der Präsidentschaft Aboud Jumbes ab 1972 durften Sansibaris wieder zu Studienzwecken auf das tansanische Festland und nach Übersee.

\section{Selektionsmechanismen}

Nicht alle Gruppen konnten in gleicher Weise von den Studienmöglichkeiten profitieren, und die Schilderungen in Interviews waren - selbst bei Personen in ähnlichen Positionen - heterogen. Handlungsspielräume wurden unterschiedlich wahrgenommen und waren äußerst situationsabhängig. Während ein Geograf und heutiger Universitätsprofessor versicherte, dass die Destination nicht individuell beeinflusst werden konnte (,You don’t choose where you go“48), meinte ein Professor der Rechtswissenschaften diametral entgegengesetzt, es sei „not a question of being sent, but of choice“ gewesen: „People were fighting to get us“.49 Beide waren in etwa zur selben Zeit nach Deutschland zum Studium aufgebrochen, der erste allerdings (mit der Erinnerung der Alternativlosigkeit) in die DDR, der zweite (mit der Erinnerung der Wahlfreiheit) in die BRD. Neben NachwuchswissenschaftlerInnen hatten auch höherrangige Counterparts in Entwicklungsprojekten bei entsprechender Vorbildung einen privilegierten Zugang zu Stipendien, während Angehörige von Partei und den Massenorganisationen zumindest auf Möglichkeiten hoffen konnten, mehrmonatige Seminare internationaler Organisationen oder Fortbildungen bei Gewerkschafts- und Parteischulen im Ausland zu absolvieren.

46 Ewald Weiser, DDR-Lehrer nach Sansibar, in: Ulrich van der Heyden/Franziska Benger, Hg., Kalter Krieg in Ostafrika: Die Beziehungen der DDR zu Sansibar und Tansania, Berlin 2009, S. 213-250, hier: S. 239; Burgess, Race, S. 200-201.

47 Zum Konzept des gatekeeper state siehe Cooper, Africa since 1940.

48 Interview \#11, Tansanischer Doktoratsstudent in der BRD.

49 Interview \#14, Tansanischer Doktoratsstudent in der BRD. 
Die größte Gruppe der StipendiatInnen für reguläre Universitätsstudien waren junge Männer und (deutlich weniger) Frauen mit Hochschulreife, die den tansanischen „manpower"-Prioritäten folgend zumeist naturwissenschaftliche und technisch orientierte Studien verfolgten. Sie waren entsprechend jung, in der Regel ledig, hatten (nach 1966) in den meisten Fällen den National Service absolviert und eventuell einige Jahre Berufserfahrung (v. a. nach der Musoma Resolution 1974). Die meisten tansanischen Studierenden in der DDR und in den RGW-Ländern generell gehörten zu dieser Gruppe. Von ihnen wurde die Stipendienvergabe meist als hierarchischer und weitgehend alternativloser Selektionsprozess beschrieben, in dem die Wahl eines Ziellandes als „Luxus“ und die Absolvierung des Auslandsstudiums als Pflicht galt.. ${ }^{50}$ Ab Mitte der 1970er-Jahre erhöhte sich der Anteil von DoktoratsstudentInnen und älterer BewerberInnen. Das Höchstalter für DAAD-Stipendien lag bei 32 Jahren, während es in der DDR keine explizite Altersgrenze gab. Zwischen 1976 und 1989 war bei 46\% aller vom DAAD abgelehnten tansanischen BewerberInnen das Alter ein ausschlaggebendes Kriterium. ${ }^{51}$

Die Stipendienkontingente wurden in bilateralen Abkommen festgelegt und direkt durch das tansanische Bildungsministerium vergeben. Vor 1967 wurden viele Stipendienangebote, auch solche der BRD und der DDR, direkt in Zeitungen inseriert, um KandidatInnen möglichst schnell ausfindig zu machen. ${ }^{52}$ Nach 1967 kamen Formulare zum Einsatz, die noch vor dem Abschluss in der Sekundarschule ausgefüllt wurden. In diesen Formularen konnten die SchülerInnen auf einer Dreierliste Präferenzen angeben, was - also welche Studienfächer - aber nicht wo sie studieren wollten. Die zentrale Bedeutung dieses Schrittes für die Biografie zeigt sich darin, dass sich fast alle InteriewpartnerInnen noch exakt an ihre erste und zweite Präferenz erinnerten; ebenso, wie sie in den Monaten darauf gespannt auf eine Nachricht vom Bildungsministerium im Radio oder in der Zeitung warteten. Nicht für alle war das Ziel ein Überseeaufenthalt. Manche hätten aus familiären und Beziehungsgründen bevorzugt in Nairobi oder Dar es

50 Interview \#3, Tansanischer Doktoratsstudent in der DDR.

51 Eigene Erhebungen auf Grundlage verschiedener Dokumente aus dem DAAD-Archiv, B 212/ 91392 bis B 212/91395; ebd., Die Auswertung beruht auf Schreiben des DAAD an die BRD-Botschaft in Dar es Salaam zwischen 1976 und 1989. Die Gesamtzahl der Bewerbungen war höher, allerdings konnten nicht alle Akten eingesehen werden. Erst 1986 wurde für angehende DissertantInnen das Höchstalter auf 36 Jahre heraufgeschraubt, zeitgleich gingen die Bewerbungszahlen wieder in die Höhe. DAAD-Archiv, B 212/91198/1, Glimm (DAAD) an Benad, Bonn, 2.12.1986; BMZ, B 213/63790, BRD-Botschaft, Entwicklungspolitischer Zweijahresbericht, Dar es Salaam, August 1987, S. 11. 52 Sadleir, Tanzania, S. 283. 
Salaam zu studieren und baten (erfolglos) nicht nach Rumänien oder in die DDR, sondern innerhalb Ostafrikas delegiert zu werden. ${ }^{53}$

Die Erzählungen über das Überseestudium waren von drei Motiven durchzogen: Pflicht (gegenüber dem Entwicklungsstaat und der Bevölkerung Tansanias), Gelegenheit (im Ausland studieren zu können) und Meritokratie (dass man sich diese Chance durch eigene Leistungen erarbeitet hatte). Alle diese Motive kreisen um den Nexus von Bildung, manpower und Entwicklung und stellten zentrale Elemente des tansanischen Sozialvertrages für die Bildungseliten unter Ujamaa dar: Der Staat finanzierte die Bildung, dafür bestand die Pflicht, für den Staat zu arbeiten. Es handelt sich bei den Erzählungen um Aufstiegsnarrative, in denen die sozialräumliche Mobilität als verdienter Lohn individueller Anstrengungen und Resultat staatlicher Unterstützung dargestellt wird. Oft thematisiert wurde die eigene soziale Herkunft. Mehrere InterviewpartnerInnen erwähnten, dass sie aus nicht-privilegierten Familien stammten und ihre Bildungsabschlüsse der damaligen egalitären Politik im Allgemeinen und Julius Nyerere im Besonderen zu verdanken seien. ${ }^{54}$ Für sie hatten die Systemkonkurrenz und Tansanias Diversifizierungsstrategie Aufstiegsmöglichkeiten eröffnet, die ihnen anderweitig verwehrt geblieben wären:

Als wir in [Ost-]Deutschland ankamen stellten wir fest, dass $85 \%$ von uns Bauernkinder waren. Ich erinnere mich nur an einen, der der Sohn des Bürgermeisters von Dar es Salaam war. [...] Damals richteten sie sich wirklich nach den Zensuren, nicht danach, wen du gekannt hast oder was du getan hast, sondern nur nach den Zensuren. ${ }^{55}$

Auch hier tauchen wieder die Motive Meritokratie und Gelegenheit auf. In der BRD und der DDR wurde meritokratischen Kriterien unterschiedlich viel Gewicht beigemessen, um die Stipendien zu vergeben. Der DAAD wollte generell nur jene fördern, die zur „Spitzengruppe der Studenten oder jüngeren Akademiker ihres

53 Interview \#19, Tansanischer Student in Rumänien; Interview \#78, Tansanischer Student in der DDR.

54 Ein Interviewpartner erzählte, dass seine Eltern - die eine pastoralistische Lebensweise verfolgten, wie er betonte - ihm den Schulbesuch eigentlich verwehren wollten. Dank des tansanischen Bildungssystems, das eine kostenlose Ausbildung ermöglichte, habe er es aber sogar zu einem veterinärmedizinischen Studium in die DDR geschafft. Interview \#78, Tansanischer Student in der DDR.

55 Interview \#65, Tansanischer Student in der DDR. Die eingesehenen (in ihrer Quantität allerdings nicht repräsentativen) Lebensläufe tansanischer Studierender an der Karl-Marx-Universität Leipzig bestätigen, dass der Beruf der Eltern in der Regel Bauer bzw. Bäuerin war. 
Landes gehören“. ${ }^{56}$ In der DDR fühlte man sich zwar einer anti-elitären Bildungspolitik verpflichtet, aber es war - wie Djagalow und Evans für die analoge Lage in der Sowjetunion Anfang der 1960er-Jahre formulieren - eine veritable „Herausforderung, unterprivilegierte Bewerber zu finden“, die auch die Anforderungen an ein Hochschulstudium erfüllten. ${ }^{57}$ Da immer wieder Personen mit ungenügenden Qualifikationen vorgeschlagen wurden und teils sogar einreisten, versuchten BRD- wie DDR-VertreterInnen, „,auf künftige Delegierungen stärkeren Einfluss zu nehmen“. ${ }^{58}$ Das tansanische Außenministerium verbat sich derartige Einmischungen in die nationale Souveränität bisweilen und pochte auf die eigene Entscheidungshoheit. ${ }^{59}$

In der DDR war man immerhin bemüht, auch akademisch weniger Qualifizierten (wobei es sich nicht zwangsläufig um sozial Benachteiligte, sondern auch um Diplomatensöhne handelte) Bildungsmöglichkeiten zu eröffnen und Alternativvorschläge zu unterbreiten, „die von Berufsausbildungen an medizinischen Fachschulen und Ingenieurschulen bis hin zur „besondere[n] Ausnahme“ reichten, dass vier Kandidaten eine zweijährige Vorbereitung auf ein Hochschulstudium machen durften, die eigentlich exklusiv für „Delegierte der Bruderparteien“ vorgesehen war. ${ }^{60}$ Generell scheint die flexiblere Anwendung von Leistungskriterien und Bereitschaft, Alternativlösungen zu suchen, dazu geführt zu haben, dass tansanische Institutionen versuchten, leistungsschwächere SchulabgängerInnen häufiger in kommunistische Länder zu schicken. ${ }^{61}$ So empfing die So-

56 DAAD-Archiv, B 212/91392/4, Anlage III zum Stipendienangebot 1977/78; ebd., Jahresstipendien für ausländische Studenten und junge Akademiker - Allgemeine Richtlinien zum Stipendienangebot.

57 Rossen Djagalov/Christine Evans, Moskau 1960: Wie man sich eine sowjetische Freundschaft mit der Dritten Welt vorstellte, in: Andreas Hilger, Hg., Die Sowjetunion und die Dritte Welt: UdSSR, Staatssozialismus und die Antikolonialismus im Kalten Krieg 1945-1991, München 2009, S. $83-105$, hier: S. 91.

58 PAAA, MfAA, B 279/74, Förster (MHF) an DDR-Generalkonsulat VRT, o.O., 28.9.1972, S. 2; BArch Koblenz, B 212/26037, Püllen an Hauck (DAAD), Dar es Salaam, 4.3.1967.

59 BArch Koblenz, B 212/26037, Ministry of Foreign Affairs an BRD-Botschaft, Dar es Salaam, 20.7. 1966. Siehe auch HHStAW, 507, 10497 Bd. 1, Reuss an Voigt, o.O., 3.6.1961. Vgl. zum Fall zweier Counterparts aus Niger, die aufgrund schwacher Zeugnisse vom DAAD kaum unterzubringen waren: DAAD-Archiv, B 212/91836/1, DAAD an Zentralstelle für Ernährung und Landwirtschaft der DSE, o.O., 26.11.1982; ebd., BRD-Botschaft an DAAD, Niamey, 2.9.1982; ebd., DAAD an BRDBotschaft Niamey, o.O., 11.5.1981.

60 PAAA, MfAA, B 279/74, Gomille (MHF) an DDR-Generalkonsulat in der VRT, o.O., 26.7.1972; ebd., Förster (MHF) an DDR-GK in der VRT, o.O., 28.9.1972, S. 2.

61 PAAA, MfAA, B 279/74, DDR-Generalkonsul Hollender, Aktennotiz über Gespräch mit StS Mkundi im Ministerium für Bildung, Dar es Salaam, 9.9.1972; ebd., DDR-Generalkonsul Hollender, Aktennotiz über Gespräch mit StS Meena im Ministerium für Bildung, Dar es Salaam, 26.10.1972. 
wjetunion auch TansanierInnen, die aus Leistungsgründen keinen Platz an der Universität Dar es Salaam bekommen hatten. ${ }^{62}$ Erst ab Mitte der 1970er Jahre nahm die DDR, u.a. durch den Leistungsabfall in naturwissenschaftlichen Fächern, eine Vorselektion in Dar es Salaam vor und lehnte wiederholt BewerberInnen ab; 1976 etwa konnte keiner der von Tansania vorgeschlagenen Kandidaten die erforderlichen Noten vorweisen. ${ }^{63}$

Trotz staatlicher Quotierungen von Sekundarschulplätzen, die zur Auflösung regionaler Diskrepanzen führen sollten, profitierten von den Stipendien überproportional viele Personen aus sozioökonomisch stärkeren Regionen wie Kilimandscharo, Mbeya und Bukoba, die eine Tradition missionarischer Bildung und cash crop-Produktion aufweisen. ${ }^{64}$ Mitunter spielten hier, was in den meisten Interviewnarrativen mit ihrer Betonung der Meritokratie und sozialer Mobilität unerwähnt blieb, auch klientelistische Netzwerke und die Manipulation des symbolischen Kapitals eine Rolle. Ein Ingenieur (selbst aus der Region Kilimanjaro) wies darauf hin, dass eine gefälschte Geburtsurkunde oder persönliche Kontakte in die Ministerien genügten, um die staatliche Quotenpolitik zu unterlaufen. Ihm zufolge wütete Nyerere, als dieser bei einem BRD-Besuch feststellen musste, dass es sich bei vielen Studierenden in Westdeutschland um Chagga aus der Kilimandscharo-Region handelte, die offensichtlich seine auf nationalen Ausgleich ausgerichtete Bildungspolitik „,sabotiert“ hätten. ${ }^{65}$

Die politische Haltung spielte kaum eine Rolle bei der Selektion. Mitte der 1970er Jahre scheint der Großteil der Studierenden im Ausland die TANU-Mitgliedschaft besessen $\mathrm{zu}$ haben, was jedoch nicht als Indikator für eine enge Bindung an die Partei gesehen werden kann. ${ }^{66}$ Mitgliedschaften in der Jugendorganisation oder der Einheitspartei wurden als pragmatische Entscheidungen für das eigene Weiterkommen beschrieben. Wer ein Parteibuch vorzeigen musste,

62 Nicholson, Teaching Tanzania, S. 222.

63 TNA, Dar es Salaam, FA/E 160/11, Part C, Böhme (DDR-Botschaft) an Principal Secretary des tansanischen Bildungsministeriums, Dar es Salaam, 5.11.1976, Bl. 65.

64 Buchert, Education, 113. Im Fall der 28 interviewten Personen, die in Ost wie West studierten, kam ein Viertel (7 Personen) aus der Kilimanjaro-Region, gefolgt von Mbeya (4) und vier weiteren Regionen mit je 2 Personen (Shinyanga, Arusha, Tanga, Kigoma). Die restlichen 7 Personen kamen aus sieben anderen Regionen. Die Überrepräsentation Kilimanjaros und Mbeyas ist also auch hier gegeben, gleichzeitig lässt sich aber eine breite Variation konstatieren. Das entspricht in etwa den Verhältnissen bei Bachelor-Studierenden an der Universität Dar es Salaam in den 1970er Jahren, wo Kilimanjaro, Mbeya und Kagera deutlich überrepräsentiert waren. Siehe Justinian C.J. Galabawa, Funding, selected issues and trends in Tanzania higher education, in: Higher Education 21 (1991), S. 49-61, hier: S. 59.

65 Interview \#104, Tansanischer Student in der DDR, Doktoratsstudent in der BRD.

66 So etwa 93\% aller delegierten Studierenden in den USA: Nicholson, Teaching Tanzania, S. 215. 
aber noch nicht beigetreten war, tat das im Zuge der Reisevorbereitungen. ${ }^{67}$ Deutlich relevanter als die Übereinstimmung mit der Parteipolitik war die Bindung an den Staat. Wie erwähnt mussten sich BezieherInnen öffentlicher Stipendien verpflichten, nach dem Abschluss mindestens fünf Jahre im Staatsdienst tätig zu sein - eine Regelung, die bereits in der Kolonialzeit eingeführt worden war. Ein wesentlicher Aspekt der Eigenfinanzierung oder bei Stipendien von Privatorganisationen wie der Aga Khan Stiftung war, dass diese Pflicht entfiel, wobei private entwicklungspolitische Organisationen oder westdeutsche Missionshilfswerke oft analoge Regelungen für den Dienst in den eigenen Reihen einführten. ${ }^{68}$

Auf tansanischer Seite wirkten im Laufe der 1960er Jahre auch die Imperative der Nationalisierung und „Afrikanisierung“ auf die Selektion ein, wenngleich oft informell. 1967 stellte man beim DAAD fest, dass Tansania und Kenia bei der Auswahl von StipendiatInnen nun darauf pochten, nur noch StaatsbürgerInnen zu berücksichtigen. Lediglich in Einzelfällen wurden fortan BewerberInnen mit britischen Pässen - also in der Regel Personen asiatischer Herkunft, die sich gegen die tansanische Staatsbürgerschaft entschieden hatten - oder Angehörige anderer afrikanischer Staaten vorgeschlagen. Gerade tansanische „Inder“ sahen sich mit einem generalisierten Misstrauen konfrontiert. Das tansanische Ministerium stimmte der DAAD-Bewerbung eines tansanischen Staatsbürgers aufgrund seiner asiatischen Herkunft nur „mit Bedenken“ zu. ${ }^{69}$ Angesichts der zunehmenden Spannungen in Ostafrika, die in der Ausweisung aller „Inder“ aus Uganda durch Idi Amin 1971 die extremste Ausprägung erfuhr, aber sich auch in Sansibar und am tansanischen Festland niederschlug, bevorzugten Personen asiatischer Herkunft - wenn die Migration teils auch mehrere Generationen zurücklag - häufiger, nach dem Studium in westlichen Ländern zu bleiben statt zurückzukehren. $^{70}$

Auffällig ist schließlich der geringe Anteil von Frauen bei Überseestudierenden, der allerdings für die Bildungsmobilität zwischen Süd und Nord in diesen Jahren für fast alle Länder ähnlich ausfällt. 1977 waren von 1.170 delegierten tansanischen StudentInnen in Übersee gerade einmal 31 Frauen, also 2,6\%. ${ }^{71}$ Die

67 Interview \#41, Tansanischer Student in BRD.

68 BArch Koblenz, B 212/26037, Scheibe (DAAD) an Hellmann (DAAD), o.0., 12.9.1967; Schott, Matomora Matomora, S. 65.

69 BArch Koblenz, B 212/30032, Hefter Nr. 2, Scheibe (DAAD), Reisebericht Daressalam / Tansania, 3.-6.9.1967, o.O., o.D., S. 5-6. Für ähnliche Äußerungen im Falle Kenias siehe ebd., o.A., Aktenvermerk zu Reise nach Nairobi/Kenia, 10.-14.9.1967, o.O., o.D.

70 URT, Annual Manpower Report to the President 1970, Dar es Salaam 1971, S. 92-94.

71 URT, Manpower Report 1977, S. 62. 
beiden deutschen Staaten bildeten hier keine Ausnahme. 1976 waren nur 2 von 89 tansanischen Studierenden in der DDR Frauen. Beim DAAD gingen zwischen 1975 und 198986 Bewerbungen aus Tansania ein, davon neun (10,4\%) von Frauen. Zu einem großen Teil lässt sich der geringe Anteil von Frauen als Resultat ihrer Unterrepräsentation im tansanischen Bildungssystem erklären. Die Ursachen für diese Unterrepräsentation wiederum sind komplex und umfassen patriarchale Gesellschaftsstrukturen, aus vorkolonialer und kolonialer Zeit fortwirkende Muster der Arbeitsteilung und damit verbunden die Doppelbelastung, die Frauen mit Produktions- und Reproduktionsaufgaben zukam - wobei letzterer in den Rollenbildern oft höhere Bedeutung beigemessen wurde. ${ }^{72}$ Weiblichkeit und Mobilität, Mutterrolle und berufliche Karriere galten weithin als Widersprüche. Viele Männer hinderten ihre Ehefrauen und Töchter, eigenständige berufliche Existenzen aufzubauen oder ,allein“ ins Ausland aufzubrechen. ${ }^{73}$ Das am ehesten akzeptable Mobilitätsmodell eines weiblichen Auslandsstudiums in patriarchalischer Logik war, den Ehemann bei dessen Auslandsaufenthalt zu begleiten.

Die Stipendienvergabepolitik der deutschen Staaten verstärkte diese Ungleichheitsmechanismen weiter. Archivmaterialien und Interviews legen nahe, dass es sich bei den wenigen Frauen, die mit öffentlichen Stipendien in der DDR und BRD studierten, meist um Frauen handelte, die ihren Ehemännern „folgten“ insbesondere, wenn es sich bei ihren Ehemännern um Doktoratsstudenten handelte.

Für die meisten bedeutete ein Überseestudium jedoch eine jahrelange Trennung von Familienangehörigen. Stipendienvergebende Stellen in der BRD waren der Meinung, dass mitreisende Ehefrauen prinzipiell keine Aufenthaltserlaubnis erhalten sollten - aus Kostengründen aufgrund des knappen Wohnraums, aber auch, weil Ehefrauen die Stipendiaten vom Deutscherwerb und ihrer Hauptaufgabe, dem zielstrebigen Abschließen des Studiums, abhalten würden. ${ }^{74}$ Frauen, die mit ihren Kindern, aber ohne mitausreisenden Partner ein Überseestudium antreten wollten, bekamen vom DAAD, vom auch für Männer üblichen Kinderzuschlag abgesehen, keine günstigeren Bedingungen; Flug- und andere Kosten für die Kinder wurden nicht übernommen. ${ }^{75}$ Einer Bewerberin aus dem Jahr 1989 wurde das Stipendium erst gewährt, als sie belegte, dass für die Betreuung ihrer

72 Lal, Militants; Stella Bendera, Moving Beyond Issues of Access and Equity in Promoting Education for Girls in Tanzania, in: Christine Heward/Sheila Bunwaree, Hg., Gender, Education and Development: Beyond Access to Empowerment, London 1999, S. 117-132.

73 Ivaska, Cultured States, S. 116.

74 HHStAW, 507/1192, Rundschreiben Ministerialrat Barth (Hess. Ministerium für Wirtschaft und Technik), 15.6.1970.

75 DAAD-Archiv, B 212/91392/3, DAAD an BRD-Botschaft Dar es Salaam, o.O., 16.6.1980. 
drei Kinder in Tansania gesorgt war. ${ }^{76}$ Männer hatten derartige Belege nie vorzulegen. Auf DDR-Seite war die Mitnahme von Familienangehörigen in den Abkommen über die Stipendienvergabe von vorneherein explizit ausgeschlossen. ${ }^{77}$ Selbst wenn beide Ehepartner ein Stipendium erhielten, war die Mitnahme der Kinder ausgeschlossen, was ein Ökonom, der gemeinsam mit seiner Frau (einer Ärztin) in der DDR ein Doktoratsstudium absolviert hatte, als „inhuman, [...] nasty experience“ beschrieb. ${ }^{78}$ Dass beide die jahrelange Trennung von den Kindern dennoch in Kauf nahmen, weist auf eine Opportunitätsstruktur hin, in der Stipendien für ein Auslandsstudium rar und begehrt waren - wobei sich die Motive aber auch mit der Zeit wandelten.

\section{Persönliche Motive}

Selbst wenn die Stipendienprogramme staatlich gelenkt waren, waren doch individuelle Motive letztlich ausschlaggebend dafür, dass ein Überseestudium angetreten wurde. ${ }^{79}$ Für den Großteil war es wohl wie für einen Bewerber aus dem Jahr 1977, der ein Stipendium für ein Ingenieurstudium in der DDR oder ,jedes andere Land in Übersee“ beantragte: Das zentrale Ziel war, sich Wissen und einen möglichst prestigereichen Studienabschluss anzueignen, der unter den spezifischen tansanischen Bedingungen , unter denen z.B. unternehmerische Tätigkeiten stark eingeschränkt waren, einen sozioökonomischen Aufstieg ermöglichte. ${ }^{80}$ Über dieses Aufstiegsmotiv hinaus lassen sich aber noch weitere Motive herausarbeiten, die TansanierInnen für ein Studium in den deutschen Staaten angaben entweder retrospektiv im Interview oder aber in Bewerbungsschreiben, Immatrikulationsbögen und Lebensläufen, die in Archiven überliefert sind. Eine

76 DAAD-Archiv, B 212/91395/3, DAAD an BRD-Botschaft, Bonn, 1.2.1989.

77 BArch Berlin, DQ 1/12533, Arbeitsplan zwischen der Regierung der DDR und der Regierung der Vereinigten Republik Tansania über die kulturelle und wissenschaftliche Zusammenarbeit in den Jahren 1983-1985, S. 13; ebd., DR 3/2. Schicht/B 1449/1b, Arbeitsplan zwischen der Regierung der DDR und der Regierung der VRT über die KWZ und WTZ in den Jahren 1975 bis 1976.

78 Interview \#42, Tansanischer Student und Doktoratsstudent in der DDR; siehe auch UAL, WR 1979/131, Borschberg (Abt. AS im DIB) an Fröhlich (Institut für Tropische Landwirtschaft), Leipzig, 18.8.1975.

$79 \mathrm{Zu}$ Migrationsmotiven angolanischer und mosambikanischer „VertragsarbeiterInnen“ in der DDR siehe Marcia C. Schenck, From Luanda and Maputo to Berlin. Uncovering Angolan and Mozambican Migrants' Motives to Move to the German Democratic Republic (1979-1990), in: African Economic History 44 (2016), S. 202-234.

80 TNA, FA/E 160/11, Part C, Bewerbungsschreiben A. M. an Principal Secretary, Ministry of Foreign Affairs, Dar es Salaam, 6.1.1977, Bl. 176. 
Analyse, wie sich die Motive verschoben, erlaubt zugleich Einblicke in den Wandel von Wahrnehmungen und Opportunitätsstrukturen. Die Motive spiegeln Selbstbild und Zukunftserwartungen und verweisen dabei auch auf den historischen Kontext.

Viele junge TansanierInnen hatten keinen konkreten Begriff von Deutschland oder gar der BRD und der DDR. Auch von ulaya, ein dehnbarer Begriff Europas, der mitunter auch Nordamerika und andere vorwiegend als „weiß“ wahrgenommene, westliche Länder mit einschloss, existierten von kolonialen Zerrbildern abgesehen oft wenig konkrete Vorstellungen. Die Logik der Systemkonkurrenz war für viele im Gegensatz zu diesem Sprung von Tansania nach ulaya nur von untergeordneter Bedeutung:

We didn't know that there is a big difference between the Eastern Bloc and the Western Bloc. For us, Europe was Europe and we were happy that we were going there. [...] We didn't know how different it is, but we knew it is something better. ${ }^{81}$

Interne Differenzierungen von ulaya waren wenig bekannt, aber der qualitative Unterschied zu Tansania - ,we knew it is something better“ - stand fest. Nur sehr wenige wollten spezifisch in einem kommunistischen Land (oder gar spezifisch in der DDR) studieren. ${ }^{82}$ Das Motiv des Roten Mekka ${ }^{83}$ spielte nur Ende der 1950erJahre und Anfang der 1960er-Jahre eine gewisse Rolle; danach nur noch in Einzelfällen. Hinzu kam ein mit Technik-, Modernitäts-, Kolonial- und Disziplinierungsbegriffen verwobenes Germanophilie-Motiv, das die Kolonialvergangenheit und stereotype Deutschlandbilder mit dem eigenen Stipendium verband und insbesondere in offiziellen Kontexten und Anträgen verwendet wurde. ${ }^{84}$ In einem Formular für ein DAAD-Stipendium schrieb ein Bewerber am 24.11.1961, also noch vor der Unabhängigkeit:

When I look at the stable Central Railway line, recall the marvellous scientific inventions by Germans and listen to the unequalled praises to German, I find myself forced to study from there. ${ }^{85}$

81 Interview \#63, Tansanischer Student in der DDR und Doktoratsstudent in der BRD; ähnlich Interview \#66, Tansanischer Student in der BRD.

82 UAL, StuA 109 336, Lebenslauf K.G., o.D. [ca. 1965], Bl. 5.

83 Matusevich, Journeys of Hope; Woodford McClellan, Black Hajj to „Red Mecca“: Africans and Afro-Americans at KUTV, 1925-1938, in: Maxim Matusevich, Hg., Africa in Russia, Russia in Africa: Three centuries of encounters, Trenton, NJ 2007, S. 61-84.

84 Interview \#32, Tansanischer Doktoratsstudent in der BRD; Interview \#75, Tansanischer Student in der DDR und Doktoratsstudent in der BRD.

85 BArch Koblenz, B 212/26037, DAAD-Bewerbung L. R., Dar es Salaam, 24.11.1961. 
Ein anderer Bewerber beteuerte, er sei ,anxious to learn in FRG, [...] having read the history of the country and knowing how hard working and rigorous the Germans are“, und auch im tansanischen Außenministerium blieb die Ansicht, dass „Deutschland“ für technische Studien besonders geeignet sei, über Jahrzehnte hinweg eine Konstante. ${ }^{86}$ Das fraglos wichtigste und für wohl fast alle Studierenden zutreffende Motiv ist das bereits erwähnte Aufstiegsmotiv, das auch die Pragmatik in der Wahl des Studienorts erklärt. Bereits im vorherigen Kapitel über den tansanischen Entwicklungsstaat wurde die zentrale Bedeutung des Studiums für soziales Prestige, beruflichen Aufstieg und den damit verbundenen Zugang zu ökonomischen Ressourcen dargestellt. Die hohe Selektivität des Bildungssystems und die Knappheit von Studienplätzen machten aus Stipendienangeboten einmalige Gelegenheiten. Dementsprechend wurde um diese Chance gekämpft.

In den 1960er Jahren wurden wiederholt Tansanier, die bereits in der DDR angekommen waren, zurückgeschickt, weil ihre Fähigkeiten als ungenügend eingeschätzt wurden. ${ }^{87} 1972$ wurde von einer neu eingereisten Gruppe verlangt, Einstufungsprüfungen zu absolvieren. Die Tansanier protestierten mit der nicht unbegründeten Furcht im Hinterkopf, dass das bereits zum Greifen nahe Studium gefährdet sein könnte. Ein DDR-Funktionär machte von offenen Drohungen Gebrauch, wie sich ein Absolvent der Tropischen Landwirtschaft erinnerte:

[He said,] "Look here you students, you Tanzanians, our universities are not markets where you can bargain so you will have to do the examination. That is the principle, short of that you will go home." [...] We are coming from different backgrounds, so everybody asked himself, what about if it came true, I have to go back home, will I ever find a chance again? You see, so that's why now we were divided. Everybody was thinking about himself, not as a group. ${ }^{88}$

Gerade diejenigen, die aus ärmeren Familien stammten, sahen in dem Auslandsstipendium eine einzigartige Aufstiegsmöglichkeit. ${ }^{89}$ Diese Aufstiegsvisionen war keineswegs stabil oder zeitlos. In den 1960er-Jahren war - angesichts der

86 DAAD-Archiv, B 212/91198/2, G. J. M. an DAAD, Dar es Salaam, 15.1.1990; TNA, FA/E.160/11, Part C, Mandari (Außenministerium) an Tansan. Bildungsministerium, o.0., 18.1.1977; BArch Koblenz, B 212/26037, DAAD-Bewerbung K. E., Dar es Salaam, 24.11.1961; DAAD-Bewerbung N.N. M., Dar es Salaam, 27.11.1961.

87 Siehe mehrere Dokumente hierzu in PAAA, MfAA, C 350.

88 Interview \#65, Tansanischer Student in der DDR. Einzelne Kiswahili-Phrasen des Zitats wurden auf Englisch übersetzt.

89 Siehe zu diesem Aspekt auch Sara Pugach, Eleven Nigerian Students in Cold War East Germany: Visions of Science, Modernity, and Decolonization, in: Journal of Contemporary History 54/ 3 (2019), 551-572. 


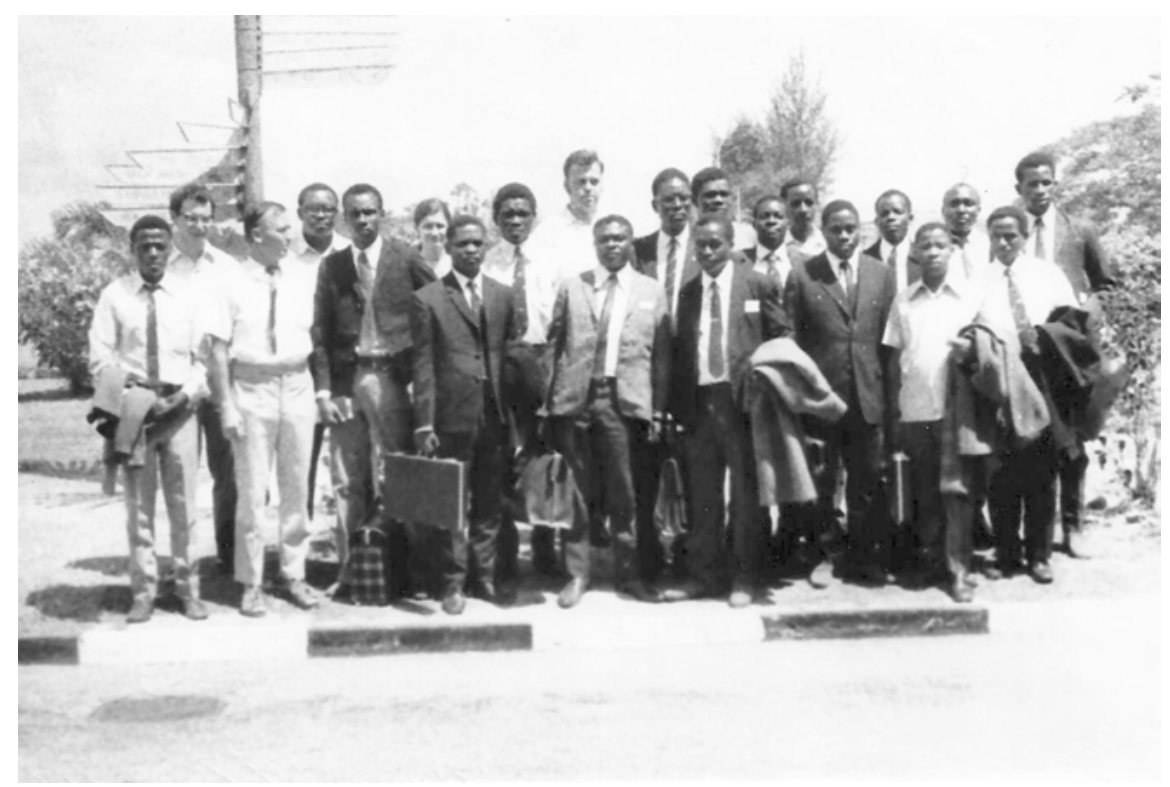

Abbildung 4.1: Tansanier auf dem Weg zur Berufsausbildung in der DDR werden auf dem Flughafen Dar es Salaam von DDR-Botschaftspersonal verabschiedet, Fotografie, 11.1.1974 (Quelle: Privatbesitz).

großen Bedeutung des Staates und dem hohen Prestige des Beamtentums wenig erstaunlich - der Dienst für die eigene Regierung das höchste Ziel. ${ }^{90}$ Der Wunsch, die Karriereleiter zu erklimmen, wurde auch verknüpft mit Entwicklungszielen und Visionen einer wissenschaftlich verbesserten Moderne, wie am Beispiel eines selbst verfassten Lebenslaufs aus dem Jahr 1968 deutlich wird:

The main aim of coming to this country is to take further studies in Veterinary Medicine. After my studies in the G.D.R. I should like to spend most of my time in the Research [sic] work [...] Many tribes here are cattle and goat/sheep keepers. But in order to make [the] best use of the animals [...] they have got to know how to look after their animals properly, to cure and control disease outbreaks. ${ }^{91}$

90 BArch Koblenz, B 2212/26037, Bewerbungen von K. E., N. N. M. und L. R. für ein DAAD-Stipendium, alle 24.11.1961.

91 UAL, StuA 30798, Handgeschriebener Lebenslauf C. S., o.O., 23.9.1968, Bl. 9. Diese Lebensläufe gehörten zu den standardmäßigen Bewerbungsunterlagen für die Zulassung zu einem DDR-Studium. 
In solchen Äußerungen schlug sich ein ausgeprägter Sendungsgedanke nieder. Die pastoral wirtschaftenden Ethnien repräsentierten die wissensmäßige und temporale Rückständigkeit. Sie stellten das imaginierte Interventionsfeld für die Zukunft dar. Leander Schneider hat diese Verschränkung von Zeitverständnis und Entwicklungsdenken (developmentalist temporality) in tansanischen Zeitungsdiskursen nachgewiesen und auch gezeigt, dass sich RepräsentantInnen des Staats und der Partei damit selbst als fortschrittlich und zukunftsorientiert positionierten. ${ }^{92}$ Die Studierenden, die solche Motive äußerten, verorteten sich in Übereinstimmung mit den Erwartungen der Entsende- und Empfängerregierungen in einer Avantgardeposition, allerdings nicht in Richtung Kommunismus oder einem partikularen Afrikanischen Sozialismus, sondern in Richtung einer universalen, durch wissenschaftliches Wissen kreierten Moderne. Mit der Annahme der eigenen Fortschrittlichkeit unter (angehenden) Studierenden ging ein Habitus einher, der die eigene Bedeutung für die Heimat als selbstverständlich annahm. Ein Student der Tropischen Landwirtschaft gestand 1968, er sei nach nunmehr einigen Jahren des Aufenthalts in der DDR aufgrund des vielen intensiven Studierens kein guter Fußballspieler mehr, „denn ich habe wirklich keine Zeit [zum Trainieren]. Ich meine, ich muss mich anstrengen, da das Volk auf mich wartet. [...] Ich möchte meiner Heimat helfen." ${ }^{\text {"93 }}$

Mit der einsetzenden Krise des Entwicklungsstaates und der Wirtschaft wurden Auslandsaufenthalte zunehmend zu einer Strategie, um direkten (d.h., nicht erst nach dem Abschluss) und kurzfristigen Zugang zu ökonomischen Ressourcen zu erhalten: das Wirtschaftsmotiv. Dabei ging es vielfach nicht um Akkumulation, sondern um Lebenshaltungskosten, gerade im Fall von Familienvätern. Der DAAD bekam ab der zweiten Hälfte der 1970er-Jahre immer wieder Schreiben von Stipendiaten, die um den Unterhalt ihrer Familie besorgt waren und daher ihr Studium abbrachen. ${ }^{94}$ Wie andere Formen von Auslandsaufenthalten wurde das Auslandsstudium in den 1980er-Jahren, als der tansanische Schilling im Land sowie gegenüber westlichen Währungen rapide an Wert verlor, zu einer immer mehr wirtschaftlich orientierten Aneignungsstrategie. Das Promotionsstudium in der BRD - so ein Landwirtschaftsexperte, der seinen ersten Studienabschluss in Leipzig gemacht hatte - wurde ,a common thing to do to make more money“. ${ }^{95}$ „Die Chance, sich in dieser Zeit ein Auto anzusparen oder

92 Schneider, Government, S. 94-98; vgl. auch Ivaska, Cultured States.

93 UAL, StuA 12124, Lebenslauf R. C., o.O., o.D. [ca. 1968], Bl. 23; vgl. auch UAL, StuA 12124, Application form, Dar es Salaam, 27.6.1966, Bl. 1.

94 DAAD-Archiv, B 212/91392/3, Zum Besuch des Vice-chancellors Prof. Kuhanga, Bonn, 16.7. 1982, S. 2.

95 Interview \#63, Tansanischer Student in der DDR, Doktoratsstudent in der BRD. 
sich vom Stipendium ein Sparbuch mit Devisen anzulegen, ist für jeden Studenten eine Verlockung“, hielt ein BMZ-Beamter 1990 nach einer Tansania-Dienstreise fest und forderte die Geber auf, bei der Erfüllung dieser materiellen Interessen „ein gewisses Entgegenkommen [zu] zeigen“. ${ }^{96}$ Karriereziel vieler war spätestens ab den 1980er Jahren nicht mehr der Dienst für einen zunehmend ephemeren, schlecht zahlenden Staat, sondern eine Tätigkeit im privaten Sektor, im aid business oder direkt im Ausland. VertreterInnen beider deutscher Staaten klagten in den 1980er Jahren immer wieder über ihre Machtlosigkeit, wenn ausgebildete Counterparts nicht in den vorgesehenen Projekten, sondern in anderen staatlichen Einrichtungen eingesetzt wurden oder aus eigenen Stücken in die Privatwirtschaft abwanderten. ${ }^{97}$ Wie die Motive waren auch die Erfahrungen in Deutschland vielschichtig und zeitabhängig.

\subsection{Erfahrungen auf beiden Seiten der Mauer}

In beiden deutschen Staaten waren TansanierInnen eine vergleichsweise überschaubare Gruppe. Ihre Erfahrungen sind nur punktuell mit signifikanten Migrationsbewegungen von Arbeitskräften (wie im Falle Mosambiks für die DDR ab 1978) oder MigrantInnen, die oft um Asyl ansuchten (wie im Falle Ghanas ab den 1970er-Jahren in der BRD) verbunden. Mehr noch als Sprach- und Vorbereitungskurse waren es andere TansanierInnen oder anglofone Studierende aus Afrika, die den Neuankömmlingen in sozialer Hinsicht eine „sanfte Landung“ und Orientierungswissen boten. ${ }^{98}$ Neben Universitätseinrichtungen und Sozialisierungsangeboten wie Musikgruppen (siehe Abbildung 4.299), Wohnheimen, Bars und Discos nutzten manche Studierende auch kirchliche und andere christliche Gemeinschaften als Räume, um soziale Netzwerke aufzubauen. Das gilt wiederum für beide deutsche Staaten. Leere Kirchen und leblose Gottesdienste in Deutschland sorgten bei manchen christlichen TansanierInnen allerdings auch für Enttäuschung und eine vorübergehende Stilllegung religiöser Praktiken

96 BMZ, B 213/48210, Dienstreisebericht Referat 124, Konsultationen mit Projektbesuchen, Bonn, 9.3.1990.

97 SAPMO BArch Berlin, DY 30/15205, Bericht über die Parteiarbeit II/84 der GO Textilkombinat Mbeya/Tansania, Mbeya, 7.6.1984, Bl. 218; Interview \#110, DDR-Diplomat; Interview \#25, GTZExperte.

98 Interview \#95, Tansanischer Master-Student in Großbritannien und Doktoratsstudent in der BRD.

99 Das 1978 zählte das Ensemble fast 200 Mitglieder. (UAL, DIB 259, „Ausländische Studenten an Universitäten der DDR“, Stand: Ende Stj. 77/78, Bl. 52.) 
(wenngleich nicht der Überzeugungen). Ähnliches in Bezug auf die zeitweilige Stilllegung religiöser Praktiken berichteten muslimische InterviewpartnerInnen. ${ }^{100}$ Im Fall von zwei ehemaligen Doktoranden in der BRD wurden Doktorvater bzw. Doktormutter als enorme Stützen gelobt, die die gerade frisch eingetroffenen Studierenden oft zu sich nach Hause einluden oder sogar anfangs bei sich wohnen ließen, Flüge zur Familie nach Tansania bezahlten und insgesamt eine $\mathrm{Zu}$ neigung (upendo) zeigten, als wären sie Verwandte. Hier handelte es sich um Lehrende, die zuvor bereits in Tansania gelebt und an der Universität Dar es Salaam unterrichtet hatten und ihre Betreuungsfunktion offensichtlich bis tief die private Sphäre ausweiteten, was als großer Unterschied zum distanzierten Betreuungsverhältnis in Tansania erfahren wurde. ${ }^{101}$

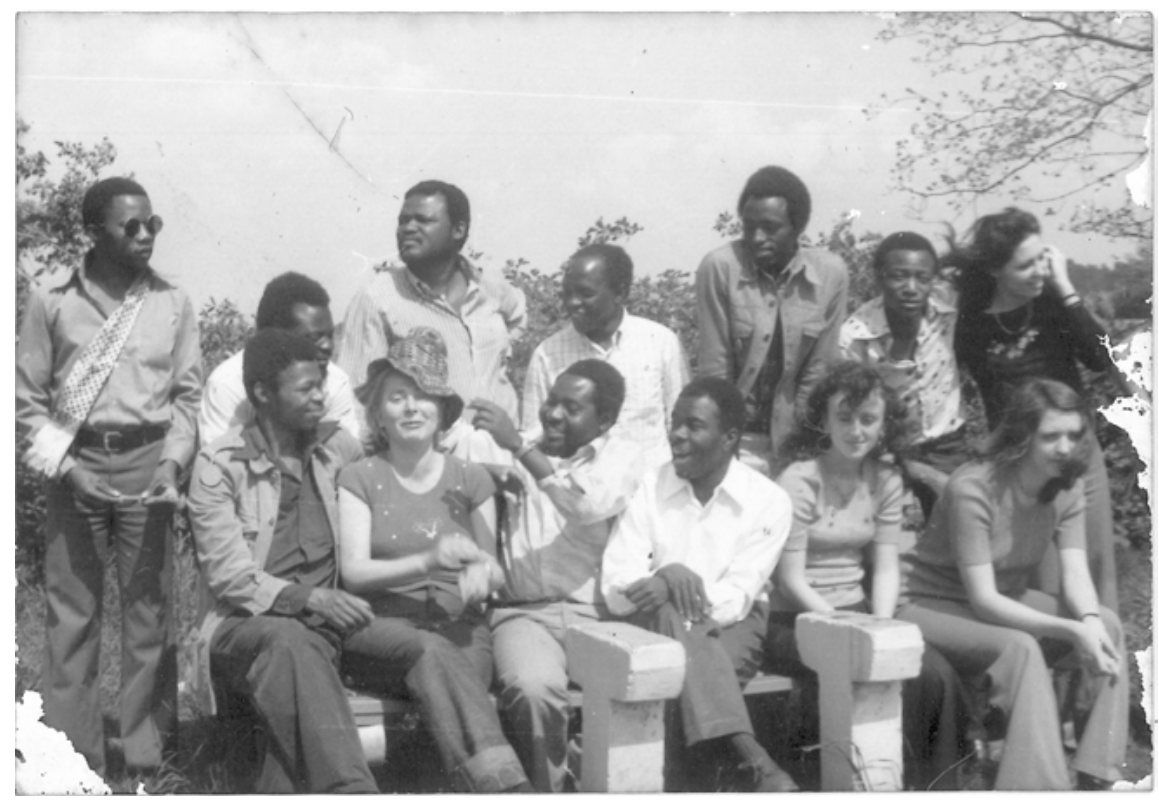

Abbildung 4.2: Fotografie von Mitgliedern der Musikgruppe „Ensemble Solidarität“ der KarlMarx-Universität aus Tansania, Südafrika, der DDR und Griechenland (Quelle: Privatbesitz)

100 Vgl. auch Mac Con Uladh, Studium, S. 187-189.

101 Interviews \#1 und \#41, Tansanische Doktoratsstudenten in der BRD. 
Jene, die ein DAAD-Stipendium erhielten, waren materiell abgesichert. ${ }^{102}$ Schwierig wurde die Situation in der BRD erst, wenn man den Aufenthalt nicht als „Programmstudent“ des DAAD oder Stipendiat einer Stiftung, sondern als ,freier Student" ohne private Finanzierungsquellen bestritt. In der DDR hingegen waren alle tansanischen Studierenden Teil des staatlichen Stipendienprogramms. Ausländische StudentInnen bekamen ein frei verwendbares Stipendium von monatlich 300 Mark, also fünfzig Prozent mehr als deutsche StudentInnen; hinzu kamen umfassende Sozialleistungen. Trotz dieser umfangreichen Absicherung erhielten nur jene, die im „Osten“ studierten, zusätzlich Devisen aus Tansania. Wie auch einige andere Regierungen asiatischer oder afrikanischer Länder opferte die tansanische Regierung jährlich rund US\$150 ihrer knappen Fremdwährungsreserven pro Kopf, um die Beziehung zu den Studierenden in den RGWStaaten aufrecht zu erhalten. ${ }^{103}$ Die jährliche Zahlung wurde durch die Moskauer Botschaft weitergeleitet und von den EmpfängerInnen Ahsante Nyerere („Danke Nyerere") genannt. Im Falle Tansanias waren die Devisentransfers möglicherweise eine Reaktion auf Klagen von Studierenden in den osteuropäischen Ländern, die auch in tansanischen Zeitungen erschienen. 1964 hieß es etwa in einem Leserbrief eines tansanischen Studenten aus der Sowjetunion, man müsse ständig für Lebensmittel anstehen; die Regierung solle für angemessene Bedingungen sorgen, um die Flucht von Studierenden in den Westen zu verhindern und die Rückkehr von Fachkräften zu sichern. ${ }^{104}$ Die politische Führung goutierte derartige Forderungen vorerst nicht: 1966 zeigte sich Außenminister Bomani bei einem BRD-Besuch ,besonders erfreut über den guten Geist, der unter den tansanischen Studenten, die er in Deutschland angetroffen habe, vorherrsche und den er auf ihre dortige Umgebung zurückführt“. Alle Studierenden seien patriotisch eingestellt, was „im krassen Gegensatz zu der Haltung [stehe], die er vor einiger Zeit bei tansanischen Studenten in Moskau kennengelernt habe, die völlig materialistisch orientiert gewesen seien und nur daran interessiert waren, mehr Geld zu

102 Die Stipendienhöhe in der BRD hing von der jeweiligen Organisation ab. 1977 erhielten DAAD-StipendiatInnen monatlich zwischen 650 und 1000 DM - abhängig vom akademischen Grad - und 200 DM zusätzlich bei mitreisendem Ehepartner. Wiedmann, Probleme, S. 151-153. Stipendien während der 1960er Jahre waren nur geringfügig niedriger: 280 Mark für StudentInnen, 470 Mark für AspirantInnen (Hirschinger, Spionage, S. 95).

103 TNA, Acc. 597, FA/E160/11 (Part C), Malipo ya posho 1979/80 - Wanafunzi wote wasomao G.D.R. toka Tanzania. Die Liste führt 1200 tansanische Schilling pro Person auf, was zum damaligen Wechselkurs exakt US\$150 entsprach.

104 BArch Koblenz, B 213/439, BRD-Botschaft an AA, Dar es Salaam, 11.9.1964. 
erhalten“. ${ }^{105}$ Trotzdem kam es zum regelmäßigen Transfer des Ahsante Nyerere gen Osten.

Überseestudierende in der BRD wiederum mussten sich mit Problemen auseinandersetzen, die es im Staatssozialismus in dieser Form nicht gab. DAADStipendiatInnen waren in Unterkunftsfragen oft auf sich allein gestellt und stießen insbesondere in den 1960er Jahren auf Probleme, in Städten wie Frankfurt am Main, Bremen oder München eine Bleibe zu finden. Vorurteile gegen Schwarze mehrere Quellen sprechen unabhängig voneinander von einer offensichtlichen Korrelation der negativen Erfahrungen mit dunkler Hautfarbe - erschwerten das Finden einer Unterkunft auf dem freien Wohnungsmarkt zusätzlich. ${ }^{106}$ Diskriminierungserfahrungen mussten auch in Bars, Discos, Restaurants, Geschäften und auf den Straßen dies- und jenseits der Mauer gemacht werden - und zwar lange vor 1990. ${ }^{107}$ Einige ehemalige BRD-Studierende erwähnten soziale Isolation und Einsamkeit als Probleme, wobei dies vereinzelt auch in der DDR vorkam - gerade an Universitäten außerhalb Leipzigs. ${ }^{108}$ Die meisten TansanierInnen waren aber fraglos in der Lage, während ihres Aufenthalts zahlreiche freundschaftliche (und z.T. auch familiäre) Bande zu knüpfen, und einige von ihnen konnten diese bis in die Gegenwart zu erhalten. Die in manchen Publikationen vertretene These, dass ausländische Studierende in der DDR ,wegkaserniert“ worden seien und kaum Kontakt zur DDR-Bevölkerung gehabt hätten - oder wenn, dann vorwiegend in „offizialisierter“, regulierter Form - lässt sich angesichts des sehr breiten Spektrums von Erfahrungen genauso wenig verallgemeinern wie die entgegengesetzte Behauptung, dass die ausländischen Studierenden vollständig integriert gewesen seien. ${ }^{109}$

105 BArch Koblenz, B 102/86803, BRD-Botschaft an AA, Dar es Salaam, 1.8.1966.

106 Interview \#41, Tansanischer Student in BRD; HHStaW, 507/11139, Krog (Ref. III/31), Aktenvermerk zu Besprechung mit Landesgeschäftsführung des Jugendsozialwerks, Wiesbaden, 22.6. 1962, S. 3; DAAD-Archiv, B 212/91392/3, DAAD an BRD-Botschaft Dar es Salaam, o.O., 13.5.1981; Frankfurter Allgemeine Zeitung, Afrikaner kommen kaum unter, 25.11.1964; vgl. auch die Umfragen von Aich, Farbige, S. 85-133.

107 Vgl. auch Aich, Farbige, S. 232-249; Bizimana, White Paradise, S. 43-44.

108 Interviews \#3 und 34, Tansanische Doktoratsstudenten in der DDR; Interview \#35, Tansanischer Arzt für Spezialisierung in der BRD.

109 Zur ersten Position siehe Patrice G. Poutrus, Aufnahme in die „geschlossene Gesellschaft“: Remigranten, Übersiedler, ausländische Studierende und Arbeitsmigranten in der DDR, in: Jochen Oltmer, Hg., Handbuch Staat und Migration in Deutschland seit dem 17. Jahrhundert, Berlin, Boston 2016, S. 967-995. Für die zweite Position siehe Peter Sebald, Völkerfreundschaft oder Auslandsinformation. Impressionen zum Wirken der Deutsch-Afrikanischen Gesellschaft., in: Ulrich van der Heyden u.a., Hg., Die DDR und Afrika: Zwischen Klassenkampf und neuem Denken, Münster 1993, S. 79-94, hier: S. 82. 


\section{Studieren in der DDR}

Die Betreuung in der DDR war engmaschig. Wie Verantwortliche betonten, trug nicht nur der Hörsaal, sondern der Aufenthalt in seiner Gesamtheit zur Meinungsbildung über die DDR bei. ${ }^{110}$ Aus diesem Grund waren manche VertreterInnen des Hochschulwesens der Ansicht, „dass wir für die ausländischen Studierenden während der Jahre der Ausbildung die ganzen 24 Stunden jedes Tages verantwortlich sind“, was auch die „politische und ideologische Betreuung“ beinhaltete. ${ }^{111}$ Dazu gehörte neben der Einbindung in Seminargruppen auch die Betreuung durch FDJ-Mitglieder. Ein tansanischer Interviewpartner beschrieb die FDJ als zum „Stasi-System“ zugehörig, weil KollegInnen bei schwachen Studienleistungen Informationen über das Privatleben einholten, die dann zu „Aussprachen“, Verwarnungen und ähnlichen Disziplinierungsmaßnahmen führen konnten. ${ }^{112}$ „Fürsorge“ und Begleitung waren mit DDR-spezifischen Hierarchien verbunden, wobei es auch hier ein derart breites Spektrum konkreter Arrangements und Erfahrungen gab, dass keinesfalls von einem allumfassenden oder gar funktionierenden Kontrollsystem ausgegangen werden kann. ${ }^{113}$

Trotz dogmatischer Komponenten kann ein Studium in der DDR keinesfalls pauschal als „Polit-Studium“ abqualifiziert werden, wie es im Westen - und auch in Tansania - teils noch bis heute getan wird. ${ }^{114}$ Schon an den persönlichen Erfahrungen und Begegnungen zeigt sich ein differenzierteres Bild. So erinnerte sich ein tansanischer Veterinär sowohl an einen flamboyanten Professor, der SEDMitglied „aus vollem Herzen“ gewesen sei, wie auch an rein fachlich orientierte Dozenten bis hin zum regimekritischen Professor, der in seinem Unterricht keine Studierenden im FDJ-Dress sehen wollte. ${ }^{115}$ Andererseits war die Priorität der

110 UAL, DIB 259, Jünger (Abt. AS im DIB), Ausführungen des stv. Ministers Heydorn, Leipzig, 12.2.1978, Bl. 82-83. Siehe auch Mac con Uladh, Studium, S. 178, 188.

111 UAL, DIB 259, Jünger (Abt. AS im DIB), Ausführungen des stv. Ministers Heydorn, Leipzig, 12.2.1978, Bl. 82 .

112 Interview \#65, Tansanischer Student in der DDR: „FDJ pia ilikuwa system ya Stasi.“

113 Das belegen schon die zahlreichen Berichte über die ungenügende Vorbereitung und das geringe Wissen der FDJ-,„Betreuer“. So heißt es etwa in einer Einschätzung aus dem Jahr 1962: „Die meisten Betreuer und damit die Institute sind über das kulturelle Leben der Ausländer und deren Beziehungen zu unserer Bevölkerung nicht informiert.“ UAL, DIB 37, Prodekan Dorn, Einschätzung des Standes des Ausländerstudiums dner Wirtschaftswissenschaftlichen Fakultät der Karl-Marx-Universität, Leipzig, 17.4.1962.

114 So eine häufige Annahme in der BRD; hier etwa die Süddeutsche Zeitung, Afrika-Politik mit Braunbuch und Rotlicht, 8. 2.1966.

115 Interview \#65, Tansanischer Student in der DDR. 
Vermittlung von Fachwissen auch in den DDR-Konzeptionen angelegt. Für die „Erziehungsarbeit mit den Studenten aus den nichtsozialistischen Ländern“ galt die Devise: „Je besser sie fachlich ausgebildet werden, desto besser werden sie in ihrer Heimat zum Ansehen unserer Republik beitragen. "116 In beiden Staaten absolvierte die Mehrheit der TansanierInnen Studien in technischen, medizinischen und naturwissenschaftlichen Fachbereichen (Tabelle 4.1).

Tabelle 4.1: Tansanische Studierende in der BRD (WS 1980/81) und der DDR (WS 1982/83) nach Studienrichtungen (Quellen: Gross u. a., Akademiker, 303; TNA, FA/E 160/11, Part C, Tanzania Students in GDR 1982/83)

\begin{tabular}{lrrrr}
\hline Studienfachgruppe & \multicolumn{2}{c}{ BRD } & \multicolumn{2}{c}{ DDR } \\
& Absolut & Anteil & Absolut & Anteil \\
\hline Sprach- und Kulturwissenschaften & 10 & $20,8 \%$ & 5 & $9,3 \%$ \\
Sport & 0 & $0,0 \%$ & 1 & $1,9 \%$ \\
Wirtschafts- und Gesellschaftswissenschaften & 8 & $16,7 \%$ & 7 & $13,0 \%$ \\
Mathematik und Naturwissenschaften & 4 & $8,3 \%$ & 0 & $0,0 \%$ \\
Medizinische Wissenschaften & 6 & $12,5 \%$ & 4 & $7,4 \%$ \\
Agrar-, Forst- und Ernährungswissenschaften & 7 & $14,6 \%$ & 8 & $14,8 \%$ \\
Technische und Ingenieurwissenschaften & 13 & $27,1 \%$ & 23 & $42,6 \%$ \\
Kunstwissenschaften & 0 & $0,0 \%$ & 2 & $3,7 \%$ \\
Unbekannt & 0 & $0,0 \%$ & 4 & $7,4 \%$ \\
\hline Gesamt & $\mathbf{4 8}$ & $\mathbf{1 0 0}$ & $\mathbf{5 4}$ & $\mathbf{1 0 0}$ \\
\hline
\end{tabular}

Die fachliche Qualität der Studien wurde von InterviewpartnerInnen generell sehr gelobt. Kritisiert wurde am ehesten die fehlende Tiefe in bestimmten Spezialgebieten oder, für den Fall der DDR, die Abwesenheit moderner Computertechnologie (was allerdings die Vergleichsperspektive mit der BRD voraussetzte). ${ }^{117}$ Manche waren laut eigener Aussage nach ihrem DDR-Studium überrascht, dass es ihnen im Vergleich zu TansanierInnen mit BRD-Abschlüssen an nichts mangelte und sie ohne Probleme eine Promotion an einer bundesdeutschen Universität angehen konnten. Die Annahme, dass das westliche Bildungssystem per se überlegen war, hatte die Erwartungshaltung geprägt und konnte erst durch eigene Erfahrungen widerlegt werden. Deutlich wurde in allen Interviews, dass das Studium als einseitiger Wissenstransfer angelegt war, in dem es kaum

116 Arbeitsplan für die politisch-ideologische und kulturelle Betreuung der ausländischen Studenten an der TH für Chemie Leuna-Merseburg vom 22. 2.1961, zit. nach Hirschinger, Spionage, S. 98.

117 Tansanischer Student in der DDR, Doktoratsstudent in der BRD; E-Mail an den Autor, 9.1. 2015. 
Möglichkeiten gab, eigenes Wissen einzubringen, auch in der BRD, wo SympathisantInnen Tansania als eines der „ideologisch führenden Länder der Dritten Welt gerade auf dem Gebiet der Ausbildung und Erziehung“ priesen. ${ }^{118}$ Die üblichen Repräsentationen von ausländischen Studierenden bilden diese Konzeption ebenfalls ab (Abbildung 4.3119).

Einige TansanierInnen waren in ihren Fächern mitunter die besten ausländischen Studierenden, zeigten Leistungen über dem Durchschnitt ihrer deutschen KollegInnen oder überflügelten diese sogar und leisteten gerade in den weitgehend sprachunabhängigen naturwissenschaftlichen Fächern wie Mathematik Nachhilfe. ${ }^{120}$ Auf dieser Ebene war der Wissenstransfer also keinesfalls nur einseitig. Exmatrikulationen aufgrund von Leistungsproblemen gab es in der DDR (für die BRD lässt sich das aufgrund des Fehlens desaggregierter Statistiken nicht nachvollziehen) nur in Ausnahmefällen - zuerst wurde von persönlichen Gesprächen bis hin zur Ausübung von Druck eine Reihe von Methoden angewandt, um den Lernerfolg zu verbessern. Selbst bei extrem schwacher Studienleistung brauchte es üblicherweise erst eine Note der Heimatregierung, bis die DDR zu diesem Schritt, der einem Scheitern des DDR-Ausländerstudiums gleichkam, bereit war. ${ }^{121}$ Dass manche Lehrkräfte ausländische Studierende bewusst milder beurteilten, ist dabei nicht auszuschließen; in einem internen Dokument aus dem Jahr 1988 wird etwa ausdrücklich gefordert, dass „falsches Solidaritätsdenken“ in Form von geringeren Leistungsanforderungen $\mathrm{zu}$ unterlassen sei. ${ }^{122}$

Obwohl das DDR-Studium nicht pauschal als „Politstudium“ abqualifiziert werden kann, gab es doch Aspekte, die auf eine marxistisch-leninistische Indoktrinierung abzielten. Zwar war der Unterricht in einer adaptierten, ,abgeschwächten“ Form des Marxismus-Leninismus für Studierende aus nicht-sozialistischen Ländern erst ab 1969 obligatorisch, aber schon zuvor wurden sie zur

118 PAAA, ZW 119384, Wedel (FES), Projektbeschreibung für Reintegrationsseminar für tansanische Studenten vom 3. bis 5. Mai 1976 in Bad Godesberg, Bonn, 31.3.1976, S. 3.

119 Die Original-Bildunterschrift endet mit den Worten: „Direktor Kaletta erklärte den Gästen die Anlage. In fünf Jahren wollen die Studenten als Agraringenieure in ihre Heimatländer zurückkehren.“

120 UAL, DIB 262, Jünger (Abt. AS), Entwurf „Überlegungen zu den Jahresanalysen der Universitäten, Hoch- und Ingenieurhochschulen“, o.D., o.O., [ca. 1977], Bl. 44; ebd., StuA 10288, Vorschlag zur Leistungsprämie, o.D. [ca. 1965], Bl. 3; ebd., StuA 109336, Institutsdirektorin Prof. Dr. Eva Müller, Stellungnahme zum Aspiranturantrag, 24.12.1964, Bl. 57; Interview \#76, Tansanische Studentin in der DDR; Interview \#92, Tansanischer Student in der DDR.

121 UAL, StuA 117206,Antrag auf Wechsel der Studienrichtung, 4.11.1965, Bl. 26.

122 BArch Berlin, DR 3/2. Schicht/4059, Vorlage zur Dienstbesprechung Nr. 239/88, Studienjahreseinschätzung Ausländerstudium, o.D. [1988], S. 4. 


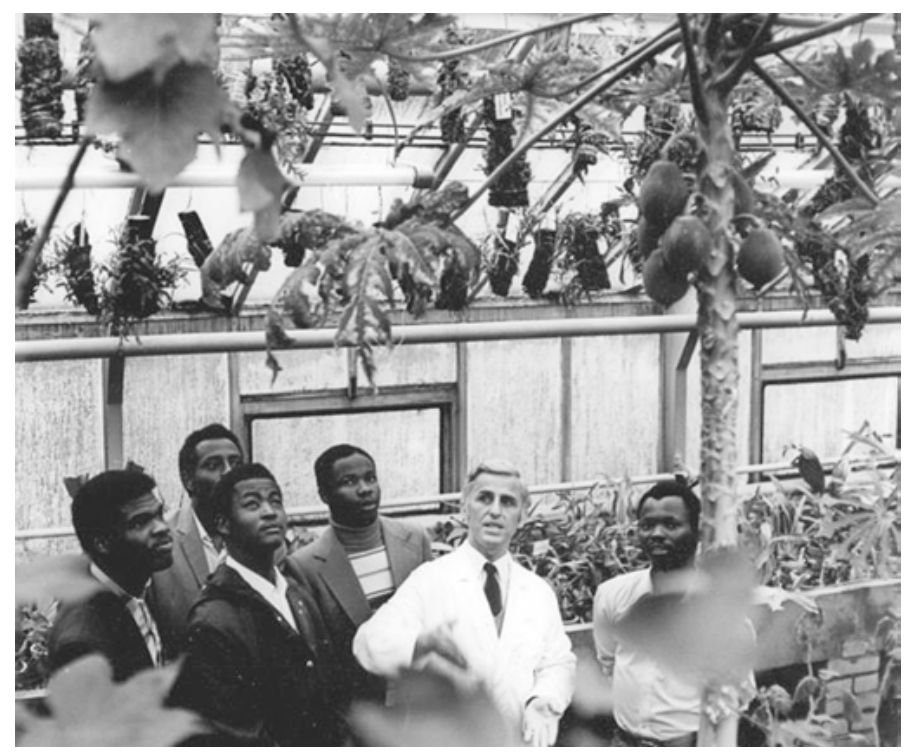

Abbildung 4.3: Darstellung des einseitigen Wissenstransfers im Botanischen Garten in Leipzig, 22.9.1973. Unter den fünf afrikanischen Studenten befindet sich ein Tansanier (Quelle: Bundesarchiv, Bild 183-N0922-0018; Fotograf Wolfgang Kluge, lizensiert unter Wikimedia Commons).

freiwilligen Teilnahme angehalten - wenn auch mit wenig Erfolg. ${ }^{123}$ In der Fachrichtung Tropische Landwirtschaft - eine der wenigen Studienrichtungen in der DDR mit überwiegend ausländischen StudentInnen - waren Prüfungen nicht nur in Genetik, Mathematischer Statistik und Bodenerhaltung abzulegen, sondern auch in den Fächern Agrarökonomie der DDR, Philosophische Grundfragen unserer Zeit, und Grundfragen der revolutionären Hauptströme unserer Zeit. ${ }^{124}$ Die Letzteren waren stark durch marxistisch-leninistische Theorien geprägt. In Interviews wurde der verpflichtende Charakter derartiger Lehrveranstaltungen betont: „Man musste es machen“, „sonst hätte man exmatrikuliert werden können“, waren einige der verwendeten Formulierungen. ${ }^{125}$ Zwei Interviewpartner erzählten, dass

123 Hirschinger, Spionage, S. 101; Mac Con Uladh, Studium, S. 192. Im selben Jahr war der Pflichtunterricht in Marxismus-Leninismus auch in der Sowjetunion eingeführt worden, siehe Constantin Katsakioris, Creating a Socialist Intelligentsia. Soviet Educational Aid and its Impact on Africa (1960 - 1991), in: Cahiers d'Études africaines LVII/2 (2017), S. 259-287.

124 UAL, StuA 070903, Prüfungsprotokoll John S. K., Leipzig, 5.3.1979, Bl. 1-2.

125 Interview \#78, Tansanischer Student in der DDR. Im Original: „lazima ufanye“ „unaweza ukafukuzwa“. 
sie die Prüfungen in marxistisch-leninistischen Fächern nicht bestanden hatten und deswegen verwarnt wurden. Wie einer der beiden erzählte, wurde im Unterricht u.a. die Teleologie vermittelt, dass die DDR die höchste Stufe der menschlichen Entwicklung darstelle:

In Marxismus-Leninismus, we were learning that the evolution - monkeys develop and develop, feudalism, capitalism - the ultimate human development is communism. The human being is most developed when the human being becomes a communist. So people like West Germans they are still in their process towards the highest human nature of development. ${ }^{126}$

Das Bestehen der Prüfung sei nicht zuletzt aufgrund seiner anderen Leistungen von ihm verlangt worden, um das Studium fortsetzen zu können:

In engineering mechanics, in mathematics I was the best. But I failed Marxism-Leninism. So they told me intelligence does not separate the subjects. So it means you have failed Marxismus-Leninismus deliberately. So my results were not recognised. Until I repeated the subject and passed it equally good like other subjects. ... I was not interested in the course. It was not contributing anything to my civil engineering career. Of course they were right that I failed deliberately. ${ }^{127}$

DDR-Quellen geben Aufschluss darüber, dass es sich hier um keinen Einzelfall handelte: Lektionen wurden nicht passiv hingenommen, sondern aus verschiedenen Perspektiven hinterfragt. Das konnte, wie im obigen Fall, aus einem technokratischen Bildungsverständnis heraus geschehen, in dem nur fachlich relevante Kurse verpflichtend sein sollten; ${ }^{128}$ in anderen Fällen aus einer Universalismuskritik heraus, der zufolge religiöse Aspekte oder regionale Besonderheiten zu berücksichtigen seien (wie es z.B. der Afrikanische Sozialismus tue) und der Marxismus-Leninismus keine Allgemeingültigkeit beanspruchen könne. ${ }^{129}$ Retrospektiv ordneten manche den Marxismus-Leninismus-Unterricht aber auch normalisierend als ein „Fach wie jedes andere“ ein und verglichen ihn mit Kursen in Development Studies in Tansania, deren Absolvierung an der Universität Dar es Salaam ebenfalls für alle Studierenden verpflichtend war (siehe Kapi-

126 Interview \#75, Tansanischer Student in der DDR und Doktoratsstudent in der BRD.

127 Ebd

128 Fitschen, Wissenschaft im Dienste des Sozialismus, S. 659.

129 BArch Berlin, DR 3/2. Schicht/4058, Studienjahresanalyse Ausländerstudium (Studienjahr 1978/79), S. 7. Iranische Studierende wurden mit der Meinung wiedergegeben, dass der Islam die eigentlich revolutionäre und damit dem Marxismus-Leninismus überlegene Ideologie sei. 
tel 7). ${ }^{130}$ In dieser Hinsicht bot das Wissen über das, was in Tansania als normal galt, auch einen Standard für die (retrospektive) Bewertung und Entexotisierung des Studiums in der DDR.

Diplomarbeiten und Dissertationen in der DDR befassten sich direkt mit der Frage, welche Erfahrungen im Prozess sozioökonomischer Entwicklung die DDR und andere kommunistische Länder gemacht hatten; andere behandelten das Ujamaa-Umsiedlungsprogramm oder Swahili-Romane aus marxistisch-leninistischer Perspektive (was auch an der Universität Dar es Salaam zu dieser Zeit oft vorkam). ${ }^{131}$ Rivalisierende neo-marxistische Erklärungsmodelle zur Politischen Ökonomie Tansanias - z. B. vom Tansanier Issa Shivji oder dem Westdeutschen Peter Meyns - wurden ausführlich diskutiert und zurückgewiesen. In einem Gutachten über die Dissertation des Ökonomen Kassim Guruli, der das UjamaaModell aus marxistisch-leninistischer Sicht kritisierte, lobte ein DDR-Professor:

Es ist [...] dem Verfasser beizupflichten, wenn er sich nachdrücklich vom ,afrikanischen Sozialismus‘ als einer nationalbürgerlichen Ideologie, die einen ,dritten Weg‘ u.a. durch Verschmelzen verschiedener Eigentumsverhältnisse predigt, abgrenzt. ${ }^{132}$

TansanierInnen, die sich anders als Guruli zum Afrikanischen Sozialismus oder zu maoistischen Positionen bekannten, galten hingegen als politisch unreif, ideologisch verwirrt oder einfach nur ahnungslos. So schrieb ein Völkerrechtsprofessor über einen tansanischen Studenten, er sei „Anhänger der Politik des jetzigen Regierung in Tansania“, spreche „stets von einem sozialen Humanismus, der für afrikanische Länder geeignet wäre“, habe jedoch „in Wirklichkeit [...] keine Ahnung von Humanismus, vom ,Afrikanischen Sozialismus‘ oder etwa vom wissenschaftlichen Sozialismus." ${ }^{133}$

130 Interview \#47, Tansanischer Doktoratsstudent in der DDR; Interview \#76, Tansanische Studentin in der DDR

131 Siehe z. B. die Promotionsakten UAL, WR 1979/131; ebd., WR 1984/237; ebd., UAL, WR/19379. 132 UAL, WIFA 0411, Gutachten von Prof. Kramer zur Dissertation „Die volkswirtschaftliche Planung in den Entwicklungsländern, dargestellt am Beispiel Tansania“, o.O., o.D. [1969], Bl. 18. 133 UAL, StuA 116549, Dr. jur. P. Terzopoulos (Institut für Völkerrecht), Einschätzung des Studenten O.G.C., 5.1.1968, Bl. 7; s. auch ebd., StuA 12291, Beurteilung des Studenten K., 27.11.1963, Bl. 28 sowie ebd., StuA 117206, Einschätzung des Herder-Instituts über Y. A. H., Leipzig, 6.6.1964, Bl. 43. 


\section{Kritik und Organisation in der DDR}

Studentenorganisationen waren für die beiden deutschen Staaten, insbesondere für die DDR, eine ambivalente Angelegenheit. ${ }^{134}$ Einerseits waren sie gewünscht als Instrument, das Zugehörigkeitsgefühl zum Entsendeland zu stärken und die Rückkehrwahrscheinlichkeit zu erhöhen. Andererseits konnten diese Organisationen politische Dynamiken entwickeln, die diplomatischen Interessen zuwiderliefen. In beiden deutschen Staaten galten die Vereinigungen als Beitrag gegen den brain drain und Instrument zur Stärkung nationaler Identitäten. Sie stützten somit die Bevorzugung des nationalstaatlichen Konzepts vor sprachlich, ethnisch oder politisch definierten Identitäten - was wiederum Ausdruck des patriotischentwicklungspolitischen Imperativs und seiner Anbindung an Nationalstaaten war. Quinn Slobodian zufolge reagierten DDR und BRD in den 1960er Jahren ähnlich auf unliebsame Kritik von Studierenden aus der „Dritten Welt“: sie ließen lediglich Räume „überwachter Freiheit“ (supervised freedom) zu, in denen jeglicher politischer Aktivismus, der staatliche Interessen gefährdete, im Zaum gehalten und notfalls unterdrückt werden konnte. ${ }^{135}$ Am Beispiel der tansanischen Studentenunion in der DDR lässt sich zeigen, wie unterschiedlich die Erwartungen an derartige Organisationen waren - und wie unterschiedlich ihre Tätigkeit bewertet wurde.

Die DDR-Führung sah ausländische Studierende generell einerseits als „handels- und außenpolitisches Kapital“, aber auch als Risikoelement, da sie „negative Gruppierungen“ bilden konnten und so „die vom Westen ausgehende Zersetzung unterstützten“. ${ }^{136}$ Ein Instrument zur Disziplinierung ausländischer Studierender, ohne den Widerstand der Entsendestaaten hervorzurufen, war die Bildung „nationaler Studentenunionen“ und die obligatorische Mitgliedschaft in diesen Vereinigungen. ${ }^{137}$ Jegliche Veranstaltung der Organisationen musste angemeldet werden, nicht zuletzt weil sich die Staatssicherheit - wobei hier nicht geklärt werden kann, ab wann und in welchem Umfang - für die Tätigkeiten der studentischen Organisationen interessierte und diese ,politisch-operativ absi-

134 Die folgenden Argumente werden unter Angabe von Beispielen ausgeführt für die BRD in Grosskopf, Kulturschock, S. 42 und Quinn Slobodian, Dissident Guests: Afro-Asian Students and Transnational Activism in the West German Protest Movement, in: Wendy Pojmann, Hg., Migration and Activism in Europe since 1945, New York 2008, S. 33-56; für die DDR in Mac con Uladh, Studium, S. 193-195.

135 Slobodian, Bandung, S. 646.

136 Fitschen, Wissenschaft im Dienste des Sozialismus, S. 666.

137 UAL, DIB 259, Ausländische Studenten an Universitäten der DDR, Stand: Ende Stj. 77/78, Bl. 54-55. 
cherte“. ${ }^{138}$ Zumindest vereinzelt setzte das MfS inoffizielle MitarbeiterInnen ,zur Erarbeitung von Informationen zu Entwicklungstendenzen in den afrikanischen Studentenverbänden“ ${ }^{\text {“ }}$ in. ${ }^{139}$

Die faktische Haupttätigkeit der Union tansanischer Studenten in der DDR war - ganz im Sinne der DDR-Führung - eher kulturell denn politisch und bestand darin, die Erlaubnis zur Durchführung von Vollversammlungen, Festen an Nationalfeiertagen, Exmatrikulationsfeiern und Studentendiscos zu beantragen und Räumlichkeiten, Essensmarken und Nächtigungsplätze zu organisieren. Bei Vollversammlungen in den 1970er und 1980er-Jahren wurden meist zwischen 70 und 100 TansanierInnen erwartet, dazu noch einmal so viele deutsche und internationale Gäste. Die Programmpunkte umfassten häufig kulturelle Darbietungen wie Chorgesang und Tänze, aber auch Reden der AmtsinhaberInnen; manchmal gab sich sogar der Botschafter aus Moskau die Ehre. Den Abschluss bildete die obligatorische Disco. ${ }^{140}$ Während Vereinigungen anderer Länder, z. B. Vietnams, straff organisiert waren und die Studierenden in Zusammenarbeit mit der Botschaft streng überwachten und Kontakte wie auch Freizeitgestaltung zu regulieren suchten, war der Disziplinierungseffekt bei tansanischen Studierenden eher gering. ${ }^{141}$ Ehemalige Funktionäre der tansanischen Union betonten in Interviews, dass die Union das Augenmerk auf den Studienerfolg der Mitglieder legte und den Kontakt zur zuständigen Botschaft (also nicht im deutlich näher gelegenen Bonn, sondern in Moskau) hielt. Einfache Mitglieder hingegen erinnerten sich vor allem an Parties und die Orientierungsfunktion für Neuankömmlinge: es habe ohnehin kaum ernsthafte Probleme und damit keinen Handlungsbedarf gegeben. ${ }^{142}$

Zumindest ein Fall ist erwähnenswert, in dem Handlungsbedarf gesehen, aber jede für die DDR autoritätsgefährdende Handlung im Keim erstickt wurde. Ausgangspunkt war der Tod eines tansanischen Studenten unter ungeklärten Umständen - laut DDR-Seite ein Selbstmord, was unter den Studierenden bezweifelt wurde. Ein Repräsentant der Union setzte sich dafür ein, den Todesfall genauer untersuchen zu lassen, stieß aber auf Gegenwehr der DDR-Behörden:

[Sie sagten,] „Du bist nicht Vertreter deiner Regierung, also halte gefälligst deinen Mund.“ [...] Die Warnung war, dass sie mich, wenn ich weitermachen würde, exmatrikulieren. Nicht

138 BStU, MfS, HA XX 16587, HA XX/8, Information über geplante Veranstaltung im Verantwortungsbereich, Berlin, 29.12.1981.

139 BStU, MfS, HA XX 2597, Einsatz zur Aufklärung äthiopischer Studenten, o.J. [1989?], Bl. 6. 140 UAL, DIB 346, Bl. 13-30 (verschiedene Dokumente).

141 Schmelz, Bildungsmigranten, S. 67-68, 71-72.

142 Interview \#34 und \#104, Tansanische Studenten in der DDR. 
explizit, aber ich weiß, dass es in diese Richtung ging. [...] Weil ich Angst hatte und das Studium beenden wollte, bin ich dann ruhig geblieben. ${ }^{143}$

Eine wirkliche Interessenvertretung sei unter diesen Bedingungen nicht möglich gewesen, wie er weiter ausführte: „Ostdeutschland hätte mir nicht erlaubt, mich mit politischen Fragen zu befassen. Das war verboten.“ Jegliche politische Betätigung, die gegen den Willen der Behörden ging, wurde durch gezielte Druckausübung auf die agierenden Einzelpersonen unterbunden; diese fügten sich meist mit Blick auf das Ziel, das Studium abzuschließen. Ähnlich gingen manche Studenten mit der halb-freiwilligen Einbindung in die DDR-Rituale internationaler Solidarität um. ${ }^{144}$ Jener ehemalige Ingenieurstudent, der sich auch über sein negatives Auffallen in den Marxismus-Leninismus-Prüfungen geäußert hatte, erinnerte sich an seine Teilnahme an der Demonstration zum Tag der Arbeit unter dem Leitbegriff des Zwangs (force):

\begin{abstract}
When we were in East Germany, we were also forced to be active politically. For example, we had the celebration of 1 May. What they did: the Tanzanian flag was brought to the start of the demonstration. Knowing that we have two or three Tanzanian students, the flag is there. So we have to march. Past the party leaders. And to demonstrate against imperialism, against capitalism. You have to! Because otherwise the flag will still [be] lying there and they will know that you did not attend the procession. So, we were marching. Through the party, SED leaders. And we were in the announcements: "Hier kommt das tansanische Proletariat im Kampf gegen den Imperialismus! Hoy-yeh! Hoy-yeh! Hoy-yeh!” And we march it through (lacht). And you cannot tell them "That is not true!” No, we are marching (lacht). [...] I was angry, but what do you do? You wanted to survive. ${ }^{145}$
\end{abstract}

In manchen Narrativen wurden die „Überlebensstrategien“ in der DDR mit jenen verglichen, die bereits in bestimmten Kontexten in Tansania Anwendung fanden.

143 Interview \#65, Tansanischer Student in der DDR. Im Original: „Wasingeruhusu kushughulika na politics hiyo ilikuwa ni marufuku na nakumbuka nilipata shida pia kwa sababu ya hilo [...] nilipewa onyo kwamba sisi tunazungumza na serikali yako wewe sio mwakilishi wa serikali yako kwa hiyo tafadhari funga mdomo. [...] [0]nyo lilikuwa kama ningeendelea wangenifukuza shule. [...] [S]io wazi lakini najua kwamba huo ndio ulikuwa muelekeo. [...] nikastopishwa nikaambiwa ninyamaze mimi sio mwanasiasa, ubalozi wa Urusi ndio uliotakiwa kuchunguza hilo jambo ndio alikuwa mwakilishi wa pale. Kwa hiyo na mimi ni kwa sababu nilikuwa naogopa nataka kumaliza shule nikanyamaza.“

144 Roland Jahn, Wir Angepassten. Überleben in der DDR, München 2015, S. 79 - 85. Vgl. für ein Beispiel eines Studenten in Polen HHStAW, 507/11330, A. D. an Barth, Frankfurt/Main, 16.3.1967, S. 2: „Ich wurde ausgewählt ein Schimpfplakat zu tragen, das beschriftet war mit Slogans gegen den westlichen Imperialismus an der Spitze des Umzugs“.

145 Interview \#75, Tansanischer Student in der DDR, Doktoratsstudent in der BRD 
Wie im paramilitärischen National Service in Tansania, befand ein anderer Interviewpartner, musste man auch in der DDR den „Mund halten“ (kufunga mdomo):

Sich zu widersetzen hat einem nicht geholfen. Es war ähnlich wie in der Armee, als wir beim National Service waren. Wenn dir etwas gesagt wird, dann machst du das einfach und widersetzt dich nicht, das hilft nichts. Mach einfach, und wenn deine Zeit um ist, dann gehst du. Und weil wir den National Service durchlaufen haben, haben wir das verstanden. ${ }^{146}$

Bereits in Tansania erprobte Strategien für den Umgang mit autoritären Strukturen wurden in der DDR aus dieser Perspektive also eher aktualisiert und adaptiert denn gänzlich neu eingeübt. ${ }^{147}$ Berichte über den tansanischen nationalen Studentenverband vermerkten in den 1960er und 1970er-Jahren wiederholt, dass unerwünschte „bürgerliche“ und „maoistische“ Ideologien vertreten wurden, aber 1977 „prinzipiell beseitigt“ seien, wofür insbesondere die „straffe Leitungsmethode“ in der Studentenunion als Ursache genannt wurde. ${ }^{148}$ In den 1960er und frühen 1970er-Jahren stellten gerade der Maoismus und die chinesische Kulturrevolution ein Modell für das Aufbegehren gegen Autoritäten bereit, mit dem auch Studentengruppen und Intellektuelle in der DDR sympathisierten. ${ }^{149}$ Für Studierende aus Ländern der „Dritten Welt“ ging es hierbei aber weniger um das Aufbegehren gegen DDR-Autoritäten, sondern eher um eine divergente Vision der Weltrevolution und eine Solidarität aller „farbigen Völker“. Wer diesen Ideen anhing, so fürchtete man in der DDR, würde nicht den globalen Kampf der Arbeiterklasse gegen den Kapitalismus, sondern den Nord-Süd-Gegensatz als weltgeschichtlichen Hauptkonflikt sehen. In den 1980er-Jahren flammten Debatten über den Maoismus nur noch vereinzelt auf. ${ }^{150}$ Gleichzeitig wurde aber auch durchaus realistisch - darauf hingewiesen, dass globale Kräfteverschiebungen (der Rückzug der USA aus Vietnam, die sozialistische Orientierung des gerade unabhängig gewordenen Angola) die Stärke, Überlegenheit und Zukunftsträch-

146 Interview \#43, Tansanischer Student in der DDR, Doktoratsstudent in der BRD. Im Original: „Hata kama ulikuwa unabisha kitu ili kufanyeje kwa sababu kubisha ilikuwa haikusaidii. Ilikuwa inafanana kama na jeshi kama tulivyokuwa National Service ukiambiwa kitu fanya unafanya basi hakuna kubisha hakukusaidii we fanya ukifikisha muda wako unamaliza unaondoka. Na kwa sababu tulipita National Service tulielewa.“

147 Vgl. auch Interview \#34, Tansanischer Doktoratsstudent in der DDR.

148 BArch Berlin, DR 3/2. Schicht/4058, Jahresanalyse des Ausländerstudiums und Einschätzung der Situation in den Verbänden der ausländischen Studenten, 1975/76, o.O., o.D., S. 8.

149 Quinn Slobodian, The Maoist Enemy. Chinas Challenge in 1960s East Germany, in: Journal of Contemporary History 51/3 (2016), S. 635-659.

150 BStU, MfS, HA II 28716, IM Thoralf Winter, Bericht, Magdeburg, 25.1.1982, Bl. 56. 
tigkeit des Sozialismus sowjetischen Stils demonstrierten. Ein Interviewpartner erinnerte sich, dass er während seines DDR-Aufenthalts - in der Mitte der 1970erJahre - sehr skeptisch gegenüber marxistisch-leninistischen Theorien, aber angesichts der andauernden Befreiungskämpfe, Revolutionen und Regierungswechsel in Welt durchaus der Meinung gewesen sei, dass sich die Welt unaufhaltsam auf dem Weg zum Sozialismus befinde. ${ }^{151}$

In politischen Fragen verliefen die Trennlinien dabei keinesfalls einfach zwischen ausländischen und DDR-Studierenden; einige der ausländischen Studierenden „traten gelegentlich sehr offensiv im Sinne der SED auf“, wie Frank Hirscher bemerkt hat. ${ }^{152}$ Andererseits merkten ausländische Studierende durch private Kontakte mit DDR-KommilitonInnen schnell, dass die Parteidirektiven an der Basis nicht geteilt wurden und viele junge Menschen, ohne es offen auszusprechen, „gegen das System waren“, wie sich ein tansanischer Ingenieur erinnerte. ${ }^{153}$ Eine allzu kritische Haltung gegenüber dem Staat war auch in Tansania weitgehend unerwünscht; die 1968er-Bewegung wurde daher mit Misstrauen beäugt.

\section{Tansanische Studierende und das westdeutsche 1968}

Chief Kunambi, Rektor des University College Dar es Salaam, zeigte sich bei einem Besuch in den beiden deutschen Staaten 1969 wenig begeistert von dem studentischen Aufbegehren in der BRD. An der Karl-Marx-Universität in Leipzig angekommen, mokierte er sich einerseits über die „steif[e] und weltfremd[e] Atmosphäre“ an westdeutschen Universitäten, andererseits auch über die Achtundsechziger-Bewegung. Kunambi betonte, dass er von Studierenden, die Universitätsgebäude stürmten und so die Öffentlichkeit schockieren und das ,Verfaulen der Gesellschaft“ offenbaren wollten, nichts halte und verlieh seiner Erleichterung Ausdruck, dass es in der DDR nicht so weit gekommen sei. ${ }^{154} \mathrm{Ku}$ nambis Haltung war kein bloßes diplomatisch geschicktes Entgegenkommen den Haltungen seiner Gastgeber gegenüber, sondern entsprach dem zeitgenössischen Umgang mit Studentenprotesten in Dar es Salaam, ganz besonders im Jahr 1966, als die Protestierenden allesamt vorübergehend exmatrikuliert worden waren (vgl. Kapitel 2, Kapitel 7).

151 Interview \#75, Tansanischer Student in der DDR und Doktoratsstudent in der BRD.

152 Hirschinger, Spionage, S. 100.

153 Interview \#75, Tansanischer Student in der DDR, Doktoratsstudent in der BRD.

154 UAL, DIB 164, Hans-Joachim Wienhold, Bericht über den Besuch von Chief Kunambi, Registrar of the University College Dar es Salaam, Leipzig, 12.1.1969, Bl. 36. 
Interviewaussagen zufolge war die Kohäsion unter den tansanischen Studierenden in der BRD gering und größere Zusammenkünfte, wie es sie in der DDR gab, selten. Gründe dafür sind die heterogenen, dezentralen Entsendekanäle und die Verstreuung über das ganze Bundesgebiet. Wenn es Treffen gab, dann am ehesten auf Geheiß der Botschaft in Bonn. Die Tanzanian Students Union (TASU) der BRD wurde Anfang der 1970er-Jahre bei einem Reintegrationsseminar der Friedrich-Ebert-Stiftung gegründet. ${ }^{155}$ Im Anschluss baute die TASU einen internen Informationsdienst auf, organisierte kleine Arbeitstagungen in verschiedenen Städten und rief 1976 mit Unterstützung der Friedrich-Ebert-Stiftung ein zweites, bundesweites Reintegrationsseminar ins Leben, auf dem sich auch hochrangige tansanische Minister, die gerade mit Nyerere durch Europa tourten, den Fragen der StudentInnen und Auszubildenden stellten, die vor allem um ihre statusgerechte Wiedereingliederung in die tansanische Gesellschaft besorgt waren. ${ }^{156}$ Laut Interviewaussagen gab es in den folgenden Jahren keine weiteren großen Treffen. ${ }^{157}$

Über die Karriereinteressen ihrer Mitglieder hinausgehend aktiv scheint die TASU nur bis etwa Mitte der 1970er Jahre gewesen zu sein, als der Medizinstudent Matomora Matomora als Präsident fungierte. Als Missionsstipendiat durchlief Matomora in der international zusammengesetzten Linken der BRD einen Politisierungsprozess und geriet so in Opposition zu der Missionsgesellschaft, die sein Medizinstudium finanzierte. Seine Erfahrungen sind eine Sonde in damalige Denkweisen, Aktivismusformen und ihre Grenzen. Matomora war als weitgehend apolitischer Medizinstudent mit einem Stipendium einer Missionsgesellschaft in die BRD gekommen und hatte Anfang der 1970er-Jahre in Köln u.a. durch den Kontakt zur Afrikanischen Studentenunion (ASU), die strikt antiimperialistisch und sozialistisch ausgerichtet war, eine Politisierung erfahren. Damaliger Präsident der ASU war Somé aus Obervolta (später Burkina Faso), der Schatzmeister war ein Tansanier, und Matomora übernahm bald das Amt als Generalsekretär. ${ }^{158} 1973$ erschütterte die Ermordung des guinea-bissauischen Befreiungskämpfers Amílcar Cabral durch einen portugiesischen Offizier die afrikanische Community. ${ }^{159} \mathrm{Ca}$ bral wurde in der Sozialistischen Internationale allgemein geschätzt und hatte die Ausrichtung der ASU mit seinen Reden und Schriften über Befreiungskampf und

155 BArch Koblenz, B 213/7683, Banger (FES) an BMZ, o.O., 13.7.1973.

156 PAAA, ZW 119384, Wedel (FES), Projektbeschreibung für Reintegrationsseminar für tansanische Studenten, Bonn, 31.3.1976, S. 1-2.

157 Interview \#41, Tansanischer Doktoratsstudent in der BRD; Interview \#66, Tansanischer Student in der BRD.

158 Schott, Matomora Matomora, S. 86.

159 Ebd., S. 87-88. 
Neokolonialismus stark beeinflusst. 1968 war ihm auf der Frankfurter Buchmesse vom Sozialistischen Deutschen Studentenbund (SDS) der alternative Friedenspreis verliehen worden, was ihn auch in der BRD bekannter machte. ${ }^{160}$ Nach der Ermordung Cabrals organisierte Matomora in seiner Funktion als Sekretär der ASU ein Sit-in vor der Kölner Universität. Im Gegensatz zu vorherigen Aktionen, die auch unter deutschen Studierenden Unterstützung und in der Öffentlichkeit ein breites Echo bekamen - wie z.B. 1964 dem Protest gegen den Besuch des kongolesischen Ministerpräsidenten Moïse Tshombé in West-Berlin (ein Protest, den Rudi Dutschke als zentral für die Prägung neuer Protestformen beschrieb ${ }^{161}$ ) oder 1969-1971 gegen den Bau des Cabora Bassa-Staudamms im noch von Portugal beherrschten Mosambik - blieb dieser Protest in seiner Mobilisierungswirkung allerdings sehr beschränkt. ${ }^{162}$ Matomoras Schritt vom Sympathisant linker Positionen zum engagierten Aktivisten sollte trotzdem Auswirkungen auf seinen Lebensweg haben, denn dem Missionswerk, das Matomoras Studium finanzierte, war sein Engagement für Befreiungsbewegungen ein Dorn im Auge.

1974 entschied der Weltkirchenrat, die mosambikanische Befreiungsbewegung FRELIMO materiell zu unterstützen. In konservativ-christlichen Kreisen galt die FRELIMO aufgrund ihrer marxistischen Ausrichtung hingegen automatisch als anti-christlich. ${ }^{163}$ Matomora wurde zur Brüdergemeinde in Wiedenest gerufen, wo man ihm ein Papier vorgelegte, mit dessen Unterzeichnung er den Schritt des Weltkirchenrats verurteilen und damit beweisen sollte, dass er gewillt war, der kommunistischen Indoktrination zu widerstehen. Matomora verweigerte die Unterschrift und erinnerte sich an das Gespräch als Neuauflage der „Inquisition“. ${ }^{64}$ 1975 wurde er vom Missionswerk informiert, dass er nach seinem Abschluss nicht wie vorgesehen in der tansanischen Gemeinde (in Matomoras Heimatregion) arbeiten dürfe, wo das Missionswerk tätig war: Es sei nicht sicher, ob er Menschen für den christlichen Glauben gewinnen oder sie politisch beeinflussen wolle. ${ }^{165}$ Nun musste Matomora selbst für seine Rückkehr und berufliche Integration Sorge tragen.

160 Seibert, Vergessene Proteste, S. 77.

161 Slobodian, Foreign Front.

162 Für vorherige Aktionen siehe Niels Seibert, Vergessene Proteste. Internationalismus und Antirassismus 1964-1983, Münster 2008, S. 27-34, 71-98; Slobodian, Foreign Front, S. 61-73. 163 Zum Antiimperialismus und Antirassismus-Programm des Weltkirchenrats siehe Seibert, Vergessene Proteste, S. 78.

164 Hanna Schott, „Idealisten sind wir immer noch.“ Protokoll einer Männerfreundschaft, in: Wort und Tat 3 (2011), S. 5-6, hier: S. 5.

165 Schott, Matomora Matomora, 94-95. 
Dieser willkürlichen Sanktion ungeachtet war der Disziplinierungsversuch augenscheinlich fehlgeschlagen, da Matomora das Stipendium anscheinend weiter bezog und sich auch weiterhin zu seinen politischen Überzeugungen bekannte. Sozialdemokratische Kreise in der BRD waren von ihm sehr angetan. 1976 bezeichnete ein Vertreter der Friedrich-Ebert-Stiftung ihn nach einem Seminar als Mann „von beachtlichem intellektuellem und organisatorischem Format, der nach seiner bald bevorstehenden Rückkehr in Tanzania gesellschaftspolitisch eine bedeutende Rolle zu spielen verspricht“. ${ }^{166}$ Das Seminar habe über Matomoras Person hinausgehend „den Nachweis erbracht, dass die tansanischen Studenten eine ideologisch-politisch gefestigte und homogene Gruppe darstellen“ und „über politische Grundsatzfragen gut informiert [sind]““.167 TansanierInnen gehörten für den Autor des Berichts „politisch zu den bewusstesten des afrikanischen Kontinents“ und brächten auch das richtige kollektive Selbstbild mit: Ihr Auslandsstudium sei für sie die „Bildung [...] weniger Auserwählter im Hinblick auf Nutzen und Bedürfnis der Masse des Volkes“. ${ }^{168}$ Da der Bericht an das BMZ gerichtet war, das die Mittel für das Seminar bereitgestellt hatte, sind kritische Töne in diesem Text nicht zu erwarten. Die Idealisierung der tansanischen Gruppe mag also mit dem Zweck des Berichts zusammenhängen. Trotzdem ist festzuhalten, dass sich der Ton auch problemlos in die sozialdemokratische Begeisterung für Nyerere und Tansania einfügte.

Matomoras Politisierung in der BRD tat seiner fachlichen Qualifikation letztlich keinen Abbruch. Als frisch ausgebildeter Arzt stieg er in einem kirchlichen Krankenhaus in Kilimatinde (Region Dodoma) ins Berufsleben ein, machte in seinem Fachbereich eine steile internationale Karriere und nahm auf Einladung seines Doktorvaters 1991 eine Lehrstelle in Public Health in Heidelberg an. ${ }^{169}$ Für seine erneute Rückkehr nach Tansania spielte wieder ein Kontakt auf Grundlage des entwicklungspolitischen Feldes eine entscheidende Rolle. Mit materieller Unterstützung von Heinz-Horst Deichmann, dem Begründer der größten europäischen Einzelhandelskette für Schuhe, widmete sich Matomora zunehmend einem multisektoralen Entwicklungsprojekt in seiner Heimatregion, in die er 1998 zurückkehrte - über zwei Jahrzehnte nach dem Konflikt mit der dort tätigen Missionsgesellschaft, die ihm das Überseestudium ermöglicht hatte. ${ }^{170}$

166 PAAA, ZW 119384, Seminarbericht Reintegrationsseminar für tansanische Studenten, Bonn, 31.5.1976, S. 2.

167 PAAA, ZW 119384, Wedel (FES), Projektbeschreibung für Reintegrationsseminar für tansanische Studenten, Bonn, 31.3.1976, S. 2.

168 Ebd.

169 Schott, Matomora Matomora, S. 104, 118.

170 Ebd., S. 136. 
Die ideologischen und an entwicklungspolitischen Idealen ausgerichteten Projektionen gingen aber an den individuellen Motiven und Lebenswegen oft deutlich vorbei, wie auch das Beispiel einer Tansanierin zeigt, deren BRD-Studium (anfangs) von ihrer Familie finanziert wurde. Die Intention der Eltern war gewesen, dass sie ihren zukünftigen Mann kennenlernen sollte, der bereits in der BRD Zahnmedizin studierte und ähnliche Erfahrungen wie er machen sollte. Die arrangierte Beziehung zerbrach bald nach ihrer Ankunft in der BRD. Im Interview erinnerte sie sich an „ihr“ 1968 in Dimensionen der persönlichen Emanzipation und Selbstbefreiung und schloss auch die in Interviews mit Männern meist verborgene Ebene der Sexualität mit ein:

For me, I came from a very protected family. I had never been to a party, I had been in mission schools all my life, so it was like opening the eyes of a blind person. So I did everything that was forbidden then. Happily there was no HIV then (lacht). ${ }^{171}$

Politisierung und Aktivismus spielten für sie weniger eine Rolle. Sie sah sich in der paradoxen Situation, Ujamaa vor allem durch ihre westdeutschen StudienkollegInnen schätzen zu lernen - während in ihrem Heimatdorf in der Kilimandscharo-Region, das (wie fast alle Kaffeeanbaugebiete) von Umsiedlungskampagnen verschont blieb, die sozialistische Politik nur relativ geringen Einfluss hatte. Ihre Erfahrungen in der BRD wurden durchaus relevant für spätere entwicklungspolitische Aktivitäten, da sie als Absolventin eines Sozialanthropologiestudiums später u.a. für Aspekte sexueller Aufklärung im Rahmen von GTZProjekten im Gesundheitsbereich zuständig war. Ihr Studium finanzierte sie zu guten Teilen durch Nebenjobs selbst:

I was very lucky, because the lady who was getting jobs for students liked me very much and she always made sure that I got something to do. So at that time we had a lot of freedom. They were not very strict with Aufenthaltsgenehmigung, you only had to show your registration at university and you got it. ${ }^{172}$

\section{Grenzüberschreitungen}

Verdienstmöglichkeiten sprachen sich unter ausländischen Studierenden schnell herum. Gerade in den 1970er-Jahren war die Auslegung der rechtlichen Rahmenbedingungen noch relativ günstig, wie auch das Zitat oben zeigt. Tansanische InterviewpartnerInnen mit BRD-Aufenthalten kamen über persönliche Netzwerke

171 Interview \#15, Tansanische Studentin in der BRD.

172 Ebd. 
zu Jobs in Hamburger Reedereien oder Fabriken von Mercedes-Benz und Bayer. ${ }^{173}$ Mindestens zwei tansanische Doktoratsstudenten arbeiteten während der 1980erJahre als Gutachter für bundesdeutsche Behörden: Sie stellten fest, ob es sich bei Personen, die den verheerenden Krieg in Mosambik als Grund für ein Asylansuchen anführten, nicht doch um TansanierInnen handelte, die nicht vor Krieg, sondern nur vor der „Härte des Lebens“ (ugumu wa maisha) geflohen waren, was einem Interviewpartner zufolge kein legitimes Fluchtmotiv gewesen sei. ${ }^{174}$ In dieser Hinsicht unterstützten sie das eliteorientierte Migrationsregime, das zwischen der BRD und Tansania etabliert worden war und von dem sie selbst profitierten. Einige StudentInnen knüpften Kontakte mit der entwicklungspolitischen Szene und führten während oder nach Abschluss ihres Studiums Vorbereitungsseminare bei der DSE für BRD-Entwicklungspersonal durch; z.T. handelte es sich dabei um angehende oder spätere ProjektleiterInnen, die dann die aus BRD und DDR zurückgekehrten tansanischen Fachkräfte einstellten. ${ }^{175}$

Erwerbsstrategien führten bereits während der Studienzeit über den Eisernen Vorhang hinweg. Tansanische Studierende in den osteuropäischen Ländern nutzten ihre Reiseprivilegien, Netzwerke und den Zugang zu Devisen, um Grenzen zu überschreiten und Kapital aus dem Ost-West-Gegensatz zu schlagen und ihn dadurch auch zu unterwandern. Die DDR-Behörden versuchten, die ausländischen „Gäste“ mit ihren begrenzten Mitteln von Westreisen abzuhalten. Dazu gehörte 1961 die Abschreckung und Moralisierung, etwa mithilfe von Plakaten, die in mehreren Sprachen bedrohliche Slogans wie „Wer West-Berlin besucht, ist ein Feind“ verkündeten. ${ }^{176}$ Solche Einschüchterungen konnten allerdings die Tatsache nicht ändern, dass die DDR keinerlei rechtliche Handhabe hatte, um ausländische Studierende mit gültigen Pässen von Westbesuchen abzuhalten. ${ }^{177}$ Während manche Regierungen, darunter nicht nur jene marxistisch-leninistisch ausgerichteter „Bruderstaaten“ wie Mosambik, sondern auch Iraks oder Nigerias Westreisen ihrer Studierenden antragspflichtig machten, ${ }^{178}$ genossen Tansanie-

173 Schott, Matomora Matomora, S. 86.

174 Interview \#41, Tansanischer Doktoratsstudent in BRD.

175 Interview \#14, Tansanischer Doktoratsstudent in der BRD; Interview \#15, Tansanische Studentin in der BRD.

176 So 1961 im Rahmen eines Gewerkschaftslehrgangs, laut Shafi, Mbali na nyumbani, S. 471 (Übersetzung E. B).

177 Mac Con Uladh, Studium, S. 201; BStU, MfS, HA II/M 238, Heckerodt (HA II/3), Vermerk über die erste Aussprache mit dem Vertreter der ANC in der DDR, Anthony Mongalo, Berlin, 18.1.1979. 178 BStU, MfS, HA XX/3683, Probleme der politisch-operativen Sicherung ausländischer Studierender aus nichtsozialistischen Staaten in der DDR, o.O., o.D. [ca. 1975], Bl. 12. 
rInnen, die über einen Reisepass verfügten, vonseiten ihrer Regierung beinah vollständige Reisefreiheit. ${ }^{179}$

Vier verschiedene Modi lassen sich bei der Ost-West-Mobilität tansanischer (und vieler anderer) Studierender unterscheiden: erstens die Flucht vor Studienabschluss, zweitens sporadische Kurzbesuche, drittens das regelmäßige Pendeln während des Studiums und viertens das Upgrade nach Studienabschluss. ${ }^{180}$ Eine Gruppe von Studierenden nutzte den Eisernen Vorhang und die Narrative des Kalten Krieges dafür, dauerhaft auszureisen und in der BRD bzw. anderen westlichen Ländern Asyl- oder neue Stipendienanträge zu stellen. Sie stellten die politische Unfreiheit in den sozialistischen Ländern, Diskriminierung und ihre anti-kommunistische Einstellung als Hauptmotive für ihre Flucht dar. Tatsächlich scheint nur ein Teil aus Erfahrungen politischer Bevormundung oder rassistischer Diskriminierung den Weg in den Westen angetreten zu haben. Ein Teil der „Ostblockflüchtlinge aus Entwicklungsländern“, wie sie in der BRD genannt wurden, scheint eher Probleme mit dem Spracherwerb oder ungenügenden Studienleistungen gehabt zu haben, denn einige derjenigen, die in der BRD kein Stipendium erhalten hatten oder anderweitig enttäuscht wurden, kehrte wieder in die RGWLänder zurück.

Üblicher waren Kurzaufenthalte. Tansanische Studierende machten während ihres DDR-Aufenthalts häufige Ausflüge nach West-Berlin, um FreundInnen und Verwandte $\mathrm{zu}$ besuchen, das Nachtleben $\mathrm{zu}$ genießen, einzukaufen oder mit verschiedensten Jobs D-Mark zu verdienen, deren symbolischer wie ökonomischer Wert auf der anderen Seite der Mauer nochmals stieg. Der Zugang zu materiellen und symbolischen Ressourcen des Westens, dem kapitalistischen Zentrum, konnte in Ländern an der (Semi-)Peripherie der Weltwirtschaft wie der DDR und Tansania in größere Gewinne umgesetzt werden als das in der BRD selbst möglich gewesen wäre. Einkommensmöglichkeiten gab es auch für Studierende der DDR in westlichen Fabriken, Schlachthäusern, Geschäften und privaten Haushalten. Während West-Berlin am schnellsten und einfachsten zu erreichen war, nahmen einige auch eine Reise bis nach Schweden auf sich, um dort während der Sommerferien Geld zu verdienen. Derartige grenzüberschreitende Strategien verfolgten vor allem jene, die Kontaktpersonen - z.B. Verwandte oder FreundInnen - vor Ort hatten. So konnte ein Onkel in Schweden US-Dollar für die Begleichung der Reisekosten vorstrecken oder ein tansanischer Freund in WestBerlin seinen Ausweis leihen, der dem Vorarbeiter (in dessen Augen alle Afrikaner

179 BArch Berlin, DQ 1/12533, Botschaft Tansanias an DDR-Botschaft in Moskau, Moskau, 18.2. 1985. Ausnahmen waren Südafrika, Südkorea, Israel und Taiwan (die beiden letzteren wohl erst ab etwa 1967).

180 Detallierter zu diesen Mobilitätsmodi: Burton, Navigating Global Socialism. 
gleich aussahen) in der Fabrik vorgezeigt werden musste. ${ }^{181}$ Eine Studentin der Ingenieurwissenschaften pendelte regelmäßig zwischen Dresden und dem Heim einer älteren West-Berliner Dame, die eine Haushaltshilfe benötigte. ${ }^{182}$

Die Hartwährung, die die Studierenden durch Lohnarbeit oder Finanztransfers erhielten, ermöglichte ihnen dann den Zugang zu westlichen Konsumgütern, die für die Mehrheit der DDR-Bevölkerung außer Reichweite blieben, darunter Jeans, Hi-Fi-Anlagen, „verbotene“ Tonträger, Whiskey und Zigaretten. Wie Damian Mac Con Uladh schon für die 1960er-Jahre feststellt, nahmen die ausländischen Studierenden eine „Schlüsselstellung bei der Versorgung der DDR-Mangelwirtschaft“ ein, indem sie „Westwaren“ nicht nur selbst zum Statusgewinn nutzten, sondern auch an die DDR-Bevölkerung weitergaben oder verkauften. ${ }^{183}$ Diese Aussage ist angesichts der geringen Zahl der Studierenden und der Tatsache, dass die meisten diese Tätigkeiten nur in sehr geringem Maße betrieben, nicht verallgemeinerbar - aber für bestimmte Gruppen durchaus zutreffend. DDR-Lehrkräfte partizipierten mitunter an den Privilegien ihrer mobilen Studierenden, wenn sie Whiskey, Kaffee oder Zigaretten aus West-Berlin „bestellten“ (und gemeinschaftlich konsumierten) oder sich im Osten nicht erhältliche Fachliteratur mitbringen ließen. ${ }^{184}$ Das Eintauschen der Devisen gegen DDR-Mark zu einem Vielfachen des offiziellen Kurses war ebenfalls eine verbreitete Praxis; allerdings - Interviewaussagen zufolge - nie in dem Maße, dass dadurch tatsächlich von einem Geschäft oder gar der Akkumulation von Kapital gesprochen werden konnte. $^{185}$

Die Verschiebung der ökonomischen Verhältnisse äußerte sich auch in Transferpraktiken. Ab Mitte der 1970er Jahre schickten Studierende aufgrund der Versorgungsprobleme in Tansania Pakete mit Verbrauchsgütern wie Seife,

181 Eine ähnliche Begebenheit wird geschildert im jüngsten Roman von Chimamanda Ngozi Adichie, Americanah, London 2013.

182 So etwa Interview \#78, Tansanischer Student in der DDR.

183 Mac Con Uladh, Studium, S. 202.

184 Interview \#104, Tansanischer Student in der DDR und Doktoratsstudent in der BRD; BArch Berlin, DR 3/2. Schicht/4059, Anlage zur Vorlage zur Dienstbesprechung Nr. 239/88, Studienjahreseinschätzung Ausländerstudium: „Information von Universitäten und Hochschulen zu den Arbeits- und Lebensbedingungen ausländischer Studierender“, o.D. [1988], unpaginiert. Zur Bedeutung des Zugangs zu „West-Literatur“ siehe Fitschen, Wissenschaft, S. 660; Stefan Wolle, Die heile Welt der Diktatur. Alltag und Herrschaft in der DDR 1971-1989, Bonn 1999, S. 181-182; Dolores L. Augustine, Red Prometheus: engineering and dictatorship in East Germany, 19451990, Cambridge, Mass., 2007, S. 9.

185 Schmelz, Bildungsmigranten, 46, 57. Der Tausch fand damit auch mit anderen ausländischen Studierenden statt. Ein ehemaliger Student aus Simbabwe erinnerte sich, dass Studenten aus Syrien Westmark zum Kurs von 1:8 bis 1:10 abkauften. 
Zahnpasta und Kleidung, nicht unähnlich den „Westpaketen“, die millionenweise aus der BRD in die DDR geschickt wurden, an ihre Verwandten. Finanzielle Überweisungen in Richtung Tansania wurden laut einer Interviewpartnerin aber nur von jenen getätigt, die in der BRD studierten und damit höhere Stipendien in Devisen bekamen bzw. mehr Einkommensmöglichkeiten hatten. ${ }^{186}$ Die in aktuellen Studien des Migrations-Entwicklungs-Nexus immer wieder angeführte Bedeutung von Rücküberweisungen (remittances) aus der Diaspora, die sogar staatliche Entwicklungshilfezahlungen um ein Vielfaches übersteigen sollen, setzte in mancher Hinsicht den Zugang zu Devisen voraus, gleichzeitig waren aber auch Warensendungen eine Möglichkeit, Werte zu transferieren. ${ }^{187}$

Vonseiten der DDR waren die Möglichkeiten, unerwünschte Westreisen zu überwachen, zu kontrollieren oder gar zu unterbinden, sehr beschränkt. Schon Anfang der 1960er Jahre wurden Exkursionen innerhalb der DDR und in andere kommunistische Länder zur „ideologischen Festigung“ angeboten. ${ }^{188}$ Einige Tansanier - den Akten zufolge vor allem jene, die Führungspositionen in der tansanischen Studentenunion einnahmen - verbrachten ihre Ferien in Polen oder der Sowjetunion. Insgesamt wurde das Ostreisen-Angebot allerdings wenig genutzt. Generell bevorzugten tansanische wie andere Studierende, die Ferien im „Westen“ zu verbringen bzw. Praktika im Heimatland zu absolvieren, um wieder den Anschluss an den Arbeitsmarkt finden und Kontakte knüpfen zu können. ${ }^{189}$ Die bereits seit den frühen 1960er-Jahren bestehenden Sorgen der DDR-Behörden über den „Missbrauch“ der Reisefreiheit für „illegalen“ Handel mit Waren und Währung waren daher mit Freizeitangeboten allein keinesfalls zu beheben. ${ }^{190}$ Weitere Einflussnahmen sollte es durch das Lehrpersonal geben. Universitätslehrkräfte, die besonders häufig mit Studierenden aus dem nichtsozialistischen Ausland zu tun hatten wurden gezielt geschult, um kritischen Argumenten (etwa über die Unmenschlichkeit des Mauerbaus oder den höheren Lebensstandard der Arbeiterklasse im Westen, der den Sozialismus überflüssig mache) etwas entge-

186 Interview \#63, Tansanischer Student in der DDR und Doktoratsstudent in der BRD; Interview \#76, Tansanische Studentin in der DDR, Postgraduiertenkurs in der BRD; Interview \#120, Tansanischer Student in Rumänien.

187 Siehe hierzu Boris Nieswand, Der Migrations-Entwicklungs-Nexus in Afrika. Diskurswandel und Diasporaformation, in: Tatjana Baraulina u. a., Hg., Potenziale der Migration zwischen Afrika und Deutschland, Nürnberg 2011, S. $400-425$

188 UAL, DIB 259, „Ausländische Studenten an Universitäten der DDR“, Stand: Ende Stj. 77/78, Bl. 53; Fitschen, Wissenschaft, S. 667-668.

189 BArch Berlin, DR 3/2. Schicht/4058, Zu Ergebnissen und Problemen im Ausländerstudium 1975/76, o.D., S. 16; ebd., Vorlage Nr. 93/81 zur Dienstbesprechung: Studienjahresanalyse Ausländerstudium (Studienjahr 1980/81), o.D., S. 12.

190 Slobodian, Foreign Front, S. 227 (Fußnote 96). 
gensetzen zu können. ${ }^{191}$ Zur „Duldung und ideologische[n] Beeinflussung“, sprich, darauf zu hoffen, dass die Reisenden durch die Gegenüberstellung ihrer Erfahrungen zum Schluss gelangen würden, dass der Sozialismus dem Kapitalismus überlegen sei, traten ab Ende der 1970er-Jahre auch schärfere Überwachung und Kontrolle durch die Volkspolizei und die Staatssicherheit. ${ }^{192}$

Nicht zuletzt stellten auch Führungsfiguren wie Nyerere und Nkrumah Frugalitätsanforderungen an die aufstrebenden Bildungseliten. Die Macht der tansanischen Regierung, über ihr Territorium hinaus Kontrolle über die Studierenden auszuüben, war allerdings begrenzt. Ein ehemaliger DDR-Student berichtete, dass er mit den US-Dollars von der tansanischen Botschaft oder den D-Mark, die er in West-Berlin verdient hatte, in luxuriösen DDR-Hotelsuiten übernachten konnte. Ein solches Verhalten widersprach dem Ideal des entwicklungspolitisch gesinnten Studenten, der sich seines Privilegs jederzeit bewusst zu sein und für die Gesellschaft aufzuopfern hatte: „Nyerere hätte mich eingebuchtet, wenn er mich gesehen hätte“. ${ }^{193}$ Das Über-Ich - hier personifiziert durch Tansanias genügsam lebenden und moralisch integren „Vater der Nation“ - schwebte auch in der DDR durch die Köpfe, aber es war genau wie die Appelle von DDR-Seite auf symbolisch und moralisch unterfütterte diskursive Akte beschränkt und damit zu schwach, um das Verhalten durchgängig zu disziplinieren. Meldungen von Studierenden, die in osteuropäischen Ländern wegen Verdacht auf "Geschäftemachereien“ (racketeering) verhaftet wurden, erreichten auch das tansanische Außenministerium in Dar es Salaam, das dann alles daran setzte, die betroffenen Personen so schnell wie möglich aus dem Gefängnis heraus- und nach Tansania zurückzuholen. ${ }^{194}$ In den gesichteten Archivmaterialien ließen sich keinerlei Belege dafür finden, dass TansanierInnen in Deutschland aufgrund der beschriebenen Faktoren mit den Behörden in Konflikt kamen.

Die Alltagserfahrungen führten zur Annahme neuer Verhaltensweisen und differenzierten Urteilen über die Unterschiede verschiedener Gesellschaftssysteme. Besonders breiten Raum in den Interviewnarrativen nahm dabei immer wieder das Motiv von der Gewöhnung an das Zeitregime ein, ein Prozess, der in der Regel als geradezu zwangsläufige Anpassungsleistung, Selbstdisziplinierung und -optimierung gedeutet wurde:

191 Fitschen, Wissenschaft im Dienste des Sozialismus, S. 668.

192 Mac Con Uladh, Studium, S. 201.

193 Interview \#104, Tansanischer Student in der DDR und Doktoratsstudent in der BRD.

194 TNA, FA/E.160/11, Part C, Telegramm Tansanische Botschaft an Tansanisches Außenministerium, Bonn, 23.9.1981. 
Because that was drilled day in, day out during my stay in Germany. It starts with the bus which picks you up, the train you want to catch. So you are drilled to consider time as a factor. And since you are drilled, you start learning how to conserve time. So you also plan better and try to do things in a more systematic manner. ${ }^{195}$

Viele InterviewpartnerInnen erwähnten in der einen oder anderen Form eine derartige Transformation während ihres Auslandsaufenthalts. Die Verinnerlichung eines strengen Zeitregimes stand dabei oft im Zusammenhang mit der Arbeitshaltung: ,[F]rom Germany I have learnt the culture of hard work and perfectionism“. ${ }^{196}$ Zwar sei zwar auch Nyerere stets Prediger harter Arbeit gewesen, und das Motto der TANU auf dem Weg zur Unabhängigkeit lautete Uhuru na Kazi („Freiheit/Unabhängigkeit und Arbeit“), aber, wie ein ehemaliger Student in der DDR sagte, habe die Umsetzung dieser Forderungen in Tansania zu wünschen übrig gelassen. ${ }^{197}$ Diese kulturalistischen Erklärungsmuster, in der die „Entwicklung“ eines Landes als kulturell determiniert dargestellt wird, durchzogen viele Interviews. Die Figur der vollständigen Transformation der Arbeitshaltung während des Überseestudiums wurde allerdings relativiert, indem auch weitere Sozialisierungsmomente als prägend erwähnt wurden.

Manche InterviewpartnerInnen betonten, dass sie Qualitäten wie Strebsamkeit und Fleiß bereits in frühen Jahren im elterlichen Umfeld - z. B. bei der alljährlichen Kaffee-Ernte - eingeübt hatten und daraus gute Schul-, Studien- und Arbeitsleistungen resultierten. ${ }^{198}$ Und neben einer längeren biografischen Perspektive war das Bild einer Transformation während des Auslandsstudiums noch in anderer Hinsicht inkohärent: Der Umgang mit Zeit in der Planwirtschaft konnte freilich auch für Irritationen sorgen, wenn er nicht mit der „Kultur harter Arbeit“ in Einklang zu bringen war. Ein Ingenieur erinnerte sich an seinen Nebenjob in einer DDR-Brauerei, wo er „Gehalt auch für's Biertrinken“ bekam, selbst wenn die Produktionslinien wegen Lieferverzögerungen stillstanden und „die Stadt mal wieder trocken war“. Zusätzlich nannte er weitere konkrete Beispiele, die Fehlfunktionen der Planwirtschaft symbolisierten. ${ }^{199}$ In den 1980er-Jahren kam es unter ausländischen Studierenden zunehmend zu Diskussionen über Kapitalismus und Sozialismus, „, bei denen es vordergründig um einen Effektivitätsvergleich der Volkswirtschaften geht und der Unterschied letztlich einseitig auf die

195 Interview \#66, Tansanischer Student in der BRD.

196 Der ehemalige DDR-Student Martin Kivumbi, zit. nach Eckert, Herrschen, S. 241.

197 Interview \#78, Tansanischer Student in der DDR.

198 Interviews \#63 und \#104, Tansanische Studenten in der DDR, Doktoratsstudenten in der BRD.

199 Interview \#104, Tansanischer Student in der DDR, Doktoratsstudent in der BRD. 
Arbeitsproduktivität reduziert wird.“ 200 Ausländische Studierende, so dieser DDR-Bericht, zeigten sich angesichts der Nichtauslastung von Arbeitszeit überrascht.

Für manche Studierende stelle die DDR aber auch eine Vergleichsmöglichkeit im positiveren Sinne dar. Sozialistische Institutionen in Tansania und der DDR wurden miteinander in Beziehung gesetzt, und nicht zuletzt hieß es auch von Nyerere und anderen Politikern und Tansania gelegentlich, dass man von den sozialistischen Ländern lernen müsse, um den Sozialismus in Tansania aufzubauen. ${ }^{201}$ Ein Student schrieb in seinem Lebenslauf, er habe vor seinem DDRAufenthalt als Schreiber in einer Produktionsgenossenschaft gearbeitet, „die sozusagen wie eine LPG tätig ist“.202 Trotz der Implosion des osteuropäischen Realsozialismus zwischen 1989 und 1991 sprachen manche InterviewpartnerInnen immer noch positiv über Ausflüge zu Produktionsgenossenschaften. Sie verglichen DDR-Ortschaften mit Ujamaa-Dörfern und bewerteten die Exkursionen zu den LPGs als nützliche Lernmöglichkeiten, während gleichzeitig die Umsiedlungskampagne in Tansania als zumindest in der Intention richtige Idee bewertet wurde. ${ }^{203}$ In einigen Fällen traf also die Hoffnung der DDR, als nachahmenswertes Modell zu gelten, zumindest auf waches Interesse, wobei die Fehlschläge und Zwangsanwendungen in diesen Kollektivierungen weitgehend ausgeblendet blieben. Mit der Rückkehr stellte sich zudem immer auch die Frage, wie angeeignetes Wissen und Kapital in Tansania überhaupt konvertiert und eingesetzt werden konnte.

\subsection{Rückkehr nach Tansania: Kapitaltransfer und -konvertierung}

Die Rückkehr nach Tansania war in vielen Fällen kein geradliniger Prozess, sondern von weiteren Zwischenstationen und Zirkulationen gekennzeichnet - wie bereits das Beispiel Matomoras gezeigt hat, dessen Karriere und Netzwerk sich über mehrere Jahrzehnte hinweg zwischen der BRD und Tansania aufspannten. Das entsprach nicht den offiziellen Vorstellungen des patriotisch-entwicklungs-

200 BArch Berlin, DR 3/2. Schicht/4059, Zur Aus- und Weiterbildung ausländischer Bürger an Universitäten, Hoch- und Fachschulen der DDR im Studienjahr 1986/87, o.D., S. 16.

201 Julius Nyerere, Freedom and Development. A Selection from Writings and Speeches 1968 1973, Dar es Salaam 1973, S. 135-136, 148, 190.

202 UAL, StuA 12124, Lebenslauf Robert C., o.O., o.D. [ca. 1968], Bl. 23.

203 Interview \#64, Tansanischer Student in der DDR, Doktoratsstudent in der BRD; Interview \#47, Tansanischer Doktoratsstudent in der DDR. 
politischen Imperativs. Aus staatlicher Sicht war die Rückkehrplanung jedoch die Achillesferse des Überseestudiums. In Tansania existierte kein zentralisiertes System, in dem Informationen über Stipendien und Studierende gesammelt wurden. Da sowohl das Außenministerium wie auch die Fachressorts, z. B. die Ministerien für Landwirtschaft oder Gesundheit Studienplatzkontingente von Gebern erhielten, war das Bildungsministerium oft uninformiert. ${ }^{204}$ Das Bildungsministerium und die Kaderabteilung des Staates (Central Establishment) beschuldigten sich Mitte der 1970er-Jahre gegenseitig, die Verantwortung für die Reintegration der AuslandsstudentInnen nicht ernst genug zu nehmen. ${ }^{205} 1970$ wusste die tansanische Botschaft in London von 563 Studierenden, die Tansania nach Großbritannien entsandt hatte. Laut einer Umfrage der Botschaft sei die Mehrheit willens, zurückzukehren. De facto seien jedoch nur sehr wenige zurückgekehrt. 44 von den 563 Entsandten waren „non-citizens“, von denen die Botschaft annahm, dass sie sowieso kein Interesse an einer Rückkehr hatten was wohl einen Hinweis auf ihre asiatische Herkunft darstellt. ${ }^{206}$ Für die anderen hingegen stellten sich die Fragen, die 1970 auch im Manpower Report gestellt wurden: „Where are they [the graduates]? Have they left the country? Did they ever return from overseas? Are they in lower level posts?“207 1975 waren nach Angaben des Bildungsministeriums die meisten von insgesamt 186 registrierten Übersee-AbsolventInnen aus Großbritannien (57), der DDR (26), der Sowjetunion (24), Kanada (22), Jugoslawien (13), Ghana (12) und der BRD (11) zurückgekehrt. ${ }^{208}$ Im Verhältnis zu den Entsandten waren diese Zahlen besorgniserregend gering, im Falle westlicher Staaten lag die Quote teils unter 20\%.

Das 1974 gegründete Ministry for Manpower Development, das aus einer Abteilung im Planungs- und Wirtschaftsministerium hervorgegangen war, sollte bei der Identifikation des passenden Arbeitsplatzes helfen und die nach Tansania rückkehrenden AbsolventInnen ihrer Qualifikation entsprechend adäquat und effizient einsetzen. So versicherte eine Regierungsdelegation tansanischen Studierenden und PraktikantInnen auf einem Reintegrationsseminar in Bonn 1976, dieses Ministerium würde sich um die Bedürfnisse der RückkehrerInnen kümmern. ${ }^{209}$ Ab Mitte der 1970er Jahre gingen auch BRD-Behörden - noch ohne belastbare Studien - von einer weitverbreiteten „Rückkehrunwilligkeit“ unter aus-

204 Interview \#66, Tansanischer Student in der BRD.

205 URT, Manpower Report 1974, S. 45.

206 URT, Manpower Report 1970, S. 92-94.

207 Ebd. S. 102.

208 URT, Manpower Report 1975, S. 94.

209 PAAA, ZW 119384, Seminarbericht Reintegrationsseminar für tansanische Studenten vom 2. bis 5. Mai 1976 in Bad Godesberg, Bonn, 31.5.1976, S. 4. 
ländischen Studierenden aus. ${ }^{210}$ Als einer der Hauptgründe dafür wurde der „[m]angelnde Patriotismus der jungen Intelligenz“ ausgemacht. ${ }^{211}$ Ein Vertreter der Friedrich-Ebert-Stiftung nahm tansanische Studierende von diesem Generalvorwurf allerdings aus. Ideologisch hätten sie, anders als zum Beispiel ihre ghanaischen oder ägyptischen Pendants, die richtige Einstellung, nämlich den Drang, ihr Privileg, zu den „happy few“ zu gehören, sozial nutzbringend einzusetzen und ,ihrem eigenen Lande durch ihre Arbeit nach ihrer Rückkehr zu erstatten, was es ihnen in Zusammenarbeit mit der BRD offeriert hat"“. ${ }^{212}$ In der DDR wurde diese Einschätzung geteilt.

Mehrere DDR-AbsolventInnen traten vorerst den Weg in westliche Länder, oft die BRD, an - kehrten aber nach einer gewissen Zeit doch nach Tansania zurück. Die strikte Ausreiseregelung der DDR (wie auch anderer osteuropäischer Staaten) sah nach dem Abschluss die unmittelbare Remigration vor. Eine Anstellung oder der Beginn eines Postgraduiertenstudiums war nur in Ausnahmefällen möglich. Wer es hingegen schaffte, „über die Mauer zu springen“ (kuruka ukuta), konnte legale Wege finden, in West-Berlin oder Westdeutschland zu bleiben. ${ }^{213}$ Ein triftiger Grund, den Deutschlandaufenthalt nach dem Studium zu verlängern, war der Wunsch, sofort einen höheren Abschluss zu erlangen oder spezialisierte Zusatzstudien zu absolvieren. Direkte Bewerbungen noch aus der DDR für ein Promotionsstipendium beim DAAD wurden allerdings manchmal mit den bekannten entwicklungspolitischen Argumenten, die Leute sollten beim Aufbau ihres Landes helfen statt weiterzustudieren, abgelehnt. ${ }^{214}$ Leichter gestaltete sich der Zugang zu einjährigen Zusatzstudien, die teils eine spezifische entwicklungspolitische Ausrichtung hatten oder darauf abzielten, die „Reintegration“ von AbsolventInnen aus „Entwicklungsländern“ vorzubereiten. Ein MfS-Informant berichtete nach einem Gespräch mit einem Tansanier, dass finanzielle Motive und der Symbolwert westdeutscher Abschlüsse die Hauptrolle spielten. In der BRD erhalte man ein Postgraduiertenstipendium von monatlich tausend DM und könne durch einen Nebenjob noch mehr verdienen; das Geld könne dann in

210 BArch Koblenz, B 138/34571, Vermerk zur Grundsatzerklärung der Bundesregierung zur Ausbildung von Ausländern in der BRD, Kabinettvorlage des BMZ, Bonn, 15. 8.1975.

211 BArch Koblenz, B 138/34571, Grundsatzüberlegungen zur Reintegration der in der BRD ausund fortgebildeten Staatsangehörigen von Entwicklungsländern, Bonn-Bad Godesberg, 7.11.1972, S. 4.

212 Ebd., S. 3.

213 Interview \#40, Tansanischer Doktoratsstudent in der BRD; Interview \#65, Tansanischer Student in der DDR.

214 DAAD-Archiv, B 212/91392/4, DAAD an BRD-Botschaft Dar es Salaam, o.O., 7.6.1979; Interview \#63, Tansanischer Student in der DDR und Doktoratsstudent in der BRD. 
Waren (die in Tansania nicht erhältlich waren) umgesetzt oder in Tansania vorteilhaft getauscht werden. Außerdem helfe ein Abschluss aus einem westlichen Staat in Tansania einen der begehrten Arbeitsplätze „bei einem Kapitalisten“ zu erhalten. ${ }^{215}$ In Interviews wurden die Beweggründe ähnlich beschrieben und der Vergleichshorizont mit der BRD betont:

Nobody wanted to stay in East Germany for some further training there because we thought we will go back much poorer than those who are studying in West Germany. Yes. We got a bit more money and bought a car. ${ }^{216}$

Diese Motive und Aneignungsstrategien waren vor allem in den 1980er-Jahren relevant. In anderen Fällen, auch schon in vorherigen Jahrzehnten, war eine Liebesbeziehung ausschlaggebend: Mit einem BRD-Aufenthalt konnte die monate- und teils jahrelange Wartezeit überbrückt werden, die DDR-Behörden in Anspruch nahmen, um Eheschließungen mit DDR-Bürgerinnen und deren Ausreise mit ihren tansanischen Verlobten oder Ehemännern zu genehmigen. Alle diese Motive - höhere Abschlüsse, Akkumulation materieller Ressourcen, Heirat - sprechen zumindest teilweise dafür, dass eine Rückkehr nach Tansania geplant war und der Zwischenaufenthalt in Westdeutschland lediglich dazu diente, die eigene Ausgangsposition für die Reintegration zu verbessern.

Fehlende soziale Anerkennung wurde in mehreren Interviews als zentraler Grund benannt, die BRD zu verlassen. Die geschilderten Erfahrungen reichten vom diffusen Gefühl der deutschen Gesellschaft nicht anzugehören (und auch nie ein Zugehörigkeitsgefühl entwickeln zu können), bis hin zu direkter verbaler Diskriminierung und physischer Gewalt. Drei ehemalige Doktoratsstudenten erwähnten, dass sie in der BRD bzw. DDR lukrative Jobangebote unterbreitet bekommen hatten - in einem Fall eine Dozentenstelle mit einem Monatsgehalt von DM 5.000 - aber aufgrund des offenen Rassismus die direkte Rückkehr nach Tansania bevorzugten. ${ }^{217}$ Einer von ihnen wurde bei einem Überfall von Skinheads in seiner eigenen Wohnung schwer verletzt. Die Schilderungen der drei Männer bezogen sich auf die Jahre direkt vor bzw. nach der Wiedervereinigung.

Allerdings weist vieles darauf hin, dass auch schon vor der Verschärfung der Aufenthaltsbestimmungen Anfang der 1980er-Jahre und vor der Zunahme rassistischer Übergriffe kaum TansanierInnen in der BRD blieben (wenngleich

215 BStU, MfS, HA II/28716, Hauptmann Wessler, Information vom 30.4.1985, Magdeburg, 2.5. 1985, Bl. 74

216 Interview \#63, Tansanischer Student in der DDR und Doktoratsstudent in der BRD.

217 Interview \#32 und \#41, Tansanische Doktoratsstudenten in der BRD; Interview \#47, Tansanischer Doktoratsstudent in der DDR. 
Einbürgerungen, über die keine Daten vorliegen, diese Statistik verschleiern). 1981 waren gerade einmal 18 tansanische AkademikerInnen in der BRD tätig, davon die Hälfte als ÄrztInnen. ${ }^{218}$ Laut einem DDR-Arzt, der viele Jahre in Tansania tätig war und selbst TansanierInnen für Studienaufenthalte in der DDR (mit) auswählte, gingen 9 von 10 in der DDR ausgebildeten FachärztInnen in die BRD nach Köln oder West-Berlin, nur einer bzw. eine kehrte direkt zurück. ${ }^{219}$ Abgesehen von dieser Berufsgruppe, für die in der BRD besonders günstige und in Tansania besonders unattraktive Arbeitsbedingungen herrschten, ${ }^{220}$ verblieben jedoch kaum tansanische Fachkräfte in den beiden deutschen Staaten. ${ }^{221}$

Postgraduiertenstudien waren aber nicht nur aufgrund ökonomischer Faktoren attraktiv, sondern mitunter auch, weil sie ein Pflichtpraktikum (und damit eine Reise nach Tansania) beinhalteten. Ein solches Praktikum bot die Möglichkeit, die eigene Rückkehr und berufliche Eingliederung vorzubereiten und Kontakte aufzufrischen. Das Wissen darüber, welche Kurse angeboten wurden, zirkulierte durch Mund-zu-Mund-Propaganda unter Studierenden und AbsolventInnen. Manche Tansanier, die erst in der DDR studiert hatten und danach in der BRD promovierten, waren in der westdeutschen „Ellbogengesellschaft“ plötzlich mit einem ungekannten Konkurrenzdenken konfrontiert, das selbst die Beziehungen zu StudienkollegInnen anders gestaltete. ${ }^{222}$ Eher als jene, die nicht in der DDR studiert hatten, wiesen sie auf Probleme wie Arbeitslosigkeit, Verbrechen und ökonomische Ungleichheit hin. ${ }^{223}$ Das soziale Zusammenleben in der DDR wurde idealisiert und das „System“ mit expliziter Ausnahme der Überwachung für seine sozialen Errungenschaften gelobt:

We were feeling very free and we were feeling like small kings, so to say. But when we went to West Germany, then we had that social disconnect. Because you have your contacts, your

218 Gross u.a., Akademiker, S. 305. Vgl. dazu die Anzahl von ÄrztInnen anderer afrikanischer Nationalitäten: Ägypten - 123, Ghana - 161, Nigeria - 71 (ebd., 115).

219 Interview \#114, DDR-Arzt.

220 John Iliffe, East African Doctors. A History of the Modern Profession, Cambridge, New York 1998, S. 208-214. Nicht umsonst waren wohl auch in der Medizinischen Fakultät der Universität Dar es Salaam Plakate mit dem Konterfei Nyereres aufgehängt, mit dem „Ausspruch, daß diejenigen, die den Vorzug einer qualifizierten Ausbildung auf Kosten des Landes genossen hätten, die moralische Pflicht hätten, mit ihren Fähigkeiten auch diesem Lande zu dienen und beim Aufbau mitzuwirken.“ BArch Berlin, DQ 1/12533, OMR Dr. med. Armin Krebs, Bericht über einen Aufenthalt in Tansania vom 3.12. bis zum 21.12.1984, Berlin, 28.3.1985, S. 4.

221 Dieser Eindruck basiert auf Zahlen aus den bereits zitierten Manpower Reports sowie einer Vielzahl von Interviews.

222 Agnes Fazekas, „Spreche ich Kisuaheli?“, Süddeutsche Zeitung, 17.10.2010; Interview \#104, Tansanischer Student in der DDR, Doktoratsstudent in der BRD.

223 Interview \#64, Tansanischer Student in der DDR, Doktoratsstudent in der BRD. 
girlfriend in Eastern Germany. And you find West Germany not as welcoming [...] compared to the East. ${ }^{224}$

Die meisten InterviewpartnerInnen versicherten, dass sie nie erwogen hätten, nicht nach Tansania zurückzukehren. Die Gründe dafür sind wohl vor allem in politischen Faktoren und in der Disposition der Entsandten zu suchen. Trotz wirtschaftlicher Talfahrt war Tansania immer ein politisch stabiles Land, was für Ghana, Äthiopien oder Nigeria nicht der Fall ist. Motive, dem eigenen Land und der tansanischen Bevölkerung helfen zu wollen (manchmal explizit als uzalendo beschrieben, am ehesten übersetzbar als „Patriotismus“) und das angeeignete Wissen anzuwenden spielten hier eine wichtige Rolle. Nyereres Worte waren selbst jenen noch Imperativ, die zurückkehrten, als er schon aus dem Präsidentenamt ausgeschieden war. Ein Tansanier mit einem Doktortitel von einer westdeutschen Universität antwortete auf die Frage, warum er nach seiner Rückkehr eine Arbeit angenommen hatte, die ihm eigentlich nicht zusagte:

\begin{abstract}
Es war kein Zwang, aber ich habe trotzdem zugestimmt wegen dieser politischen Erziehung, die wir hatten. Wir sind zur Zeit des Sozialismus zur Schule gegangen. Deswegen hatten wir die Moral, dass du die Pflicht hast, die Opfer zurückzuzahlen, die andere gebracht haben. So hat es Nyerere gesagt, du musst deinem Land und deinen Leuten nützlich sein. ${ }^{225}$
\end{abstract}

Dieses offiziöse Motiv brachten auch andere vor. Das Leben derjenigen, die in der BRD blieben, wurde als negative Kontrastfolie zum eigenen Lebensweg herangezogen: die TansanierInnen, die in Berlin, Bremen oder München geblieben waren, hätten in den meisten Fällen nichts Sinnvolles aus ihrem Leben machen können und würden von der deutschen Mehrheitsgesellschaft nicht respektiert. Vereinzelt gab es die Ansicht, diese TansanierInnen hätten ihre „Pflicht“ nicht erfüllt.

Mehrere InterviewpartnerInnen erwähnten, dass sie schon „erwartet“ wurden, als sie sich bei einer staatlichen Stelle (zumeist dem entsendenden Ministerium) zurückmeldeten. Eine vollständige Ahnungslosigkeit auf staatlicher Seite ist also nicht zu konstatieren, eine beschränkte Übersicht und Handlungsmacht aber durchaus. Die Fünf-Jahres-Klausel (laut der alle UniversitätsabsolventInnen

224 Interview \#63, Tansanischer Student in der DDR, Doktoratsstudent in der BRD.

225 Interview \#40, Tansanischer Doktoratsstudent in der BRD. Im Original: „Kwa hiyo utakuta it was not forced lakini nilikubali tuu kwa sababu ya ile political education tuliyokuwa nayo kwa sababu sisi tulisoma wakati ule siasa ni wakati wa socialism unajua. Kwa hiyo we had the moral kwamba you have the duty to repay the sacrifices the others have made ndio Nyerere alivyokuwa akisema kwa hiyo lazima utumikie nchi yako na watu wako.“ 
mindestens fünf Jahre für den Staat arbeiten mussten), unattraktive Gehälter, fehlende materielle Anreize, unerwünschte Versetzungen sowie die sich verschlechternden Lebensbedingungen waren laut der BRD-Botschaft die Hauptgründe dafür, dass allein 1974 laut offiziellen Zahlen 60 AbsolventInnen nationaler wie ausländischer Studien erst gar „nicht zur Arbeitsaufnahme erschienen, sondern spurlos verschw[a]nden“.226

In den Interviewerzählungen erscheint die Reintegration in die dynamische und umkämpfte institutionelle Landschaft Tansanias nicht als simple, technokratische Allokation nunmehr verfügbaren Humankapitals, ausgerichtet an den Bedürfnissen des Staates, sondern als ein komplexer Aushandlungsprozess von Kapitaltransfers und -konvertierungen. ${ }^{227}$ Das erworbene Wissen und die Abschlüsse mussten aktiv validiert werden, der Wert angesparter Hartwährung oder mitgebrachter Konsumgüter war abhängig vom Zeitpunkt der Rückkehr. Der eigene Status war ab Mitte der 1970er Jahre zunehmend ungewiss. Es gab kaum Möglichkeiten, sich auf das künftige Arbeitsfeld vorzubereiten, weil mit Ausnahme von Universitätsangehörigen und Counterparts in Entwicklungsprojekten meist unklar blieb, wo die AbsolventInnen zum Einsatz kommen würden. ${ }^{228}$

Relativ unkompliziert transferierbar waren Kontakte und symbolisches Kapital innerhalb des entwicklungspolitischen Feldes, das über nationale Grenzen hinweg aufgespannt war. So konnten z. B. vier Tansanier, die in den 1970er Jahren in der DDR studiert und im Anschluss in West-Berlin einen Aufbaustudiengang am Seminar für Ländliche Entwicklung absolviert hatten, in einem GTZ-Projekt unterkommen. Kontakte mit GTZ-Experten, die ebenfalls an diesem Aufbaustudiengang teilgenommen hatten, führten dazu, dass der westdeutsche Projektleiter sich erfolgreich beim zuständigen tansanischen Ministerium für den Einsatz der Rückkehrer als Counterparts in seinem Projekt einsetzte. ${ }^{229}$ Außerdem half er bei dem häufig auftretenden Problem, die deutschen Diplomabschlüsse als MasterAbschlüsse anerkennen zu lassen, was Auswirkungen auf die möglichen Positionen und das Gehalt hatte. Unter denjenigen, die ihr Doktorat in der BRD absolvieren konnten, haben einige den Eintritt in das transnationale entwicklungspolitische Feld geschafft und nahmen nicht nur Beratungsaufgaben für die Regierung war, sondern konnten auch Consulting-Aufträge für die Weltbank, die GTZ und andere Geberinstitutionen realisieren oder von diesen angestellt werden.

226 BArch Koblenz, B 213/7679, Müllenheim (BRD-Botschaft) an AA, Dar es Salaam, 5.12.1974. 227 Kelly/Lusis, Migration and the Transnational Habitus; Erel, Migrating Cultural Capital.

228 UAL, DIB 262, Jünger (Abt. AS), Entwurf für „Überlegungen zu den Jahresanalysen der Universitäten, Hoch- und Ingenieurhochschulen“, o.D. [ca. 1977/1978], o.O., Bl. 47.

229 Interview \#63, Tansanischer Student in der DDR und Doktoratsstudent in der BRD; Interview \#102, GTZ- Projektleiter. 
Postgraduale Ausbildungen in den RGW-Ländern waren seltener. Von der Universität Dar es Salaam berichtete ein DDR-Dozent 1974 gar, dass ,grundsätzlich keine Genehmigungen zur weiteren Qualifizierung von Angehörigen der Universität in den sozialistischen Staaten mehr erteilt“ würden; wer „,in den sozialistischen Staaten studiert hat, muß in der Regel erst im Lande arbeiten oder wird zum weiteren Studium in westliche imperialitische [sic] Staaten delegiert“. ${ }^{230}$ Mit einem Studienabschluss aus der DDR gelang den AbsolventInnen meist nur der Einstieg in die mittleren Ränge staatlicher und halbstaatlicher Institutionen. Diejenigen, die keinen weiteren Abschluss im „Westen“ machten, verblieben deutlich häufiger ausschließlich im Staatsdienst - sie verfügten nicht über die Kontakte zur westlichen Entwicklungspolitik. Dieser grobe Abriss zeigt bereits, dass sich die verschiedenen Kapitalarten oft gegenseitig ergänzten bzw. überhaupt erst nutzbar machten. Zur „Inwertsetzung“ eigener Fähigkeiten und Potenziale brauchte es weitere Ressourcen. Im Folgenden werden die einzelnen Kapitalarten trotzdem für analytische Zwecke getrennt, um so die Vielfalt der Erfahrungen und Strategien aufzuzeigen, aber auch auf größere historische Dynamiken hinzuweisen.

\section{Symbolisches Kapital: Das Überseestudium als Fluch und Segen}

AbsolventInnen ohne einflussreiche Kontakte waren bei ihrer Rückkehr nach Tansania besonders abhängig von Ministeriumsentscheidungen über den neuen Arbeitsplatz. Nach der Rückkehr bekleideten diese AbsolventInnen meist mittlere Ränge in Regierung und Verwaltung; der Aufstieg in leitende Funktionen war deutlich wahrscheinlicher, wenn zusätzlich ein Promotionsstudium in BRD, DDR oder auch anderswo absolviert werden konnte. Die BRD hatte zwar schon in den 1970er Jahren das sogenannte Äquivalenzabkommen bezüglich der Anerkennung akademischer Grade mit Tansania abgeschlossen, und auch mit der DDR war nach langem Hinhalten von tansanischer Seite 1982 ein entsprechendes Abkommen unterzeichnet worden, aber nichtsdestoweniger blieb die Abwertung von Bildungsabschlüssen - die einen klassischen Topos der Migrationsforschung darstellt - ein Problem. ${ }^{231}$ Die volle Anerkennung der Abschlüsse musste im stark

230 BArch Berlin, DR 3/2. Schicht/B 1449/1b, Arnold/Beyer an MHF, Dar es Salaam, 29.1.1974. 231 Noch 1976 hielt der tansanische Außenminister die DDR mit der Erklärung hin, es würden ohnehin alle Abschlüsse anerkannt. BArch Berlin, DR 3/2. Schicht/B 1460/5b, Aktennotiz über das Gespräch des Außenministers der VRT Kaduma, beim Minister für Hoch- und Fachschulwesen Böhme, am 13.9.1976, o.D. 
britisch geprägten System Tansanias oft mit persönlichem Einsatz durchgesetzt werden. Mitunter wurde dafür die Mithilfe der deutschen Botschaften oder der jeweiligen Universitäten eingefordert, die dann Briefe an die Institutionen schrieben, in denen die AbsolventInnen untergekommen waren. ${ }^{232}$

Neben dem ungleichen Prestige von Abschlüssen verschiedener Universitäten und Länder war allen RückkehrerInnen aber ein Status als „have-been“ gemeinsam: Sie gehörten zu den wenigen Auserwählten, die es ins Ausland nach ulaya geschafft hatten. ${ }^{233}$ Aus diesem Status folgten im Berufsumfeld häufig besonders hohe Erwartungshaltungen an die Arbeitsproduktivität; im Familien- und Freundeskreis wurde zudem oft angenommen, dass ökonomische Ressourcen akkumuliert wurden und ihrer Umverteilung harrten. Nicht umsonst wird der hohe Erwartungsdruck in der Literatur als Faktor genannt, die eigene Rückkehr zu verzögern oder gänzlich ad acta zu legen - gerade bei jenen, die das Studium aus den verschiedensten Gründen nicht erfolgreich beenden konnten und einen Gesichtsverlust fürchteten. ${ }^{234}$ „I didn't want to go back to Tanzania as a loser“ meinte ein Agrarwissenschaftler, der sein Promotionsstudium in der BRD (im Anschluss an ein DDR-Studium) eigentlich abbrechen wollte, aber dann doch den Abschluss machte und später $u$.a. für die Weltbank arbeitete. ${ }^{235}$ Andere InterviewpartnerInnen erwähnten vereinzelte TansanierInnen, die bereits seit vielen Jahren - z.T. seit Anfang der 1960er - in Bremen, Berlin oder München leben würden. Informationen des MfS zufolge war West-Berlin ein regelrechtes „Sammelbecken“ von AfrikanerInnen, von denen manche ein Studium in der DDR absolviert und andere abgebrochen hatten. ${ }^{236}$

Ein höherer Abschluss oder Zusatzqualifikationen bedeuteten keinen automatischen Statusgewinn. Die Friedrich-Ebert-Stiftung stellte fest, dass TansanierInnen, die in der BRD Fortbildungen absolviert hatten, zwar „mühelos in ihren ursprünglichen Arbeitsplatz wieder eingesetzt“ wurden, die neuen Qualifikationen dabei allerdings keinerlei Berücksichtigung fanden. ${ }^{237}$ In konkreten

232 UAL, DIB 164, Fröhlich (Instituts für Trop. Landwirtschaft und Veterinärmedizin) an Principial Secretary (Ministry of Agriculture), Leipzig, 28.11.1973, Bl. 139-140.

233 Zum Begriff Have-been siehe Martin, Have-Been; Bizimana, White Paradise, S. 171.

234 Schott, Matomora Matomora, S. 105; Gross u. a., Akademiker, S. 67.

235 Interview \#64, Tansanischer Student in der DDR und Doktoratsstudent in der BRD.

236 BStU, MfS, BV Dresden, Zusammenfassung der Aufklärungsergebnisse zum Sachverhalt der angeblichen Existenz einer illegalen Organisation unter ausländischen Studierenden, Dresden, 25.6.1982, Bl. $400-401$.

237 PAAA, ZW 119384, Wedel (FES), Projektbeschreibung für Reintegrationsseminar für tansanische Studenten vom 3. bis 5. Mai 1976 in Bad Godesberg, Bonn, 31.3.1976; ebd., Seminarbericht Reintegrationsseminar für tansanische Studenten vom 2. bis 5. Mai 1976 in Bad Godesberg, Bonn, 31.5.1976, S. 2. 
Situationen konnte der Status „RückkehrerIn“ zudem direkt gegen die DDR- und BRD-AbsolventInnen gewendet werden, wie die Friedrich-Ebert-Stiftung 1976 feststellte. Tansanische Studierende, so hieß es in einem Antragsdokument der Stiftung, „sind im allgemeinen von tansanischen Stellen nicht erfaßt, und stoßen bei ihrer Rückkehr nicht nur auf Ignoranz, sondern geradezu auf Ablehnung“.238 Nährboden dafür war die weitverbreitete antiimperialistische Grundhaltung in Tansania, die sich jedoch gerade bei Autoritätskonflikten in nationalistischen und kulturchauvinistischen Idiomen äußerte. Mehrere InterviewpartnerInnen sahen sich aufgrund ihrer ausländischen Abschlüsse besonderem Misstrauen ausgesetzt; im Falle von Auseinandersetzungen konnten ihre Positionen als „fremde“ und damit für Tansania unpassende Ideen diskreditiert werden. Es war kein Kompliment, wenn ein Vorgesetzter meinte: „He brings in ideas from Europe.“239

Insbesondere die Beziehung zwischen Parteikadern der mittleren Ebene und BeamtInnen mit höheren Bildungsabschlüssen war spannungsgeladen. Beide Gruppen operierten in den Machtkämpfen mit ihrem jeweils akkumuliertem Kapital (vgl. Kapitel 2.4). Interviewpartner erinnerten sich an „ungebildete“ Parteisekretäre, die sich ihnen gegenüber „aufspielten“ und versuchten, ihre Macht gegenüber StudienabsolventInnen $\mathrm{zu}$ demonstrieren. ${ }^{240}$ Der BRD-Botschafter berichtete 1974, bei ihm hätten sich zahlreiche HochschulabsolventInnen ausländischer Universitäten, gerade jene in leitenden Positionen, „beklagt, dass Anerkennung und Karriere sich nur über ständige Teilnahme an Partei- und Gewerkschaftstreffen erreichen lassen“ und ein „Übermaß an Verbalismus“ herrsche, der „an Stelle produktiver Arbeit trete“ . ${ }^{241}$ Eine persönliche Entfaltung und fachliche Wirksamkeit schien unter solchen Bedingungen unmöglich.

Als selbstbewusste Angehörige der gebildeten Elite waren die RückkehrerInnen jedoch oft nicht bereit, sich den Anweisungen der (ab Mitte der 1970erJahre eingesetzten) ,politischen Kommissare“ in den Betrieben zu beugen, zumal sie oft die (tatsächliche oder selbstauferlegte) Aufgabe hatten, Neuerungen einzuführen und umzusetzen. Remigrierende Fachkräfte sollten, in den Worten der jüngeren Literatur über den Nexus von Migration und Entwicklung, Triebkräfte

238 PAAA, ZW 119384, Wedel (FES), Projektbeschreibung für Reintegrationsseminar für tansanische Studenten vom 3. bis 5. Mai 1976 in Bad Godesberg, Bonn, 31.3.1976.

239 Interview \#82, Tansanischer Student in der DDR; siehe auch Interview \#69, Tansanischer Doktoratsstudent in Großbritannien; ähnlich die Reaktion im Falle der ghanaischen Verwaltung: Martin, Have-Been, S. 95.

240 Interview \#104, Tansanischer Student in der DDR und Doktoratsstudent in der BRD; Interview \#120, Tansanischer Student in Rumänien.

241 BArch Koblenz, B 213/7679 (Tansania Allgemeines, Heft 12), BRD-Botschafter Müllenheim an AA, 5.12.1974. 
sozialen Wandels (agents of change) sein. ${ }^{242}$ Ein Interviewpartner erinnerte sich, dass er - zusammen mit sechs anderen Rückkehrern aus der DDR - die Idee hatte, eine tansanische Region „zu übernehmen“, um dort das im Studium der Tropischen Landwirtschaft angeeignete Wissen in die Tat umzusetzen und die Region so in eine Hochburg agrarischer Produktivität $\mathrm{zu}$ transformieren. ${ }^{243}$ Solche Gedanken - die das bereits erwähnte Selbstverständnis als Avantgarde in Erinnerung rufen - stellte er, der eine Anstellung bei der GTZ bekam, retrospektiv als naiv und nicht praktikabel dar. Ein Volkswirt mit Abschluss von einer westdeutschen Universität, der nach seiner Rückkehr eine leitende Funktion bei der staatlichen Hafenbehörde einnahm, problematisierte diese Erwartungshaltung im Interview mit Bezug auf die sozialen Beziehungen und den eigenen Status:

You are coming from West Germany, and you are trained, now whenever you are initiating changes, you have to be mindful of the fact that the others might feel that you are doing it because you believe that you are better educated. [...] So that was the biggest challenge. ${ }^{244}$

1978 argumentierte Aleck Che-Mponda, ein tansanischer Politikwissenschaftler an der Universität Dar es Salaam (und späterer Oppositionspolitiker), der erst zwei Jahre zuvor aus den USA zurückgekehrt war, in einem Leserbrief dafür, frustrierten Intellektuellen und Fachkräften die Auswanderung zu erleichtern. Mit seinem Verweis auf die ganze Menschheit und eine kosmopolitische Form der Nützlichkeit, die an die Stelle des nationalstaatlichen Rahmens treten sollte, wies er auch den patriotisch-entwicklungspolitischen Imperativ zurück:

[W]hat is better: to keep a frustrated intellectual within the country as a window dressing and risk getting possible internal enemies, or to let them go where they can be more useful to mankind? ${ }^{245}$

Che-Mponda gehörte zu jenen, die über prestigereiche Abschlüsse aus dem angloamerikanischen Raum und damit auch zahlreiche Mobilitätsoptionen verfügten. AbsolventInnen osteuropäischer Universitäten mussten hingegen schon

242 Siehe zu diesem Begriff Thomas Faist, Migrants as Transnational Development Agents: An Inquiry into the Newest Round of the Migration-Development Nexus, in: Population, Space and Place, 14/1 (2008), S. 21-42.

243 Interview \#63, Tansanischer Student in der DDR, Doktoratsstudent in der BRD.

244 Interview \#66, Tansanischer Student in der BRD.

245 Aleck H. Che-Mponda, “The alarm is false”, Daily News, 7.1.1978. Che-Mponda war Anfang der 1990er als einer der Mitbegründer einer Oppositionspartei, der Civic United Front (CUF), und späterer Gründer und Präsidentsschaftskandidat der Tanzania People’s Party eine Triebkraft für die Einführung Mehrparteiendemokratie. 
in Tansania für eine umfassende Anerkennung ihrer Abschlüsse kämpfen. Entsandtes DDR-Personal hörte Anfang der 1970 von tansanischen KollegInnen, dass Abschlüsse im Osten generell leichter zu haben seien als z. B. in England; Qualifikationen aus den kommunistischen Ländern würden in Zweifel gezogen. ${ }^{246}$ 1990 berichtete ein DDR-Dozent, „als Betreuer mit langjähriger Tätigkeit im Ausland immer wieder spöttische Bemerkungen ob des geringen Umfang[s]“ der DDR-Dissertationen vernommen zu haben. ${ }^{247}$ Ein Moment des Generalverdachts gegenüber osteuropäischen Abschlüssen bestand selbst noch im Jahr 2014 - allerdings nur bei jenen, die in westlichen Ländern studiert hatten bzw. aus der BRD kamen. Ein tansanischer Interviewpartner mit einem Doktoratsabschluss aus der BRD bezeichnete von der Moskauer Lumumba-Universität verliehene Diplome gar als „Müll“ (takataka). ${ }^{248}$

Wie expatriates gerieten auch RückkehrerInnen aus Übersee in den Verdacht, trojanische Pferde zu sein. 1968 beschwerte sich der Politiker und ehemalige Swahili-Lehrer in Leipzig, Stephen Mhando, im Parlament über die feindselige Behandlung gegenüber AbsolventInnen aus dem „Ostblock“ seitens westlich ausgebildeter BeamtInnen, die nur britische Abschlüsse anerkennen würden. ${ }^{249}$ Als Beispiel für die Schikanen nannte er den Fall zweier Ärzte, deren DDR-Abschlüsse vom Gesundheitsministerium nicht anerkannt wurden und die Kreuzverhöre über marxistisch-leninistische Indoktrinierung über sich ergehen lassen mussten. ${ }^{250} 1970$ verlangte Sansibars Gesundheitsminister Ali Sultan Issa von allen einheimischen ÄrztInnen mit Abschlüssen aus der Sowjetunion, zuzugeben, dass ihre Qualifikation zum Praktizieren ungenügend sei und zurückzutreten. Die ÄrztInnen leisteten der Aufforderung zum Rücktritt Folge, weigerten sich aber, ihre Qualifikationen selbst zu diskreditieren. Ali Sultan Issa verbot ihnen daraufhin, Sansibar zu verlassen. ${ }^{251}$ In diesem Beispiel stand jedoch kein antikommunistisches Motiv, sondern der Konflikt rivalisierender Sozialismen und die in Verbindung mit der Demonstration nationaler Souveränität Pate für die Ent-

246 BArch Berlin, DR 2/25494, DDR-Lehrerexperte B. an MfVobi, Dar es Salaam, 13. 8.1971; ebd., DR 3/2. Schicht, B 1449/1b, Legère/Brauner (KMU), Bericht über einen Studien- und Forschungsaufenthalt in Tanzania (Universität Dar es Salaam), o.O., 10.12.1974.

247 UAL, WR 1990/316, L. an ANW-Sektionsdirektor, Leipzig, 21.3.1990, Bl. 34-35.

248 Interview \#32, Tansanischer Doktoratsstudent in der BRD. Siehe auch Interview \#4, Tansanischer Doktoratsstudent in den USA (mit DAAD-Stipendium); Interview \#36, Tansanischer Facharzt mit Facharztausbildung in der BRD; Interview \#68, DED-Entwicklungshelfer und späterer Entwicklungsexperte in Tansania.

249 Roberts, Politics, S. 103.

250 Aminzade, Race, S. 159.

251 BArch Berlin, DC 20/11525, Konsulat Sansibar, Zusammengefaßter Aktenvermerk über die Gespräche mit SU-Konsul Genossen Bogow am 11. und 19.5.1970, Sansibar, 21.5.1970, Bl. 244. 
scheidung des Ministers. Sansibar hatte die Beziehungen $\mathrm{zu}$ China intensiviert, das immer mehr Gesundheitspersonal auf die Insel entsandte und Druck ausübte, ostdeutsche und sowjetische Einflüsse zu eliminieren. ${ }^{252}$ Im ersten Fall verlief die Konfliktlinie zwischen einer technokratisch und westlich orientierten Beamtenschaft auf der einen Seite und einem Politiker, der sich als Sympathisant des sowjetischen Gesellschaftsmodells deklarierte, auf der anderen. In beiden Fällen waren es die AbsolventInnen aus Osteuropa, die die Konsequenzen zu tragen hatten. Das MfS ortete in Tansania wie in anderen afrikanischen Ländern noch bis in die 1980er-Jahre hinein - oder womöglich in diesen Jahren wieder verstärkt die Aktivität „pro-westlicher Kräfte“, den fachgerechten Einsatz von DDR-AbsolventInnen $\mathrm{zu}$ verhindern. ${ }^{253}$

Eine Strategie, um der Abwertung von Abschlüssen aus kommunistischen Ländern entgegenzuwirken, war die Argumentation, dass „rein technisches Wissen überall gleich ist“, wie ein Agrarwissenschaftler betonte: „Wenn ich zwei und zwei zusammenzähle, ob in Ost oder West: Es ist vier. [...] Deshalb, ob in Medizin oder sonstwo: die Prinzipien sind dieselben. “254 Vor allem InterviewpartnerInnen, die in der DDR und Rumänien in technischen und naturwissenschaftlichen Studienzweigen studiert hatten, bedienten sich dieses technokratisch-universalistischen Arguments. Insgesamt waren DDR-AbsolventInnen im Vergleich mit anderen osteuropäischen Ländern, was das Prestige der Abschlüsse angeht, aber immer noch am besten gestellt; in den Interviews grenzten DDR-Absolventen die DDR explizit von anderen RGW-Ländern ab, mit deren Abschlüssen man „nicht vermarktbar“255 gewesen sei:

Als wir, die wir in [Ost-]Deutschland studiert hatten, zurückkehrten, waren wir durchaus anerkannt. Man sagte „Osten“, aber man wusste um den Unterschied und dass wir anders waren als die, die aus Russland zurückgekommen waren. ${ }^{256}$

So verwundert es nicht, dass RückkehrerInnen aus der DDR diplomatische und politische Karrieren bis in die höheren Ränge verfolgen konnten, darunter z.B. Isaac Sepetu (u.a. 1977-1979 Minister für Nachrichten und Medien und Botschafter in Moskau mit Zweitakkreditierung für die DDR) und Martin Kivumbi

252 Altorfer-Ong, They Came as Brothers.

253 BStU, MfS, HA II 29520, Information zur Verwirklichung der „Ordnung über die Pflege von Nachkontakten zu Bürgern aus Entwicklungsländern [...]“, Bl. 21.

254 Interview \#92, Tansanischer Student in der DDR.

255 Interview \#75, Tansanischer Student in der DDR und Doktoratsstudent in der BRD.

256 Interview \#65, Tansanischer Student in der DDR. Zitat im Original: „Kwa hiyo sisi tuliosoma Ujerumani tukifika hapa tunakuwa na heshima yetu hata kama wanasema ni East lakini walijua tu utofauti. Tuko tofauti na wale waliotoka Urusi, walijua tu.“ 
(Ökonomiestudium in der DDR, ab 1968 im Außenministerium und in den 1970er und 1980er-Jahren als Botschafter in Washington, Den Haag und Bonn). ${ }^{257}$ In wirtschaftspolitisch wichtigen Positionen waren allerdings fast ausschließlich Männer mit Abschlüssen aus westlichen Ländern zu finden und auch die oberen und mittleren Ränge der Verwaltung wurden von BeamtInnen mit westlichen Abschlüssen dominiert, von denen manche die Beziehungen zur DDR und in Richtung Osteuropa bewusst und effektiv bremsten. ${ }^{258}$ Eine Reihe westdeutscher ProjektleiterInnen vertrauten DDR-Abschlüssen hingegen, in manchen Fällen förderten sie die Anstellung von DDR-AbsolventInnen in Entwicklungsprojekten oder an der Ingenieurwissenschaftlichen Fakultät der Universität Dar es Salaam sogar aktiv.

\title{
Ökonomisches Kapital: Wechselkurse
}

War das Überseestudium in den 1960er-Jahren noch primär eine Strategie zur Aneignung von Wissen und symbolischem Kapital, so verschob sich die Bedeutung in den kommenden Jahrzehnten. Ein Literaturwissenschaftler mit einem Doktortitel aus der DDR wies im Interview darauf hin, dass die Ost-West-Differenzierung im Nachbarland Kenia weitaus spürbarer und in Tansania selbst weniger politisch denn wirtschaftlich begründet war:

\begin{abstract}
If you came from Kenya and you went to the Eastern Bloc instead of going to Western Bloc you would be looked down [upon] but if you came from Tanzania which was Ujamaa oriented... [...] I will tell you that so many big people went to the East to study. [...] And what people actually tried to find out was what you offer in the classroom, but there was also this material[ist] view in the sense that if you went to the Western Bloc you were likely to come back with a good car or something like that but if you came from the East [...] you didn't get a chance to work like those who went to the West, were they would work and find jobs work and get those cars, so there was that difference. ${ }^{259}$
\end{abstract}

Diese Erfahrung ist typisch für den Kontext der 1980er Jahre. Schon in den 1960er Jahren war es möglich gewesen, den Kaufkraftunterschied zwischen der BRD und Tansania auszunutzen. Zwischen 1970 und 1980 änderten sich die Austauschrelationen allerdings - Devisen waren nunmehr, so auch ein Agrarwissenschaftler mit DDR-Abschluss, wichtiger als alles andere geworden. ${ }^{260}$ Die Differenz zwi-

257 Eckert, Herrschen, S. 241.

258 Roberts, Ostpolitik in Afrika, S. 14.

259 Interview \#47, Tansanischer Doktoratsstudent in der DDR.

260 Interview \#65, Tansanischer Student in der DDR. 
schen offiziellem und inoffiziellem Wechselkurs (siehe Tabelle 4.2) ermöglichte profitreiche Spekulationsgeschäfte.

Tabelle 4.2: Offizielle und informelle Wechselkurse von Tansanischen Schilling zu US Dollar, 1980-1989 (Quelle: Maliyamkono, The Second Economy in Tanzania, 158)

\begin{tabular}{lrrr}
\hline Jahr & Offizieller Wechselkurs & Informeller Wechselkurs & Faktor \\
\hline $\mathbf{1 9 8 0}$ & 8,2 & 21,0 & 2,6 \\
$\mathbf{1 9 8 1}$ & 8,3 & 27,6 & 3,3 \\
$\mathbf{1 9 8 2}$ & 9,3 & 32,6 & 3,5 \\
$\mathbf{1 9 8 3}$ & 11,1 & 39,6 & 3,6 \\
$\mathbf{1 9 8 4}$ & 15,3 & 60,0 & 3,9 \\
$\mathbf{1 9 8 5}$ & 17,5 & 100,0 & 5,7 \\
$\mathbf{1 9 8 6}$ & 32,7 & 170,0 & 5,2 \\
$\mathbf{1 9 8 7}$ & 70,0 & 180,0 & 2,6 \\
$\mathbf{1 9 8 8}$ & 120,0 & 210,0 & 1,8 \\
$\mathbf{1 9 8 9}$ & 145,0 & 250,0 & 1,7 \\
\hline
\end{tabular}

Neben harter Währung waren auch Konsumgüter gefragt, um symbolisches Kapital zu sammeln, die Lebensbedingungen zu verbessern und weiteren ökonomischen Profit zu lukrieren - oder überhaupt den Lebensunterhalt bestreiten zu können. Gerade zu Zeiten sinkender Reallöhne, als ein Monatslohn im urbanen Raum kaum die Lebenshaltungskosten einer Woche deckte, waren Nebeneinnahmen unerlässlich. RemigrantInnen importierten, was Geldbörse und Netzwerke hergaben und den rechtlichen Bedingungen entsprechend eingeführt werden konnte: Kühlschränke, Computer, Gaskocher, Werkzeuge, Herde, Fernseher, Hi-Fi-Anlagen und Autos. Einige dieser Gegenstände konnten dann - viel mehr als in der DDR oder BRD - zur Generierung von Einkommen genutzt werden; somit handelte es sich bisweilen mehr um Kapital- denn Gebrauchs- oder Luxusgüter.

Soziale Kontakte in Deutschland wurden bisweilen gezielt genutzt, um Zugang zu weiteren ökonomischen Ressourcen zu erlangen. Eine Gruppe von vier Tansaniern, die in christlichen Kreisen in der DDR Anschluss gefunden hatte, war anscheinend besonders geschickt darin gewesen, den Solidaritätswillen einer evangelischen Gemeinde in materielle Werte umzuwandeln. 1988 versandten sie Elektro- und Haushaltsgeräte im Wert von über 20.000 Mark (Ost), die zu einem guten Teil durch Spenden der Gemeinde finanziert waren. ${ }^{261}$ Die unerlaubte

261 BArch Berlin, DQ 4/5432, Eingabe des Superintendenten des Kreiskirchenrates des Ev. Kirchenkreise Halle (Saale) an das Afro-Asiatische Solidaritätskomitee DDR, Halle (Saale), 8.11.1988; 
Einfuhr von Waren nach Tansania war Anfang der 1980er Jahre jedoch auch riskant. Symptome statt Ursachen bekämpfend ging der Staat entschieden gegen Schmuggel und „Wirtschaftssabotage“vor. Einige RückkehrerInnen kamen einem Interviewpartner zufolge in Konflikte mit der Exekutive, weil sie unregistrierte HiFi-Anlagen zu Hause hatten. Ein anderer erzählte, dass er auf der Straße wiederholt von Polizisten angehalten und befragt wurde, weil seine Hose augenscheinlich kein tansanisches Fabrikat war - weswegen er als Schmuggler verdächtigt worden sei. ${ }^{262}$ Wie in der DDR entstand eine Kategorie des verdächtigen Konsums; auch in Tansania gerieten Personen mit (vermeintlichen) Westfabrikaten am Körper oder im Haus schnell in Verdacht, die moralische Ökonomie des Sozialismus und des Nationalstaats zu unterwandern. In den frühen 1980erJahren konnte dieser Vorwurf jedoch willkürlich beinah jeder Person unterbreitet werden, da sich ein Großteil der Wirtschaftstätigkeiten auf den Schwarzmarkt und in personelle Netzwerke verlagert hatte (siehe Kapitel 2.3). Manche dieser personellen Netzwerke reichten noch bis in die beiden deutschen Staaten und erwiesen sich auch über ökonomische Aneignungsstrategien hinaus als nützlich.

\section{Soziales Kapital: Gekappte Bande und offene Türen}

Beide deutsche Staaten bemühten sich nur halbherzig darum, Kontakte zu den Alumni aufrecht zu erhalten. In der BRD war diese Arbeit dezentral organisiert und fallweise effektiv; in der DDR wurden „Nachkontaktaktivitäten“ erst in den 1980er-Jahren mit dem primären Ziel der Exportförderung systematisch verfolgt. ${ }^{263}$ Hierzu gehörten Einladungen der Alumni zu Botschaftsempfängen sowie gezielte Treffen mit Delegationen. Wie die BRD-Botschaft, die ähnliche Methoden anwandte, war die DDR damit wenig erfolgreich, „da die Tansanier von sich aus selten Kontakt mit der Botschaft suchen und im Umgang mit Behörden allgemein sehr zurückhaltend sind“. ${ }^{264}$ Aufgrund der ungleich umfassenderen westdeutschen Präsenz in Form von Projekten der Kapital- und Technischen Hilfe, DED-

ibid., Stv. des Ministers für Außenhandel der DDR Gädt an Ministerium für Elektrotechnik und Elektronik, 8. 8.1988. 4.000 Mark der Spenden waren dem Kauf, 4.000 Mark dem Versand der Waren gewidmet.

262 Interview \#120, Tansanischer Student in Rumänien.

263 UAL, DIB 451, Jünger (Abt. AS), Zuarbeit zur Jahresanalyse DIB 1985, o.0., 7.12.85, Bl. 27; BStU, HA II 29520, Information zur Verwirklichung der „Ordnung über die Pflege von Nachkontakten zu Bürgern aus Entwicklungsländern [...]“, Juli 1984, Bl.4-9.

264 DAAD-Archiv, B 212/91395/2, BRD-Botschaft an AA, Dar es Salaam, 11.7.1988; ebenso: BArch Koblenz, B 213/7672, BRD-Botschaft an AA, Dar es Salaam, 9. 8.1969, S. 9. 
EntwicklungshelferInnen, Privatinvestitionen und politischen Stiftungen ergaben sich jedoch trotzdem immer wieder Verbindungen, Anstellungs- und Kooperationsmöglichkeiten. ${ }^{265}$ Patronageverhältnisse gehörten zu den besten Visitenkarten. Doktorväter und -mütter konnten Türen öffnen, bis die Kooperationen mit deutschen Institutionen zu einem Selbstläufer wurden und so den weiteren Lebensweg entscheidend mitprägten. Ein Rechtsprofessor maß dem Doktoratsstudium in der BRD größte Bedeutung für seine Karriere bei:

It made me who I am today, especially my supervisor. He had retained a very unique space in my life. Because he opened so many doors for me. [...] When I wanted the Alexander von Humboldt scholarship, which unlike DAAD is very competitive, he supported me [...] And later on I had opportunities to be connected to people like Konrad-Adenauer-Stiftung, Friedrich-Ebert-Stiftung, I have published quite a number of books under FES [...]. So going to Germany opened many doors which were closed before. It was very easy to meet other people, be accepted in so many places and so on. ${ }^{266}$

Die Aussage illustriert, wie durch den Zugang zu einer Ressource der Zugang zu einer weiteren ermöglicht wurde. Das Protegé-Verhältnis zum Doktorvater ebnete den Weg zu weiteren Stipendien, internationaler Anerkennung und Kooperationsmöglichkeiten. Als Ergebnis persönlicher und institutioneller Netzwerke gibt es unter den wichtigsten JuristInnen Tansanias z. B. eine „Hamburger“ und eine „Konstanzer“ Gruppe, zu denen auch ehemalige und gegenwärtige SpitzenpolitikerInnen und DiplomatInnen zählen. ${ }^{267}$ In manchen Fällen erfüllten sich auch die Hoffnungen bundesdeutscher Wirtschaftskreise, dass die in der BRD Ausgebildeten „den Deutschen in ihrem Heimatlande die Türen öffnen“. ${ }^{268}$ Der Sansibari Haji K. I., der - nach Eigenaussage aus politischen Gründen - seine Ausbildung zum Röntgenologen in der DDR abgebrochen hatte und in die BRD gegangen war, hatte auf Kosten der hessischen Landesregierung und der Friedrich-Ebert-Stiftung eine Ausbildung als Bankkaufmann bei der Deutschen Bank gemacht. Danach absolvierte er ein Praktikum bei der Außenhandelsfirma Hansen \& Söhne, um daraufhin die Leitung ihrer tansanischen Tochterfirma zu

265 Interviews \#1, \#41, Tansanische Doktoratsstudenten in der BRD; Interview \#12, Tansanische Studentin in der BRD.

266 Interview \#1, Tansanischer Doktoratsstudent in BRD.

267 Darunter u.a. George Mwakyembe, Asha-Rose Migiro und Sospeter Muhongo.

268 HHStAW, 507/10549, Lenz an Hess. Minister für Wirtschaft und Verkehr, Mainz, 9.3.1962. 
übernehmen und sich eine persönliche Beteiligung am Unternehmen zu sichern. ${ }^{269}$

\section{Fazit}

Unter den RückkehrerInnen aus der DDR und der BRD wurde die deutsche Einheit vorweggenommen: In der Deutsch-Tansanischen Gesellschaft, gegründet von AbsolventInnen von BRD-Universitäten, entbrannte 1985 ein Streit um die Frage, ob AbsolventInnen aus der DDR ebenfalls Mitglieder werden durften. Der „liberale“ Flügel, der sich gegen das Ost-West-Denken des Kalten Krieges aussprach, setzte sich durch und erreichte die Öffnung der Organisation für DDR-AbsolventInnen - vier Jahre vor dem Mauerfall. ${ }^{270}$ Auch in anderen Hinsichten überwanden tansanische Studierende den Eisernen Vorhang sowohl als reale Grenze wie auch als ideologische Konstruktion.

Kamen aus der DDR tatsächlich kapitalistische und aus der BRD sozialistisch eingestellte Personen zurück, wie das Interviewzitat zu Beginn dieses Kapitels nahelegt? Die Erfahrungen während des Überseeaufenthaltes konnten fraglos bedeutende Transformationen anstoßen, allerdings sollten diese nicht allein durch den Auslandsaufenthalt in Isolation und erst recht nicht nur durch das simplifizierende Deutungsschema der Systemkonkurrenz betrachtet werden. Für ein adäquates Verständnis der Erfahrungen, „Überlebensstrategien“ und Narrative sind, erstens, die Verhältnisse in Tansania genauso wie die Dynamik der Dekolonisierung und andere globale Kräfteverhältnisse miteinzubeziehen. Nur die wenigsten traten ihre Reise vom Afrikanischen Sozialismus in den osteuropäischen Realsozialismus oder die westdeutsche Soziale Marktwirtschaft mit explizit politischen Motiven an - oder erfuhren ihre Bildungsmigration überhaupt in derartigen Begriffen. So ließ ein Ökonom, der in der DDR studiert hatte, eindeutig wissen: „Students were not going there to study socialism. They were going there for education. “271 Ein Auslandsaufenthalt in BRD oder DDR hatte keine

269 HHStAW, 507/11330, Haji K. I. an Hessen-Büro der FES, o.O., 18.3.1973; Haji K. I. an HessenBüro der FES, Frankfurt/Main, 14. 8.1972; Haji K. I. an Hessen-Büro der FES, Frankfurt/Main, 30. 8. 1972.

270 Interview\#66, Tansanischer Student in der BRD. Während der Feldforschungen 2014 war diese Gesellschaft ein loser Verband, keine Erinnerungsgemeinschaft im engeren Sinn. Ein substanzielles gemeinsames Interesse schien nicht zu bestehen; in materieller und organisatorischer Hinsicht waren bzw. sind derartige Vereine oft an deutsche Institutionen wie das Goethe-Institut, die GTZ/GIZ und den DAAD angebunden.

271 Interview \#42, Tansanischer Student und Doktoratsstudent in der DDR. 
eindeutig vorhersagbaren Auswirkungen auf die politische Einstellung. ${ }^{272}$ Wie andere ausländische Studierende waren auch TansanierInnen nicht nur zum stillen Lernen und Absorbieren gekommen: Sie stellten Forderungen und hinterfragten Strukturen und Denkmodelle, mit denen sich einheimische Studierende bereits arrangiert hatten. Außerdem kamen sie mit vorgeformten, wenngleich stets wandelbaren Weltsichten, in denen die Nord-Süd-Dimension oft eine wichtigere Rolle spielte als der Ost-West-Konflikt. Viele verfolgten Mobilitätsstrategien über den Eisernen Vorhang hinweg und waren oft ebenso willens zur Rückkehr wie auch gefordert, ihre Abschlüsse in Tansania aktiv zu validieren.

Daraus leiten sich einige Implikationen für die Geschichte der Entwicklungspolitik während des Kalten Krieges ab. Das Überseestudium wurde durch die Entstehung eines globalen entwicklungspolitischen Feldes zu einer Mobilitätsform, die einem größeren (aber relativ gesehen freilich immer noch kleinen) Personenkreis offenstand. Es trug zu einer intensiveren Vernetzung bei, ermöglichte neue Kontakte und den Austausch von Ideen und Erfahrungen. Signifikante Teile der „bürokratischen Bourgeoisie“, viele Counterparts in Entwicklungsprojekten und die meisten SpitzenpolitikerInnen hatten Überseestudien absolviert, waren also nicht nur „lokale Partner“ ohne internationale Erfahrung.

Tatsächlich wurde der Ost-West-Konflikt auch mit Stipendienvergaben und der (Nicht-)Anerkennung von Studienabschlüssen ausgetragen. Proklamierter Dreh- und Angelpunkt war der Transfer von „Wissen“, also kulturellem Kapital von Nord nach Süd. Von dieser Investition wiederum erhofften sich die „Geberstaaten“ politische und ökonomische Dividenden. Gleichzeitig wurden die Trennlinien des Kalten Krieges im Rahmen des Auslandsstudiums aber auch überwunden und transformiert. Die Erfahrungen tansanischer Studierender und ihre aktive Teilnahme an politischen Prozessen rufen in Erinnerung, dass die „Dritte Welt“ keinesfalls nur Projektionsfläche war. ${ }^{273}$ Konkrete Personen aus dem globalen Süden waren im Norden präsent - und zwar in „Ost“ und „West“ - und setzten sich mit globalen Fragen und Machtverhältnissen auseinander. Dabei stimmten ihre Meinungen und Handlungen durchaus nicht immer mit den Interessen der Geberinstitutionen überein.

Schließlich zeigt sich beim Überseestudium um die Mitte der 1970er-Jahre ein Bruch: Stipendienvergaben in beiden deutschen Staaten wurden nun mehr und mehr nach ökonomischen Kriterien ausgerichtet. TansanierInnen sahen das

272 Zu einem ähnlichen Ergebnis kommt: Paul Kibiwott Kurgat, Education as a Foreign Policy Tool: Kenyan Students' Airlifts to the Union of Soviet Socialist Republics and Eastern Europe, 1954-1991, PhD Thesis, Moi University 2013.

273 So die weithin übliche Ansicht, z. B. in Hein, Die Westdeutschen, S. 141, die erst mit den bereits zitierten Werken von Niels Seibert und Quinn Slobodian revidiert wurde. 
Überseestudium zunehmend als Überlebensstrategie und Möglichkeit, direkten Zugang zu ökonomischem Kapital zu erhalten und Familienmitglieder in Tansania zu unterstützen. Grenzüberschreitende Praktiken, durch die sich das Wirtschaftsgefälle zwischen „West“ und „Ost“ ausnutzen ließ, spielten hier eine entscheidende Rolle, und viele tansanische Studierende in der DDR gewannen so Einblicke in die Realitäten auf beiden Seiten der Mauer. Da StipendiatInnen im Gegensatz zur tansanischen und ostdeutschen Mehrheitsbevölkerung frei reisen konnten, waren sie in der Position, Grenzen produktiv zu nutzen. Die Gewinne aus den Überseeaufenthalten und Grenzübertritten wiederum gingen über ökonomische Kategorien hinaus, denn die Reisen brachten auch ein Erfahrungswissen mit sich, das gegen starre Weltdeutungen immunisierte. Unter den interviewten ehemaligen Studierenden gab es ein breites Spektrum ideologischer und politischer Positionen, das zu einem geteilten Kern gravitierte: Der Wohlfahrtsstaat und die daraus erwachsende soziale Sicherheit für die Bevölkerung war eine wichtige Errungenschaft der Moderne. Viele sahen wohlfahrtsstaatliche Ideale sowohl in der BRD als auch in der DDR zumindest teilweise verwirklicht und wünschten sich diese Formen gesellschaftlicher Absicherung auch für Tansania. Der Weg dahin blieb jedoch offen und umkämpft. Auch das Entwicklungspersonal aus den beiden deutschen Staaten, das nach Tansania entsandt wurde, musste sich mit der Vielfalt an Transformationsstrategien auseinandersetzen. 